\title{
WestVirginiaUniversity
}

THE RESEARCH REPOSITORY @ WVU

Graduate Theses, Dissertations, and Problem Reports

2005

\section{Investigation of internal fluid pressure in cells}

Jayendran Srinivasan

West Virginia University

Follow this and additional works at: https://researchrepository.wvu.edu/etd

\section{Recommended Citation}

Srinivasan, Jayendran, "Investigation of internal fluid pressure in cells" (2005). Graduate Theses, Dissertations, and Problem Reports. 1687.

https://researchrepository.wvu.edu/etd/1687

This Thesis is protected by copyright and/or related rights. It has been brought to you by the The Research Repository @ WVU with permission from the rights-holder(s). You are free to use this Thesis in any way that is permitted by the copyright and related rights legislation that applies to your use. For other uses you must obtain permission from the rights-holder(s) directly, unless additional rights are indicated by a Creative Commons license in the record and/ or on the work itself. This Thesis has been accepted for inclusion in WVU Graduate Theses, Dissertations, and Problem Reports collection by an authorized administrator of The Research Repository @ WVU. For more information, please contact researchrepository@mail.wvu.edu. 


\title{
Investigation of Internal Fluid Pressure in Cells
}

\author{
Jayendran Srinivasan
}

Thesis submitted to the

College of Engineering and Mineral Resources

at West Virginia University

in partial fulfillment of the requirements

for the degree of

\section{Master of Science}

In

\section{Mechanical Engineering}

\author{
Nilay Mukherjee, Ph.D., \\ Jacky Prucz, Ph.D., \\ Richard Dey, Ph.D.,
}

Department of Mechanical and Aerospace Engineering

Morgantown, West Virginia

\section{5}

Keywords: Cell Mechanics, Internal Fluid Pressure, Cell Poking 


\section{Abstract \\ Investigation of Internal Fluid Pressure in Cells}

Jayendran Srinivasan

Articular cartilage is a connective tissue that covers the ends of bones in joints, providing a nearly frictionless bearing surface for efficiently transmitting loads to the underlying joint. It is made up of specialized cells called chondrocytes that are responsible for its growth and maintenance. Studies indicate that cells remodel the tissue in response to mechanical loading. However the mechanism by which cells sense and respond to mechanical signals is poorly understood.

Studies also suggest the presence of internal fluid pressure in cells and change in this fluid pressure is believed to play a role in cellular mechanical signal transduction. This study attempted to ascertain the presence of fluid pressure in cells via the role it plays in changing cell volume and area through 3D cell poking experiments using a laser scanning confocal miscroscope.

ATDC5 and Bone Marrow Cells embedded in agarose gel were stained with two different dyes and fluorescent cross sectional images of the cell were obtained before and after poking the cell. After correcting for laser intensity and threshold fall-off effects due to photobleaching, the change in cell volume/area due to cell poking was observed. A 10\% reduction in cell volume for ATDC5 cells and a $16 \%$ reduction in volume for Bone Marrow cells were observed when an intracellular dye (CMFDA) was used. When the poking experiments were repeated with an extracellular dye (Fluorescein Dextran), a 15\% reduction in cell cross sectional area was observed. This information can be used to build a more sensitive experimental setup that can measure the internal fluid pressure of cells to give a more accurate prediction of cell behavior to different mechanical environments.

In a separate study, the modulus of elasticity of cells embedded in 3D agarose constructs were determined using an experimental/elasticity approach. Cell/Gel mixture was compressed to $30 \%$ of the gel thickness and fluorescent confocal sections were taken. The radial deformation data obtained from the experiment was curve fit with a theoretical solution obtained by Goodier to find the cell stiffness. Using this method, differences in modulus of elasticity of cells between two cells, or in the same cell before and after certain treatments can be detected. 
This thesis is dedicated to my family, friends and my advisor 


\section{Acknowledgment}

I would like to thank God for providing me this opportunity to complete my thesis.

I would like to thank Dr. Nilay Mukherjee, for giving me an opportunity to learn and work under him as a research assistant and as a graduate student. He has been a constant source of guidance and this thesis would not have been a finished product without his support. I would also like to thank Dr. Jacky Prucz and Dr. Richard Dey for their help and suggestions.

Thanks to Sunil and Lalitha Mazimdar for being a constant source of inspiration.

Special thanks to Vincent Kish, our lab technician and Sydha Salihu, for their invaluable time and guidance in this project.

Finally I would like to thank my family, for their encouragement and prayers. 


\section{TABLE OF CONTENTS}

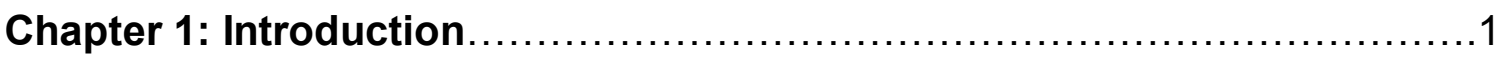

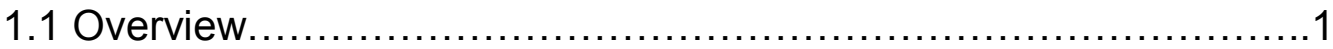

1.2 Articular Cartilage: Structure, Shape and Function...................

1.3 Structural Components of a Cell....................................

1.3.1 Cell Membrane.................................................

1.3.2 Cytoskeletal Elements..................................

1.3.3 Cytoplasm - Fluid Inside the Cell......................

1.4 Biological behavior of tissue is affected by mechanical loading.......8

1.5 Mechanotransduction Mechanisms..............................10

1.5.1 Mechanosensitive Ion Channels.......................10

1.5.2 Cytoskeleton.........................................11

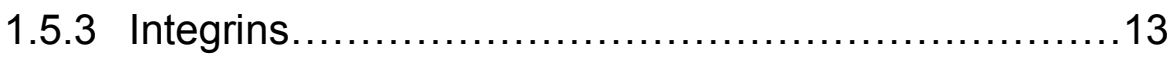

1.5.4 Fluid Flow and Pressure..............................14

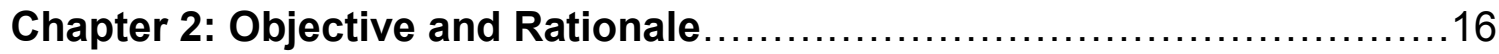

Chapter 3: Cell Poking Experiments .....................................19

3.1 Description of Experimental Setup..............................19

3.2 Description of Cell/Gel Mixture Preparation.......................20

3.3 Imaging Using Confocal Laser Scanning Microscope..............21

3.4 Fluorescent Imaging using CMFDA dye and Cell Poking...........23 
3.5 Threshold Calibration using Fluorescent Microspheres. 25

3.6 Results and Analysis of Cell Poking Experiments. .27

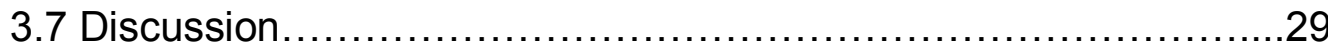

Chapter 4: Photobleaching Experiments ......................................30

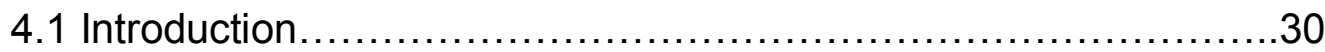

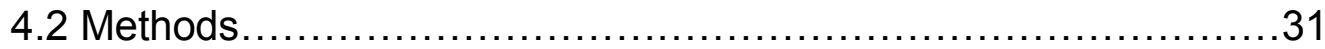

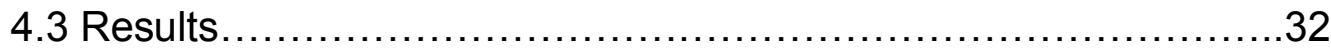

4.4 Discussion.........................................................

Chapter 5: Threshold Experiments with Fluorescein Dextran Dye.............34

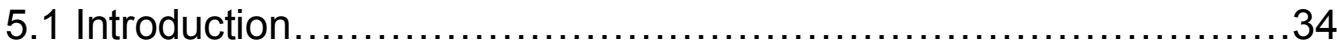

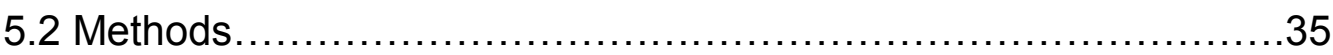

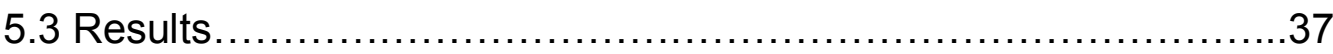

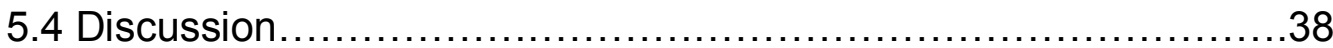

Chapter 6: Cell Poking Experiments with Fluorescein Dextran using Control...39

6.1 Introduction..........................................................

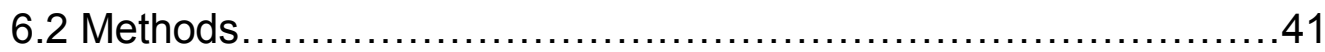

6.3 Results............................................................. 45

6.4 Discussion....................................................... 47

Chapter 7: Cell Material Properties using Experimental/Elasticity Method.49

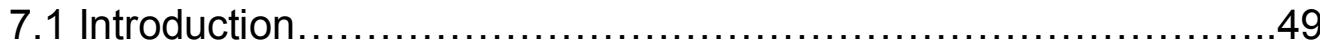


7.2 Cell/Gel Compression Study to Determine Volume Change.........50

7.2.1 Introduction .......................................... 50

7.2.2 Methods ................................................ 50

7.2.3 Results............................................... 52

7.2.4 Discussion............................................ 52

7.3 Compression Experiments to Determine Gel Properties............53

7.3.1 Introduction .......................................... 53

7.3.2 Methods................................................. 54

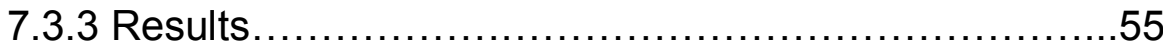

7.3.4 Discussion............................................... 59

7.4 Radial Deformation and Curve Fitting to find Cell Stiffness........60

Chapter 8: Conclusion and Future Studies.................................64

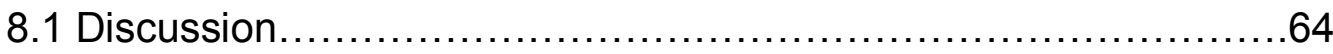

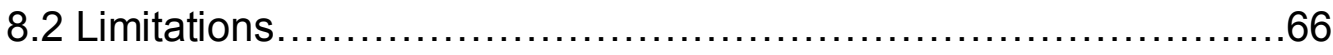

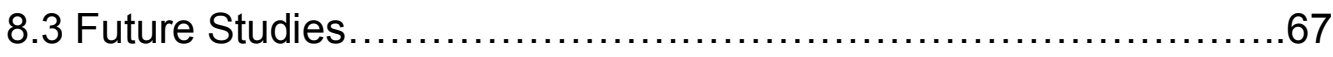

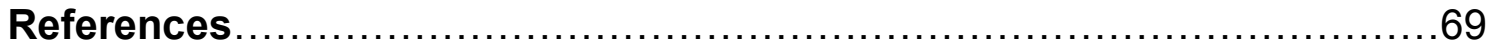

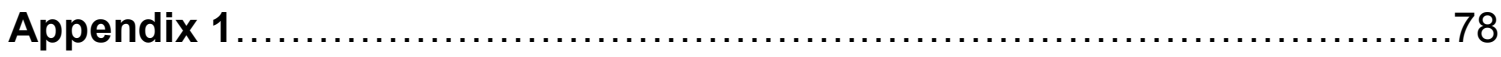

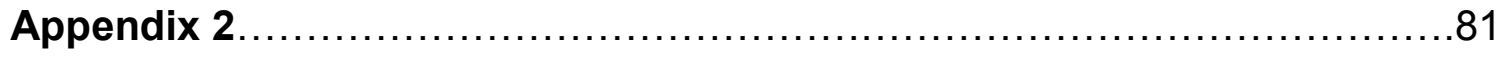

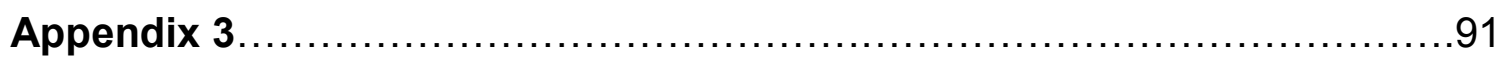

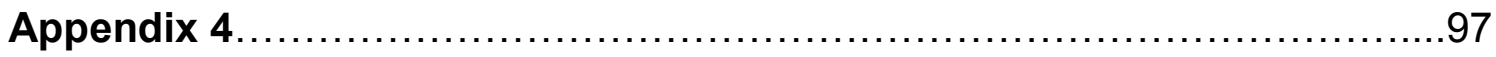

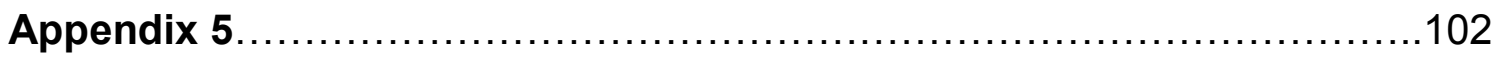

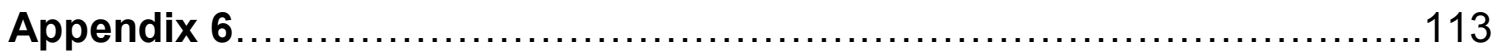




\section{LIST OF TABLES}

Table 1: Cell Volume Values of Poking Experiments Using CMFDA Dye ........28

Table 2: Average $y_{o}$ and $b$ values calculated to correct threshold fall-off due to

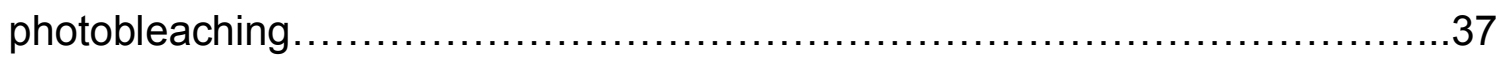

Table 3: Cell Cross-Sectional Area Values of Poking Experiments Using

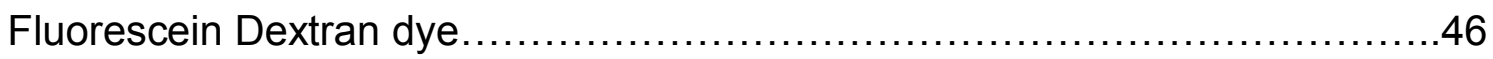

Table 4: Change in Volume of Cell due to Compression of Gel..................52

Table 5: Stiffness Values for Agarose and Alginate Gels......................58

Table 6: Inter-Repeatability Test using two different agarose gels..............58

Table 7: Intra-Observer Repeatability of agarose gel with two different

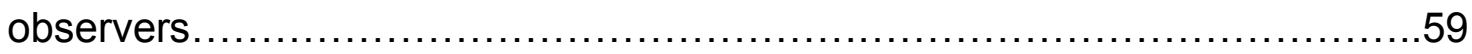




\section{LIST OF FIGURES}

Figure 1: Cartilage Tissue Structure - Histology and 3D Schematic................3

Figure 2: Cell Membrane and its Components................................ 4

Figure 3: Structure of Actin Cytoskeleton.......................................

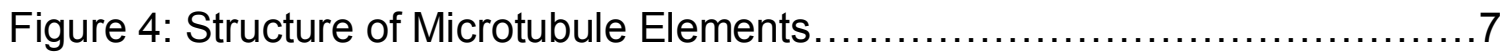

Figure 5: Ion Channel Function in Cells .......................................11

Figure 6: Mechanotransduction Through Geometric Remodeling of Cytoskeleton

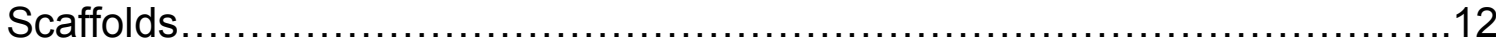

Figure 7: Actin cytoskeleton reorganization in cells............................13

Figure 8: The Cytoskeleton Connected to the Underlying ECM and Neighboring

Cells through Focal Adhesion Complexes.....................................14

Figure 9: Custom Made Mold and Experimental Setup.........................19

Figure 10: Cell Stained with CMFDA dye under 100x Objective of Confocal

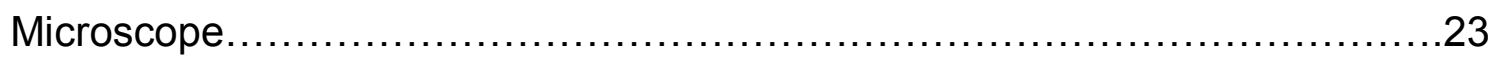

Figure 11: Cross Sectional Image of an ATDC5 Cell Before and After Poking..24

Figure 12: Serial Sections of Fluorescent Microspheres .......................26

Figure 13: Graph Showing the Volume of Beads Obtained From Calibration

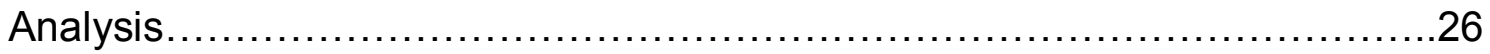

Figure 14: Effect of Photobleaching on a Cell..................................31

Figure 15: Effect of Laser Intensity on Cell Volume............................32

Figure 16: Gel/Cell stained with fluorescein dextran and Guilak's photobleaching

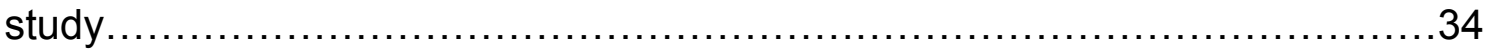

Figure 17: Graph to correct threshold fall-off due to photobleaching .............37 
Figure 18: Cross Sectional Image of a Bone Marrow Control and Experimental Before and After Poking.....

Figure 19: Method of measuring change in cross-sectional area due to poking using control and experimental cell...........................................

Figure 20: Largest Confocal Section of uncompressed and compressed cell....51 Figure 21: Experimental setup and custom-made mold to generate big gel.....54 Figure 22: Load-Time and Displacement-Time Curves for big gels..............55 Figure 23: Stress-Strain curve for big gels.................................56 Figure 24: Graphical comparison of Nussinovitch and our results...............59 Figure 25: Radial Deformation using largest cross-section of uncompressed and compressed cell...........................................................60

Figure 26: Plot of Radial Deformation at Various Angles........................61 Figure 27: Curve Fit of Theoretical and Experimental Radial Deformation

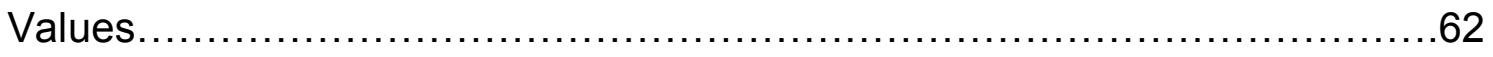

Figure 28: Cell Stained with CMFDA at 0 and 5 minutes.......................91 Figure 29: Photobleaching effect of cell stained with fluorescein dextran dye after

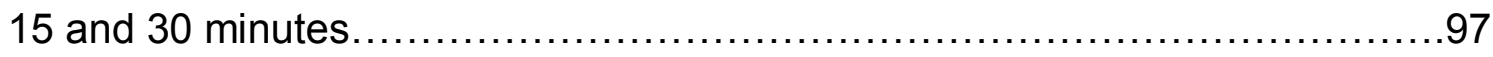




\section{Chapter 1: Introduction}

\subsection{Overview}

Articular cartilage is the connective tissue that covers the ends of bones in joints [1]. It separates bones so that they do not grind together, causing stiffness and pain. The articular cartilage reduces friction at joints such as knee and elbow, acts as a cushion to absorb the shock associated with joint use, and efficiently transmits weight loads to the underlying bone.

Once damaged, articular cartilage does not heal completely i.e. it does not regain its structure and material to become functional again. Damaged or degenerated articular cartilage leads to a painful and debilitating condition known as arthritis. Arthritis is a major health issue in United States. More than 40 million Americans suffer from some form of arthritis. Approximately 21 million Americans suffer from osteoarthritis, a degenerative joint disease. One out of every seven Americans is affected by this condition and it is one of the leading causes of disability for Americans over the age of 65 (NIAMS 2000).

Consequently, there is a lot of interest in understanding the mechanisms responsible for this disease and in finding ways to repair damaged tissue and slow or reverse degenerative process. Currently the treatment for osteo-arthritis is primarily pain management with drugs like aspirin, non-steroidal antiinflammatory drugs, corticosteroids etc.

Recent experiments have suggested that worn cartilage can be regenerated through tissue engineering approaches such as using controlled environmental stimuli [2]. Studies of rabbit and pig cartilage defects 
demonstrated that a repair process takes place, but that the resulting cartilage has inferior properties to those of normal cartilage i.e. the generated tissue does not mechanically behave like functional cartilage [3].

Though current tissue-engineered efforts are partially successful, it still cannot achieve all the steps in cartilage formation from precursor cells to functional cartilage. While it is understood that chondrocytes are the cells that make up the cartilage and that chondrocytes are responsible for making up the Extra Cellular Matrix (ECM) that govern the tissue shape and function, the exact mechanism by which this works at the cellular level is poorly understood.

\subsection{Articular Cartilage: Structure, Shape and Function}

The articular cartilage consists of specialized cells called chondrocytes that make up the extra cellular matrix (ECM) that surrounds the cells. The ECM is made up of water, proteoglycans, and collagens that combine in a distinctive manner to give cartilage its unique property [4]. Chondrocytes produce and maintain the articulate cartilage through synthesis and degradation of ECM components. This gives cartilage its strength and load-bearing capacity [5].

Based on the structure and composition of the ECM components through the depth of the tissue, articular cartilage is mainly divided into four zones. The first zone is called the surface zone. This zone is embedded in a matrix of tangentially oriented collagen fibers and has flattened disc-shaped chondrocytes [6]. The concentration of proteoglycans is relatively low when compared to other zones. The middle zone is made up of chondrocytes that are more rounded than those in the surface zone. The concentration of proteoglycans is highest in this 
zone. The third zone is called the deep zone and has collagen fibers oriented perpendicular to the tissue surface. Parallel to the orientation of the collagen fibers are chondrocytes arranged in columns. The fourth zone, called the calcified zone, separates the cartilage and the underlying subchondral bone.

Figure 1: Cartilage Tissue Structure - Histology and 3D Schematic (The rounded structures are chondrocyte cells distributed in the cartilage tissue)
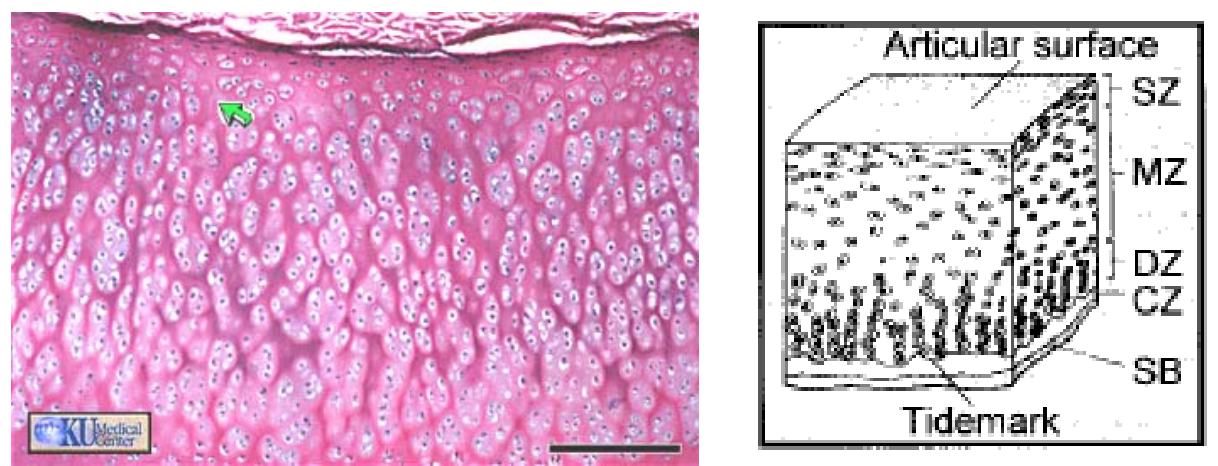

Figure on left from:

http://www.gen.umn.edu/faculty_staff/jensen/1135/webnotes/histology/CT_Cartilage

Figure on Right from:

http://www.columbia.edu/ ga29/pdf/WangBiorheol02.pdf.

The Chondrocytes make up about $10 \%$ of the total tissue volume [7]. The other major constituents of articular cartilage are water dissolved with electrolytes (such as $\mathrm{Na}+$ and $\mathrm{Cl}-$ ) which makes up $65-80 \%$ of total weight, collagen which makes up $10-20 \%$ of the total weight and proteoglycans, principally made up of aggrecan, which make up 5-10\% of the total weight [7].

Collagen provides the tensile and shear properties of the tissue by forming a dense, fibrous network [8]. Water moves through the ECM with high frictional resistance. This frictional resistance is one of the mechanisms through which cartilage support high loads. Also, water provides nutrition and lubrication of cartilage. Proteoglycans maintain the compressive strength of the cartilage [9]. 
Under normal functioning condition, these three major components of the tissue act together to give cartilage its unique biomechanical property.

Thus the chondrocytes together with the ECM control the micro-structure of cartilage that helps it to perform its mechanical function.

\subsection{Structural Components of a Cell}

\subsubsection{Cell Membrane}

The cell membrane forms the outer wall of the cell. It acts as a boundary, holding the cell contents together and selectively isolates the cell from the external environment. The cell membrane resists tensile loading, primarily from internal fluid pressure. The membrane also regulates the materials that enter or leave the cell, thereby maintaining the cell's environment.

A typical membrane is about $5 \mathrm{~nm}$ thick consisting of a phospholipid bilayer with a number of proteins scattered throughout, along with some carbohydrates (glycoproteins) and glycolipids.

Figure 2: Cell Membrane and its Components

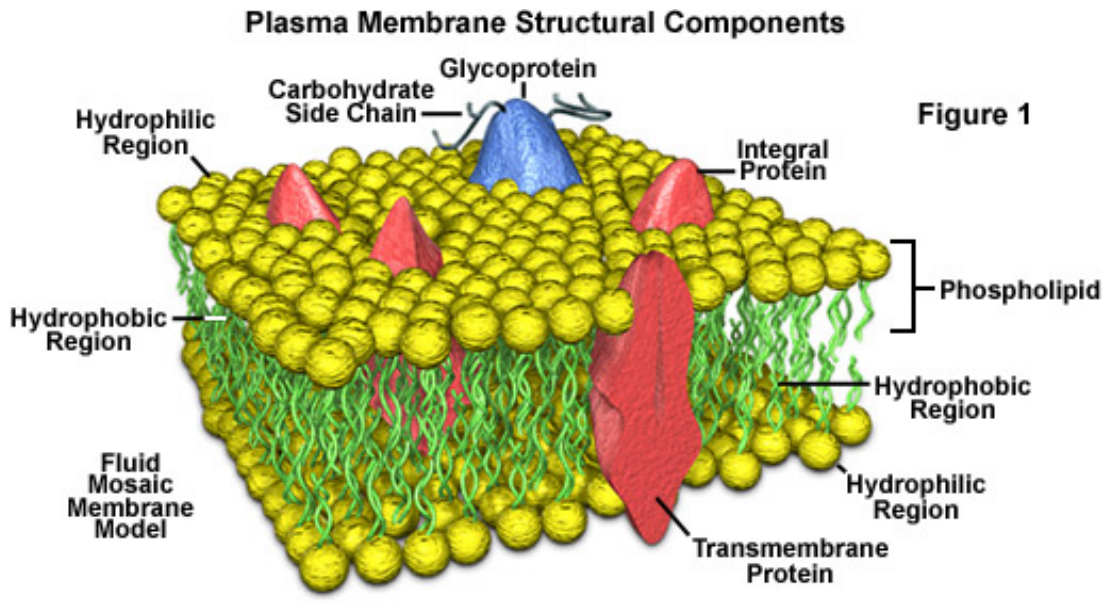


Figure from

http://micro.magnet.fsu.edu/cells/plasmamembrane/plasmamembrane.html

The membrane also plays a major role in the osmotic movement of fluid between the inside of the cell and its environment by being selectively permeable.

\subsubsection{Cytoskeletal Elements}

\section{Actin:}

Actin is one of the major structural elements of a cell. They are arranged in long polymerized chains of molecules intertwined in the form of a helix as shown in figure 3 . They range from 5 to $9 \mathrm{~nm}$ in diameter and are designed to bear large amounts of tension. They are involved in both structural stability as well as motility. The actin fibers are primarily subjected to tension. Actin filaments are physically attached to the extra cellular matrix through the plasma membrane of the cell, via proteins called integrins.

Figure 3: Structure of Actin Cytoskeleton

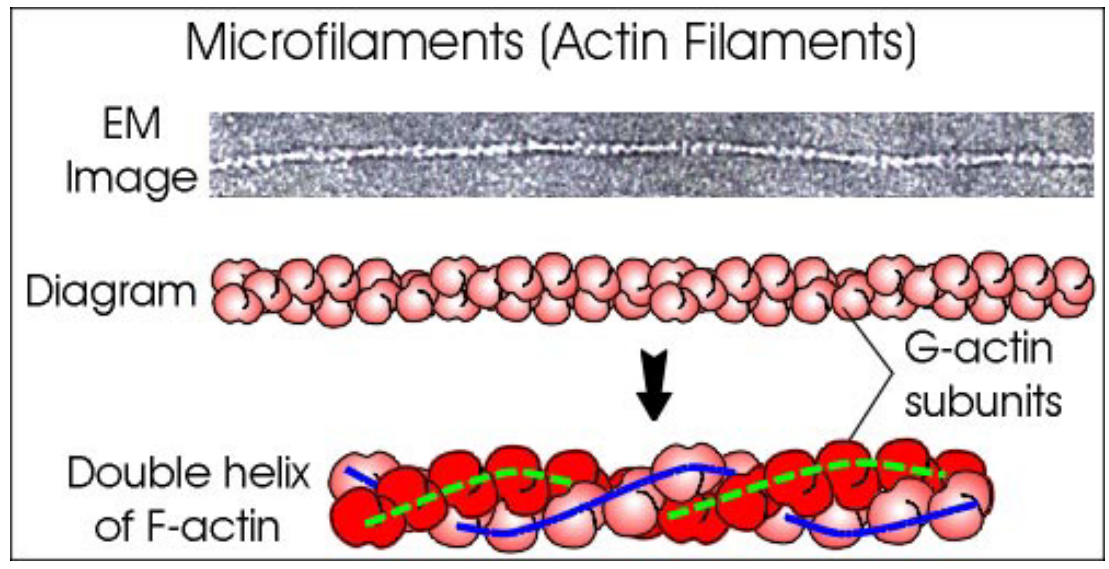

Figure from

http://www.erin.utoronto.ca/ w3bio315/microfilaments 
These filaments help to distribute and support the stresses generated within a cell as well as external stresses transmitted among cells either directly or through the ECM [10].

In many cell types, the actin network plays a dominant role in shaping the cell's mechanical behavior $[11,12,13]$. Studies have shown that the disruption of actin cytoskeleton causes a dramatic reduction of cell stiffness [14]. Other research has shown that the mechanical properties of living cells are dependent on the organization of their actin cytoskeleton [15].

\section{Microtubules}

Microtubules are another part of the cytoskeleton that gives structure and shape to a cell. Microtubules are about $25 \mathrm{~nm}$ in diameter and vary anywhere between $200 \mathrm{~nm}$ and 25 micrometers in length. These filaments are in the form of straight, hollow cylinders and carry out a number of functions, ranging from transport to structural support. Structurally, they are linear polymers of a globular protein called tubulin.

Tubulin is made of two slightly different but closely related simpler units called alpha-tubulin and beta-tubulin that are bound very tightly together. Tubulin dimers polymerize to form microtubules, which generally consist of 13 linear protofilaments assembled around a hollow core as shown in figure 4. 
Figure 4: Structure of Microtubule Elements

Figure from

http://www.ncbi.nIm.nih.gov/books/bv.fcgi?rid=cooper.figgrp.1822
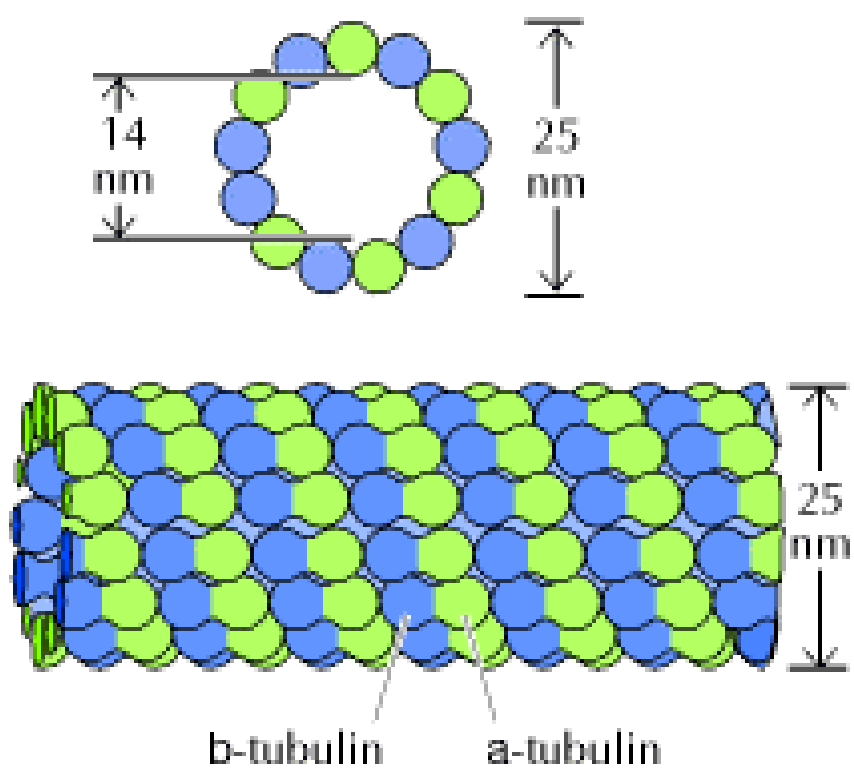

Studies indicate that microtubules are the compression bearing elements of the cell $[16,17]$. Direct visualization of microtubule dynamics in cells transfected with GFP-Tubulin showed that microtubules can buckle due to compressive loading [16].

\subsubsection{Cytoplasm - Fluid inside the Cell}

Cytoplasm is the watery environment inside the cell. The cytoplasmic fluid consists of a thick soup of proteins, carbohydrates, salts, sugars, lipids, nucleotides, and amino acids. The fluid inside the cell induces the tensile stresses on the cell wall $[18,19]$. This stress is caused by the uptake of water by the cytoplasm of the cells so that pressure is exerted at the plasma membrane on the cell wall. This fluid flow into and outside the cell is due to the osmotic 
pressure difference between the cell and its environment. When the osmotic concentration of the outside medium is increased, internal fluid pressure decreases which causes the fluid to flow from inside the cell to outside [18]. This osmotic pressure difference balances the turgor pressure in a cell.

Studies also show that mechanical stresses are transmitted from the cell surface across the cytoplasm into the nucleus [16, 20].

Thus the cytoplasmic or the internal fluid pressure is one of the important components of a cell.

\subsection{Biological behavior of tissue is affected by mechanical loading}

Articular cartilage is subjected to mechanical stresses and strains on a routine basis [21]. The most common loads on cartilage are compression, torsion and shear. The articular cartilage is built by specialized cells called chondrocytes [22]. These cells are exposed to varying strains, stresses, fluid flow and osmotic pressures in the tissue [23]. Experiments have shown that when articular cartilage is compressed, chondrocytes also undergo deformation depending on the load and magnitude [24].

Mechanical loading is an important regulator for maintaining normal cartilage characteristics [25]. The mechanical stresses and strains influence chondrocytes to remodel extra cellular matrix which enables the tissue to smoothly perform its mechanical function [26].

Studies show that a $50 \%$ static compression of cartilage explants decreased synthesis of type II collagen and proteoglycans [27]. However at low amplitudes and frequency, dynamic compression and shear increased type II 
collagen and proteoglycan synthesis [28, 29]. Other experiments in bovine cartilage explants show that a $25-50 \%$ static compression caused a transient increase in aggrecan expression. Studies have shown that aggrecan and type II gene and protein expression increased when an intermittent hydrostatic pressure was applied to human chondrocytes in a monolayer culture at a frequency of 1 $\mathrm{Hz}[30]$.

There is also evidence to show ECM synthesis increases or decreases with respect to magnitude and the duration of the applied load [31]. Research has also shown that matrix synthesis increased when a hydrostatic pressure was applied to cartilage slices within a physiological range [32]. Studies indicate that ECM stiffness increased six-fold when a dynamic load was applied over a period of time [33]. There is also evidence to suggest that cells respond to mechanical stimuli by reorganizing their cytoskeletal structure [34].

The mechanisms through which chondrocytes perceive and respond to mechanical loads are still not completely clear. One possible mechanism may involve coordinated reorganization of the cytoskeletal structure inside the cell. Another possibility is the change in the internal fluid pressure of the chondrocytes. Studies have shown that chondrocytes changed their shape and material property in response to hypo and hyper osmotic stress [22]. A third possibility is the opening of ion channels in response to stimulus. A detailed look into the various possible mechanisms will give us a better picture. 


\subsection{Mechanotransduction Mechanisms}

The process by which mechanical loading is converted into electrical and/or biochemical signals is called mechanotransduction. Recent studies confirm that growth and remodeling in all living tissues are influenced by physical forces, including gravity, tension, compression, osmotic stress and shear, and these effects are exerted at the cellular level $[35,5,22,36]$. Experimental evidence indicates that mechanical stress can alter cell growth, gene expression, differentiation, opening of ion channels, signal transduction, and apoptosis [37, $38,39,40,41]$. Some of the proposed mechanisms are:

\subsubsection{Mechanosensitive Ion Channels}

Ion channels whose gating can be altered by mechanical forces are called mechanosensitive ion channels (MS ion channels). A mechanical stimulus exerted on the cell membrane is converted into electrical or biochemical signal. The notion of mechanically gated ion channels originated from studies of specialized mechanosensory neurons [42]. Later Guharay and Sachs discovered stretch-activated cation channels. A mechanical stretch of intact tissue such as isolated myocytes, or membrane patches rapidly elicits the opening of selective cations such as potassium and sodium ions.

Since then MS ion channels have been reported in a number of cell types including osteoblastic and chondrocytic cell lines [43]. One of the most common examples is the opening and closing of a complex series of valves on the cell membrane which determines the heart cell rhythm. Some valves let certain ions like potassium $(\mathrm{K}+)$ flow out, others let different ions like sodium $(\mathrm{Na}+)$ flow in. 
Figure 5: Ion Channel Function in Heart Cells

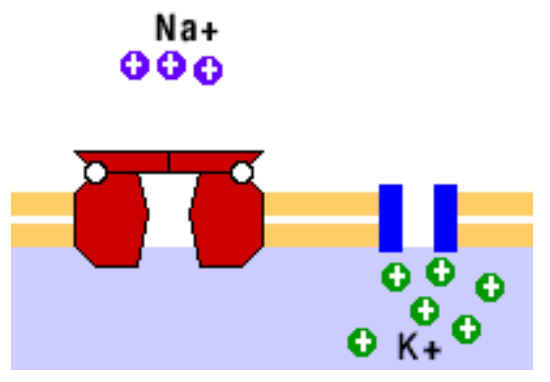

Figure from:

http://www.cellsalive.com/channels.htm

Studies also show that MS ion channels activated by micropipette aspiration could result in whole cells cytosolic calcium responses indicating that MS ion channels may be the first step in the transduction of external physiological mechanical stimuli into whole cell responses [44].

\subsubsection{Cytoskeleton}

Geometric remodeling of the cytoskeleton inside the cell is generally considered to be one of the potential force transducers in cells $[34,45]$. The cytoskeleton's structural role in the cell can make it go through many changes under load, including deformation, reorganization, assembly and disassembly [46].

Ingber in his review work on cellular tensegrity architecture suggested that the structural organization and the interconnectedness of the cytoskeleton provides a physical basis for translating mechanical forces into a biochemical response, as well as a mechanism for integrating these signals with those generated by growth factors and extra cellular matrix [36]. Ingber indicated that the discrete filamentous network provides the main path for mechanical signal transfer from the cell surface to the nucleus. 
Figure 6: Mechanotransduction Through Geometric Remodeling of Cytoskeleton Scaffolds

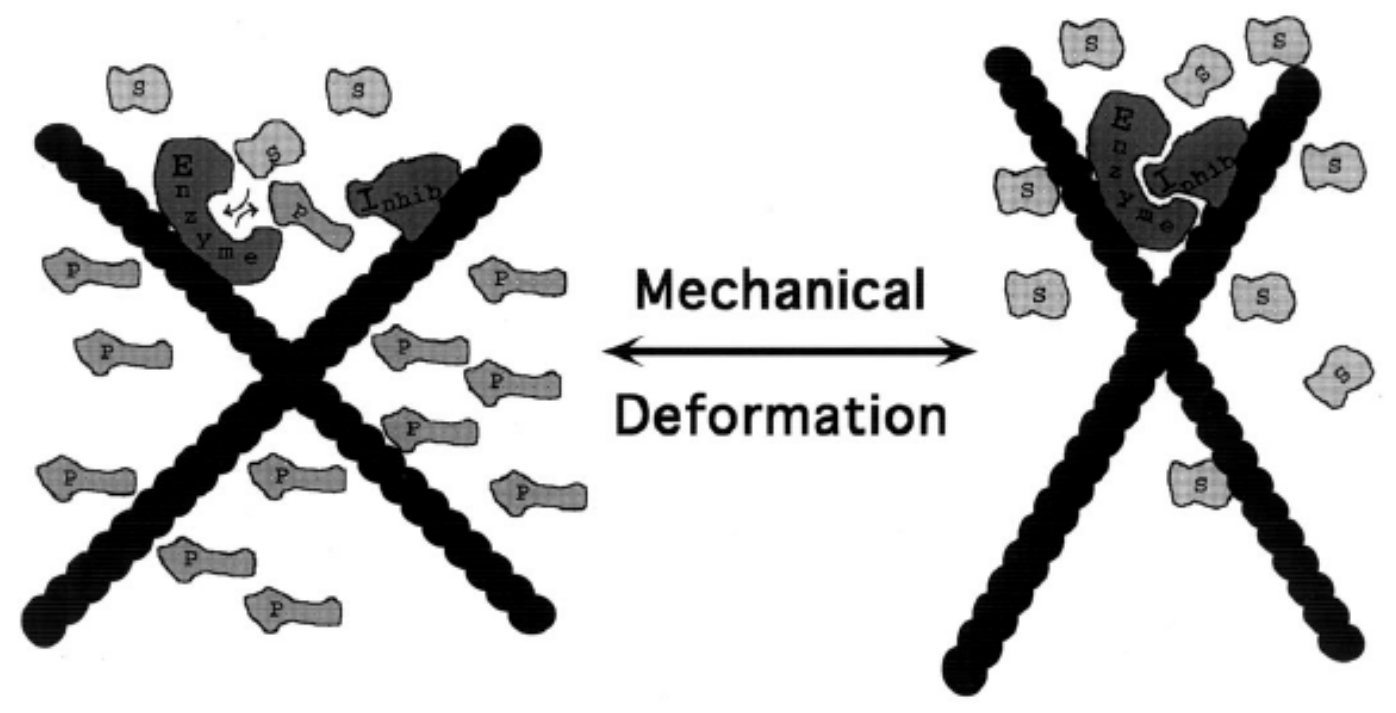

Figure From:

http://www.childrenshospital.org/research/ingber/PDF/1997/annurevphysiolIngber.pdf

Other studies also confirm Ingber's notion. One study found that vimentin, one of the cytoskeletal filaments, changed in response to swelling pressure in chondrocyte culture [34]. In neuronal cells, the cell changed its mechanical properties when the microtubule elements were dissolved indicating that the microtubules may have resisted the compression [47]. Other studies showed that chondrocytes seeded in agarose changed their cytoskeletal organization with time which appeared to affect the way nucleus deformed under load [45].

Studies in our lab by other researchers showed that during chondrogenesis (formation of cartilage), there is a clear reorganization in actin cytoskeletal structure [48]. In this study, pre chondrocytes were cultured in 3D and their actin cytoskeletons were observed on different days of culture from days 1 to 12 (See figure 7 ) 
Figure 7: The cells were stained for actin and largest cell cross sectional images were obtained using confocal microscope on Day 1, Day 3 and Day 10 of the 3D culture period. The picture illustrates actin cytoskeleton reorganization in cells from Day 1 to day 10

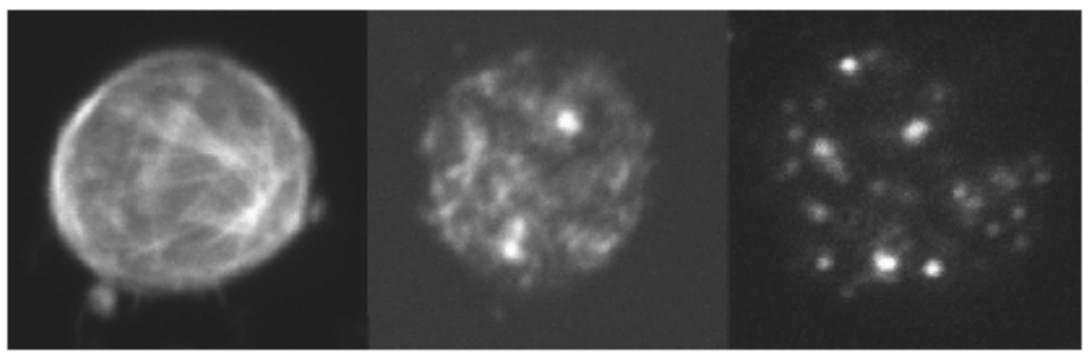

Day 1

Day 3

Day 10

Figure from:

http://kitkat.wvu.edu:8080/files/3580.1.Ayyalasomayajula Madhavi thesis.pdf

Based on the results obtained from our lab and from other studies, there was reason to believe that material properties of cells will change with alterations in cytoskeletal structure. In addition, we assumed that these changes in cytoskeletal structure will also affect the internal fluid pressure of the cell.

\subsubsection{Integrins}

In cell-matrix interactions, integrins act as the primary bridge between extra-cellular matrix and actin cytoskeleton thereby acting as cellular mechanosensors [46]. Alenghat suggested that the mechanical signals that propagate from the extra cellular matrix focus on the cell surface adhesion receptors known as integrins [49]. Several other studies indicate a central role for cell surface integrins in cellular mechanotransduction.

Figure 8: The Cytoskeleton Connected to the Underlying ECM and Neighboring Cells through Focal Adhesion Complexes

Figure from:

http://www.childrenshospital.org/research/ingber/PDF/1997/annurevphysiolIngber.pdf 


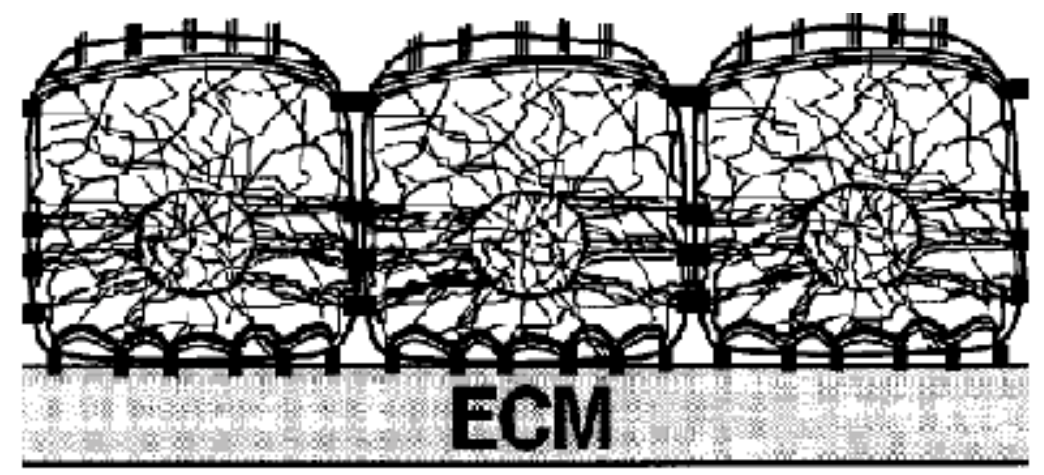

One study showed that integrins increased recruitment of many more signaling molecules to their focal adhesion sites [50]. In another study, Wright linked $\alpha_{5} \beta_{1}$ integrin as one of the components responsible for the hyperpolarization response of chondrocytes to mechanical strain [51].

\subsubsection{Fluid Flow and Pressure}

Another possible mechanotransduction mechanism is fluid flow and pressure inside the cell and its environment.

Studies show that when the ECM of cartilage is compressed, the interstitial water in the tissue exudes leading to an increase in the proteoglycan concentration and associated changes in interstitial ion concentration [52]. This increase in concentration within the tissue may be responsible for the changes in cell shape and volume during tissue compression [53, 54, 55]. Guilak and his associates observed that the disruption of the collagen network in early osteoarthritis leads to increased water content of the tissue [54]. Studies also indicate that as fluid is forced from one point to another within the bone matrix, a potential difference called a streaming potential is created as a result of which osteoblasts remodeling occurs. 
Studies also indicate that fluid shear flow activates $G$ proteins that have been replaced in liposomes suggesting that membrane fluidity alone is sufficient for cell activation [55]. Research studies also demonstrate an increase in intercellular calcium concentration in osteoblasts subjected to steady fluid shear stresses.

Smith and his associates while trying to determine the cell wall properties of yeast cells theorized that there is a certain internal fluid pressure which tries to expand the cell and its membrane $[18,19]$. Hence the cell is considered to behave like a blown-up balloon, which can resist compression.

Studies using osmotic experiments indicate the possibility of internal fluid pressure in cells [22]. Guilak found that depending on the molarity of the extra cellular fluid, chondrocyte cells either swelled or shrunk with associated changes in cell shape and volume.

Based on the above studies we hypothesized that internal fluid pressure exists in cells. 


\section{Chapter2: Objective and Rationale}

The main purpose of this thesis dissertation is to ascertain the presence of internal fluid pressure in individual cells via the role internal fluid pressure plays in changing cell volume and surface area when these cells are poked. Specifically the objectives of this study were:

a) To examine how the cells would respond when it is poked with a micropipette.

b) Evaluate the change in cell surface area (or volume) during poking.

A secondary objective of the study was to characterize the material properties of cells based on cell compression experiments using a 3-D experimental/elasticity approach. In particular, the objectives of this study were:

c) To compress cells embedded in agarose and determine whether cells compress when gel is compressed and if so, to find out the change in cell shape and volume of the cells.

d) To determine material properties of agarose gel and

e) Use the data obtained from steps c) and d) to determine the stiffness of cells embedded in agarose using an experimental/elasticity approach.

From the studies of various possible mechanotransduction mechanisms explained previously, it is reasonable to infer that fluid flow and pressure is also one of the possible mechanisms which would have an effect on cell metabolism. Guilak's osmotic challenge experiments on isolated chondrocytes indicate the possibility of internal fluid pressure in cells and suggest that changes in the fluid pressure may be associated with changes in cell volume and shape [22]. This 
change in cell shape and volume is believed to play a role in the mechanical signal transduction [56].

Smith and his associates modeled the yeast cell as an inflated, liquid-filled sphere with a permeable cell wall lending further credence to the presence of fluid pressure in cells [18]. Results of finite element studies in our laboratory of a cell modeled as a fluid-filled membrane supported by cytoskeletal (actin) filaments showed that the internal fluid pressure determines the overall stiffness of the cell more than the cytoskeletal elements [57].

Based on previous studies and on our own finite element observations in the laboratory, we hypothesized that there is a certain amount of internal fluid pressure in the cell and poking a cell will cause a change in this fluid pressure which in turn will cause a change in the volume or cross sectional area of the cell.

We set up an experimental system in which we poked cells embedded in agarose gel. We assumed that the cell is like a balloon filled with fluid. We reasoned that there would be a reduction in the volume of the cell, but that the entire cell wouldn't collapse like a balloon.

The basis for this reasoning came from studies which showed that the fluid in cells is not entirely free and some of the cell fluid might be structured or restricted [58]. It is a well known fact that the cytoplasm of a cell is crowded with proteins [59]. Muscle and Red Blood Cells are made up of $23 \%$ and $35 \%$ protein respectively by weight [60]. In general, the percentage of protein varies between $17-26 \%$ by weight in actively growing cells. These proteins have positive and 
negative charges due to their amino(+) groups and carbonyl(-) groups. As a result, the vicinal water (water near the surface) of the cell is attracted to the charges and adsorb to the protein molecules. Thus, substantial amount of fluid in the cell is structured (or bound).

Other experimental studies also show evidence of cell-water structuring. Beall and Rao examined cell water in Hamster-ovarian and Hela cells as they passed through their mitotic cycles and found that water was restricted during all phases except active mitosis [61]. Pissis and his associates in a plant cell study observed that $30 \%$ of water molecules are tightly restricted and $70 \%$ restricted to a lesser extent [62].

Based on all the above evidence, we proposed that cells when poked would reduce in cell volume or area with associated changes in cell morphology possibly indicating that internal fluid pressure also plays a major role in cellular mechanotransduction. 


\section{Chapter 3: Cell Poking Experiments}

\subsection{Description of Experimental Setup}

A specially designed experimental setup mounted on a glass stage was used for cell poking experiments. The setup consisted of a custom made mold made of brass pieces to suspend cells in a bio-material gel like agarose, a micropipette controlled by $\mathrm{XYZ}$ micromanipulators for poking the cell, and a holder to seat the custom made mold in place (Refer Figure 8).

The custom made mold was made to suspend the cell/gel mixture and consists of a cover slip two at the top and two brass pieces ground to 500 microns in the bottom and embedded to a glass slide. The gel/cell mixture is formed in between the two brass pieces using a hypodermic needle (see figure 8). The brass pieces are permanently fixed to the glass slide. The experimental approach of suspending cells in agarose gel has many advantages [38]. Agarose culture supports the cell phenotype. It also permits the shape of the cell to be

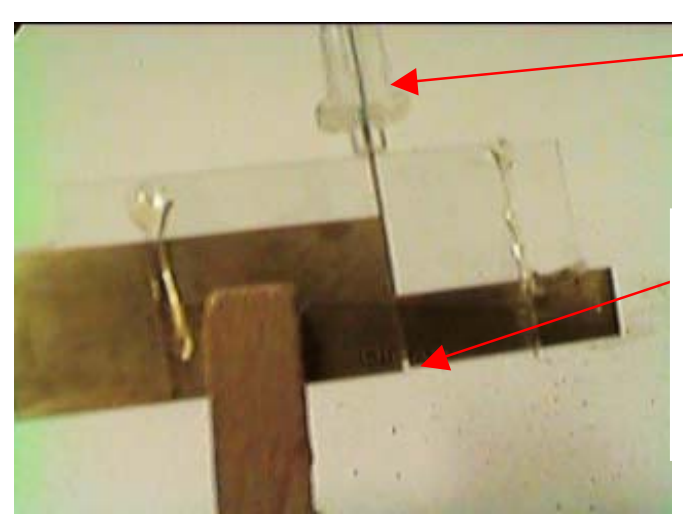

observed through the transparent gel [5].
Needle to inject cell/gel mixture

Gel/cell mixture (500 micron cube)

Figure 9: Custom Made Mold (left) and Experimental Setup (right)
Mold

Holder Micro pipette 
The micropipette (Femtotips II Eppendorf AG Hamburg, Germany) is made of glass and has a thickness of 1 micron at its tip. The XYZ micromanipulator (Parker Hannifin Daedel Rohnert Park, Ca.) helps the micropipette to move in all three directions. Since the micropipette is about 1 micron thick and the cell is about 15 microns in diameter, this allows the micropipette to poke the cell through the gel.

The custom made mold was mounted on an aluminum holder with screws which pinned the glass slide in $Y$ and $Z$ directions and allowed it to move only in the $\mathrm{X}$ direction. This helped in aligning the glass slide with the micropipette for poking purposes. Finally, the setup was supported on a glass stage with screws so that the entire apparatus could be mounted on a confocal microscope for poking and imaging.

\subsection{Description of Cell/Gel Mixture Preparation}

ATDC5 cells (a prechondrogenic cell line, Riken Cell Bank, Japan) at a density of $10^{6}$ cells $/ \mathrm{ml}$ were cultured and trypsinized using standard protocols and kept incubated $\left(37^{\circ} \mathrm{C}\right)$ in a vial. 0.25 grams of low melt agarose (Gels, prepared from low melting agarose melt at $65^{\circ} \mathrm{C}$ and remain fluid at $37^{\circ} \mathrm{C}$ ) were mixed with $12.5 \mathrm{ml}$ of water to give a $2 \%$ agarose solution. This agarose solution was then heated for 20 seconds in a microwave oven. In the meantime, a water bath was set at $37^{\circ} \mathrm{C}$ (for constant temperature control) and the ATDC 5 vial was transferred to the water bath. $80 \mu \mathrm{l}$ of melted agarose was then mixed with $40 \mu \mathrm{l}$

of cells in a separate vial in the water bath using a syringe taking care that there were no air bubbles formed during the mixing process. From this cell/gel mixture, 
$40 \mu \mathrm{l}$ was then injected in between the brass pieces using a hypodermic needle and allowed to solidify. Once the mixture solidified, a cube-shaped gel of approximately 500 cubic $\mu \mathrm{m}$ formed.

\subsection{Imaging Using Confocal Laser Scanning Microscope}

After forming the cell/gel mixture, the cells were stained with a dye (explained in section 3.4) following which the apparatus was mounted on a confocal microscope for scanning and imaging (LSM 510, Zeiss, Germany). The confocal scanning laser microscope (CSLM) provides a noninvasive means for accurate and precise quantification of the three dimensional changes in the morphology of viable cells during compression (or in this case poking) [54]. In a confocal microscope, using coherent laser light, samples are illuminated and imaged one point at a time. The reflected light passes through a pinhole into a photodetector via the focal objective. As a result, light from an out-of-focus image does not interfere with the focused image as it does not reach the photodetector. This enables the CSLM to take a series of discrete optical sections through the depth of the cell or a tissue with improved resolution. These scans, stored as digital arrays of reflected or fluorescent light intensity, are then combined to form a 3-D reconstruction of tissues and cells [63]. This method also offers the advantage of recording dynamic morphological changes in viable cells [63]. 
In this study, confocal microscopy was utilized to examine the hypothesis that poking a cell changes the internal fluid pressure in a cell and alters the cell cross-sectional area (or volume). The CSLM was used to take serial sections through the depth of the cell before and after poking. These sections were later analyzed using a commercial software to determine the change in surface area (or volume) of the cell due to poking. 


\subsection{Fluorescent Imaging using CMFDA dye and Cell Poking}

Before the cell/gel mixture is scanned with CLSM, the cells need to be stained so that there is an image contrast between the cells and its environment. In our study, we stained the cells with $10 \mu$ of $100 \mu$-mol. chloromethylfluorescein diacetate (CMFDA) (Molecular Probes, Oregon, U.S.A.) dye and left the mixture in a dark room for 10 minutes before testing. CMFDA is a cell tracker reagent whose derivatives freely diffuse through the membranes of living cells alone. Once inside the cell, these probes react with intracellular components to produce cells that are both fluorescent and viable for at least 24 hours after loading (Information obtained from www.biocompare.com.) With CMFDA indicator, viable cells appear in the viewing field as green and the surrounding gel appears as black. Once stained, the cells were ready to be tested. The setup was mounted on CLSM and the cells were initially observed under white light using a $100 \mathrm{X}$ objective. The cells were viewed under a 100X objective since the images obtained with a 100X objective facilitate easy and accurate recording of measurements (Refer Figure 10).

Figure 10: Bone Marrow Cell Stained with CMFDA dye under 100x Objective (The cell appears white as it was exported to a different software for analysis purposes)

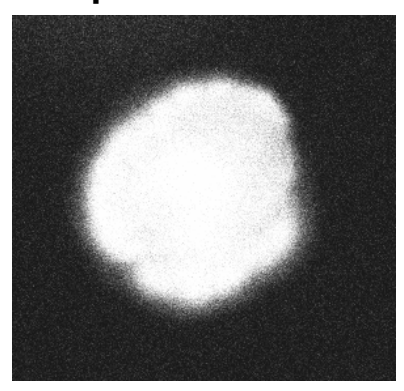

A cell at the edge of the gel was chosen for poking (once the micropipette enters the gel, the pipette bends making poking difficult). The laser light was 
then turned on and an argon laser set at $488 \mathrm{~nm}$ wavelength was used. The various parameters of the confocal microscope like pinhole diameter, amplitude offset and amplitude gain were optimized by trial and error using visual observations for proper measurements. The pinhole diameter was set at 388 microns, amplitude offset was set at 1.0 and $10 \%$ laser intensity was used. Stacks of cross sectional images of the cell chosen for poking were then taken. Volume images were recorded using $20-30$ serial sections at an interval of 1-2 $\mu \mathrm{m}$ (The thickness varied between different stacks but the same thickness was used for a particular stack of images).

The micromanipulator was adjusted in $X$ and $Z$ directions so that the micropipette aligned with the cell to be poked. Once the alignment was set, the micropipette was pushed in the $\mathrm{Y}$ direction till it poked the cell through the gel (Refer Figure 12). Care was taken to make sure that the pipette didn't poke through the entire cell. Then, optical sections of the poked cell were taken applying the same confocal parameters used before.

Figure 11: Cross Sectional Image of an ATDC5 Cell Before and After Poking (This is one of the images obtained from a stack)

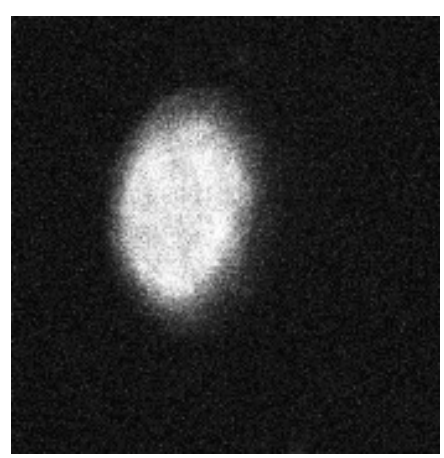

Before Poking

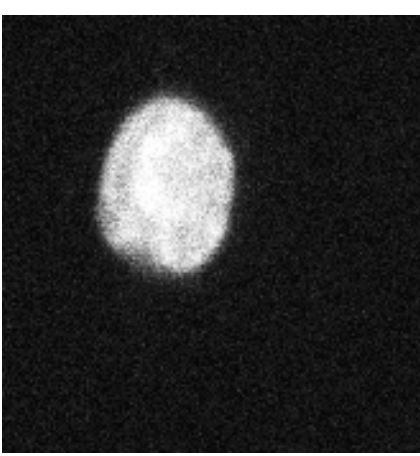

After Poking 
The experiment was repeated with the same cell line four more times to totally obtain 5 sets of data. In order to determine whether different cell lines behaved differently when poked, another cell line (Bone Marrow) was chosen. Bone marrow cells are obtained from the femur of rabbits and have the capacity to differentiate to chondrocytes or osteocytes depending on the environmental stimuli. The same set of poking experiments was repeated and 5 more sets of data were obtained.

\subsection{Determination of Threshold for Cell Poking Analysis using Fluorescent Microspheres}

To analyze the set of images scanned with a CLSM accurately, a threshold has to be established. This threshold is determined using a calibration method on fluorescent microspheres of known diameter and volume (Fluospheres, $15 \mu \mathrm{m}$ diameter; Molecular Probes) similar to the study done by Guilak and his associates [54].

A few drops of fluorescent microspheres were placed in a glass slide and a cover slip was kept over it. The glass slide was then placed under the objective in a confocal microscope and a series of optical confocal sections were scanned for one bead (Refer Figure 13). The pinhole diameter was set at 0.88 microns and 45 slices at $0.30 \mu \mathrm{m}$ thickness were taken. 
Figure 12: Serial Sections of Fluorescent Microspheres
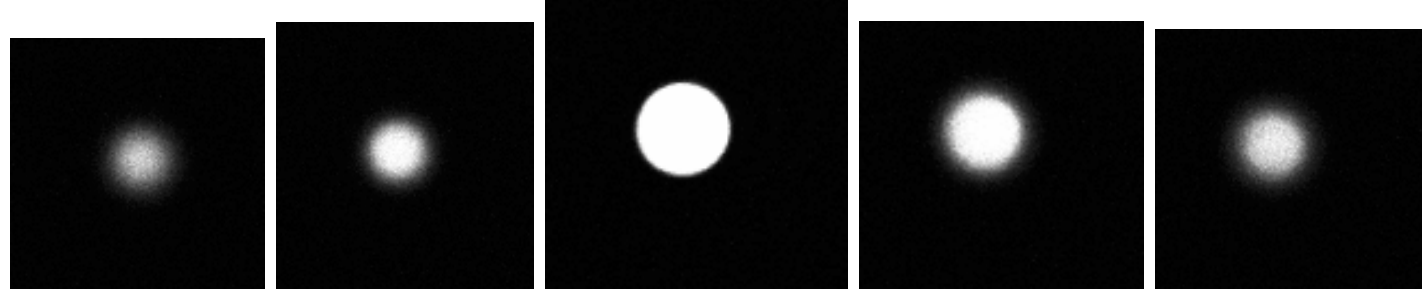

The optical sections were analyzed and the total volume of the bead was computed using different thresholds in a commercially available software called Optimas (Media Cybernetics, Nevada). The total volume was computed by adding up the areas of each confocal section and then multiplying the total area by the thickness of the section (which is constant). The volume of the bead obtained from the analysis was then compared to the actual volume of the bead to determine the optimum threshold (Refer Figure 14). The experiment was repeated a second time for reliability.

Figure 13: Graph Showing the Volume of Beads Obtained From Analysis

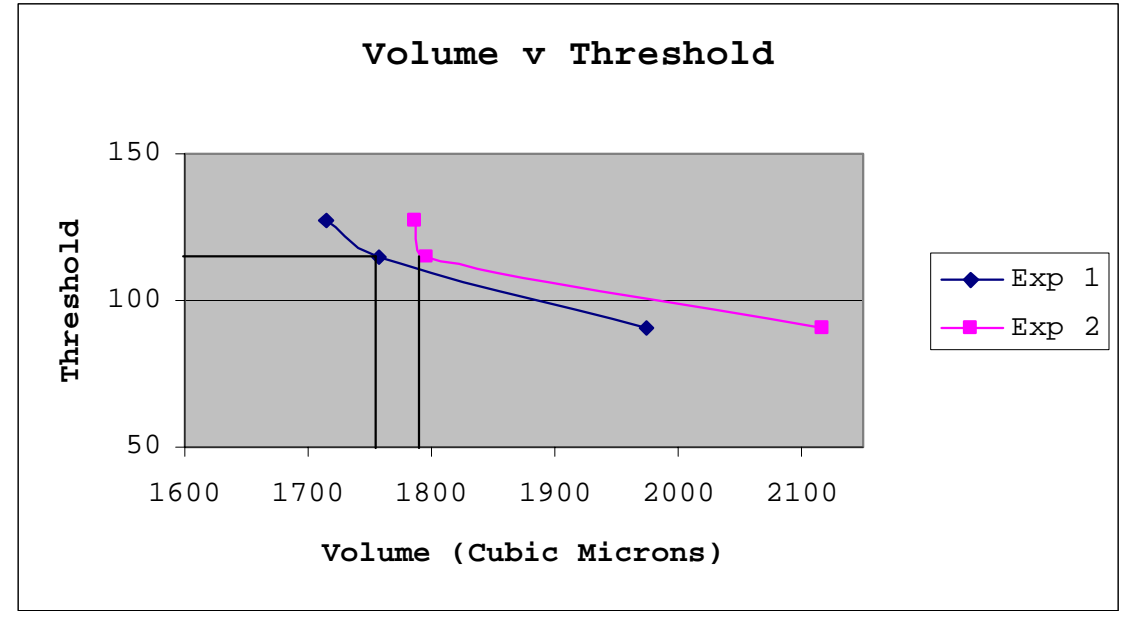

Actual Volume of Beads $=\left(4^{*} 3.14^{*} r^{*} r^{*} r\right) / 3 \quad$ r-radius of beads

$$
\begin{aligned}
& =\left(4^{\star} 3.14^{\star} 7.5^{\star} 7.5^{\star} 7.5\right) / 3 \\
& =1767 \text { cubic microns }
\end{aligned}
$$

Optimum Threshold $=115$ 
From the analysis, the optimum threshold for poking experiments was found to be $115 / 255$.

\subsection{Results and Analysis of Cell Poking Experiments}

Having obtained the optimum threshold value to be used for cell poking analysis, we examined the influence of poking on cell volume. Scanning images obtained from 10 experiments in two different cell lines (ATDC 5 and Bone Marrow) were analyzed. The cell volumes obtained before and after poking the cell were computed. The volumes were then compared to see if there was a reduction in volume of the cell after poking (Refer Table 1).

Table 1 shows that the cell volume reduced after poking in both cell lines. The mean reduction in cell volume after poking in ATDC 5 cell line was $25.63 \%$ with a standard deviation of $15 \%$. Similarly the mean reduction in volume in Bone Marrow cell line was $31 \%$ with a standard deviation of $13 \%$. This shows the presence of internal fluid pressure in cells and indicates that alterations in fluid pressure cause a change in cell volume.

A paired T-test was done for both the cell lines to determine if the change in volume obtained was statistically significant. The test gave a prob $>[t]$ value of 0.02 for the ATDC5 cell line and a prob > [t] value of 0.03 for the Bone Marrow cell line indicating that the results were statistically significant. 
Table 1: Cell Volume Values of Poking Experiments Using CMFDA Dye

\begin{tabular}{|c|c|c|c|c|c|c|}
\hline Exp No & Exp Type & Threshold & Cell Volume & Decrease in Volume & Mean Change & Std Dev \\
\hline & & & & & In Volume & \\
\hline & ATDC5 Cells & & Cubic.Microns & $\%$ & $\%$ & $\%$ \\
\hline & Before Poking & 115,255 & 837.98 & & & \\
\hline \multirow[t]{4}{*}{1} & & & & 49.16 & & \\
\hline & After Poking & 115,255 & 425.99 & & & \\
\hline & & & & & & \\
\hline & Before Poking & 115,255 & 471.92 & & & \\
\hline \multirow[t]{4}{*}{2} & & & & 31.46 & & \\
\hline & After Poking & 115,255 & 323.43 & & & \\
\hline & & & & & & \\
\hline & Before Poking & 115,255 & 656.93 & & & \\
\hline \multirow[t]{4}{*}{3} & & & & 13.76 & 25.626 & 15.01778 \\
\hline & After Poking & 115,255 & 566.54 & & & \\
\hline & & & & & & \\
\hline & Before Poking & 115,255 & 1778.39 & & & \\
\hline \multirow[t]{3}{*}{4} & & & & 20.06 & & \\
\hline & After Poking & 115,255 & 1421.63 & & & \\
\hline & Refore Poking & 115255 & 117239 & & & \\
\hline \multirow[t]{5}{*}{5} & & & & 13.69 & & \\
\hline & After Poking & 115,255 & 1011.75 & & & \\
\hline & & & & & & \\
\hline & BM Cells & & & & & \\
\hline & Before Poking & 115,255 & 2010.31 & & & \\
\hline \multirow[t]{4}{*}{6} & & & & 19.57 & & \\
\hline & After Poking & 115,255 & 1616.99 & & & \\
\hline & & & & & & \\
\hline & Before Poking & 115,255 & 6801.12 & & & \\
\hline \multirow[t]{3}{*}{7} & & & & 20.13 & & \\
\hline & After Poking & 115,255 & 5432.35 & & & \\
\hline & Before Poking & 115,255 & 1772.04 & & & \\
\hline \multirow[t]{4}{*}{8} & & & & 52.83 & 31.006 & 13.47616 \\
\hline & After Poking & 115,255 & 835.92 & & & \\
\hline & & & & & & \\
\hline & Before Poking & 115,255 & 2381.97 & & & \\
\hline \multirow[t]{4}{*}{9} & & & & 31.94 & & \\
\hline & After Poking & 115,255 & 1621.197 & & & \\
\hline & & & & & & \\
\hline & Before Poking & 115,255 & 8145.71 & & & \\
\hline \multirow[t]{2}{*}{10} & & & & 30.56 & & \\
\hline & After Poking & 115,255 & 5656.64 & & & \\
\hline
\end{tabular}




\subsection{Discussion}

The response of cells to poking was studied. The mean change in volume for ATDC5 cells was $25.6 \%$ and $31 \%$ for Bone Marrow. The reduction in volume shows that internal fluid pressure exists in cells and that altering this pressure (by poking) can possibly change cell properties due to the change in cell volume. However, there is also a significantly high standard deviation value for both the cell lines. Therefore, there is a possibility that the results might be skewed to an extent. But this high value in mean and standard deviation can at least in part be attributed to photobleaching effects of the CMFDA dye. Sometimes the established threshold $(115,255)$ couldn't differentiate between the cell border and its surroundings due to the bleaching effect (This was observed visually by the researcher during analysis) resulting in a lower volume value.

Guilak and his associates faced the same problem when they stained chondrocyte nuclei with acridine orange [56]. However we believe that not all the change in volume is due to photobleaching. We think that even if the photo bleaching caused a decrease in cell volume of $5-10 \%$, the remaining $15-20 \%$ of the cell volume change is due to the fluid pressure effect. But this cannot be said with certainty because we had not corrected for drop-off in laser intensity and photobleaching effects. We focused our further studies on the correction factors in order to get a more accurate picture. 


\section{Chapter 4: Photobleaching Experiments}

\subsection{Introduction}

One of the limitations of confocal microscopy is that the specimen is exposed to laser light above and below the plane resulting in photobleaching and phototoxic effects in some regions, even when they are not being visualized [64]. When a fluorescent molecule or a fluorophore loses the ability to fluoresce, the phenomenon of photobleaching occurs. Normally, when a fluorescent molecule absorbs laser light, the molecule elevates the electrons from the ground state to an excited singlet state (all the electrons are spin-paired). When the molecule returns to the ground state from the excited singlet state, a photon is emitted which causes fluorescence. During photobleaching, the flurophore transitions from an excited singlet state to an excited triplet state (one set of electron spins is unpaired). The excited triplet state is relatively long-lived and chemically more reactive thus allowing excited molecules more time to undergo chemical reactions with components in the environment. When this happens, flurophore undergoes irreversible destruction and loses its ability to fluoresce. Some fluorophores bleach quickly while others are more robust. Guilak found a 3-5\% decrease in the nuclear volume of chondrocytes even after correcting for photobleaching and drop-off in laser intensity effects when he took a third set of images [56]. In our study, we experienced photobleaching effects (Refer Figure 15) which might have resulted in a loss of cell volume. 
Figure 14: Effect of Photobleaching on a Cell at $10 \%$ laser intensity

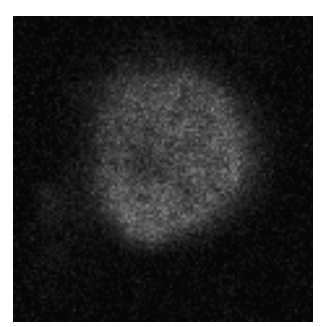

\subsection{Methods}

An experiment was set up to quantify the effect of photobleaching at different laser intensities. Cell/gel mixture was injected in the custom made mold as before and optical cross sections of a cell were taken using confocal microscopy at 0 minutes and 5 minutes of injecting the cell/gel mixture. An important thing to be noted here is that the cell was not poked or compressed or disturbed in any way. A different laser intensity was used for each experiment. Five different intensities $(10 \%, 15 \%, 20 \%, 30 \%$ and $40 \%)$ were used. Cell volumes were calculated at 0 and 5 minutes and the reduction in volume during this time period indicated the photobleaching effect due to laser intensity. 


\subsection{Results}

We examined the effect of photobleaching on cell volume. After computing the volumes at 0 and 5 minutes, we calculated the measured change in volume to compare the effect of different laser intensities (Refer Figure 16).

The graph shows that there was a $15 \%$ reduction in volume when $10 \%$ laser intensity was used. This increased to as high as $46.4 \%$ when the laser intensity was increased to $40 \%$. From the graph, it is apparent that the photobleaching effect increased with laser intensity.

Figure 15: Effect of Laser Intensity on Cell Volume

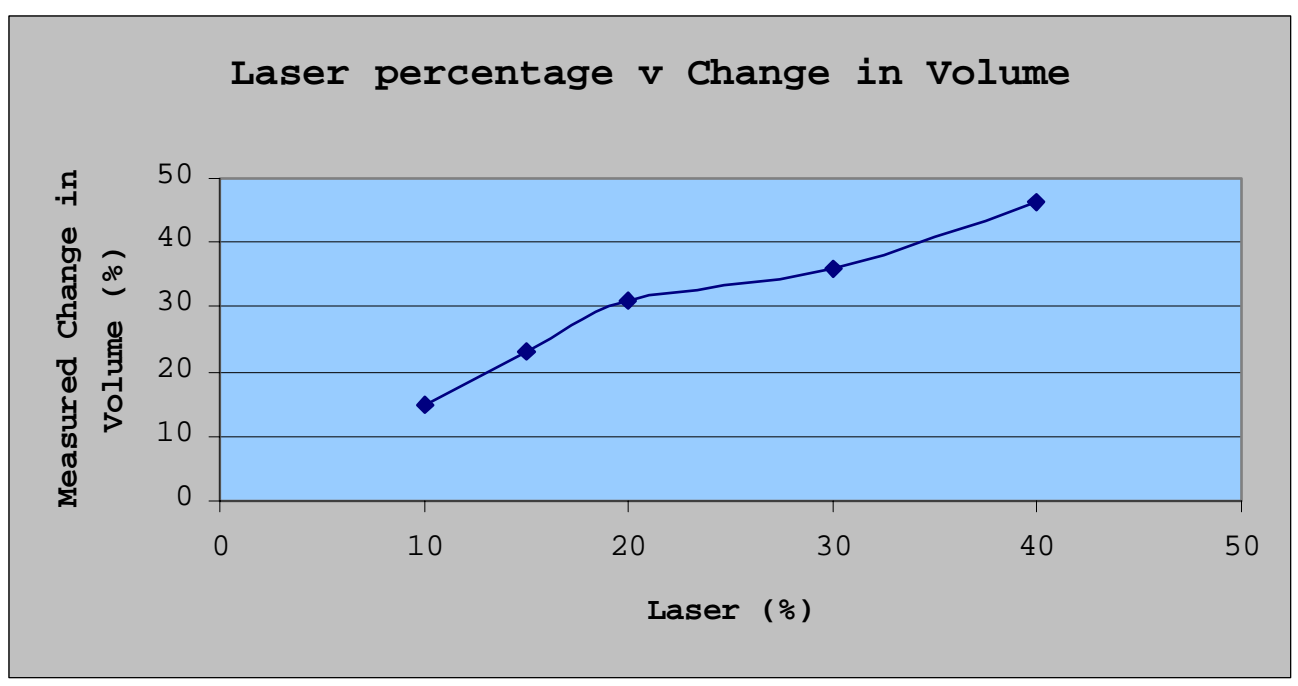




\subsection{Discussion}

The effect of photobleaching when different laser intensities are used was studied. As expected, the reduction in volume increased as the laser intensity percentages were elevated. The cell volume reduction was minimum at $10 \%$ laser intensity (15\% reduction) and maximum at $40 \%$ laser intensity $(46.4 \%)$. In all our subsequent experiments, we therefore decided to use $10 \%$ laser intensity.

In our poking experiment study, $10 \%$ laser intensity was used and our cell volume reductions were $25 \%$ and $31 \%$ respectively in ATDC5 and Bone Marrow cells. Taking into consideration the results of this photobleaching experiment, $15 \%$ of the cell volume reduction may be attributed to photobleaching. This means that the net cell volume reduction due to poking was $10 \%$ for ATDC5 cells and $16 \%$ for Bone Marrow cells. As the two experiments were performed under different conditions, (In the first study, the cell was poked but the cell was undisturbed in the laser intensity experiment) these figures cannot be established with certainty. But it does indicate that at least some percentage of cell volume reduction may have been caused due to changes in internal fluid pressure.

We conducted further studies with a different stain to support the aforementioned statement. 


\section{Chapter 5: Threshold Experiments with Fluorescein Dextran Dye}

\subsection{Introduction}

After our photobleaching experiments, we reasoned that at least part of the reduction in volume of the cell was due to change in internal fluid pressure (due to poking) and not due to photobleaching. But as we had not corrected for photobleaching effects in our poking experiments, we were uncertain. To correct this inconsistency, we decided to repeat our poking experiments with a different dye called fluorescein dextran (Molecular Probes, Oregon, U.S.A.). Fluorescein dextran, unlike the CMFDA dye which localizes in living cells, is excluded from an intact cell membrane but diffuses readily with the extracellular space, giving a high fluorescent contrast between the cell and its extracellular space i.e. in our study, agarose gel [56]. Studies by Guilak show that this dye is less prone to photobleaching. Guilak took repeated confocal scans of chondrocyte cells stained with this dye up to one hour and found that photobleaching effect doesn't significantly affect cell morphometric measurements (see graph). In fluorescein dextran, viable cells appear in the viewing field as black and the surrounding gel appears as white (Refer Figure 16).

Figure 16: Gel/Cell stained with fluorescein dextran (left) and Guilak's photobleaching study (right)

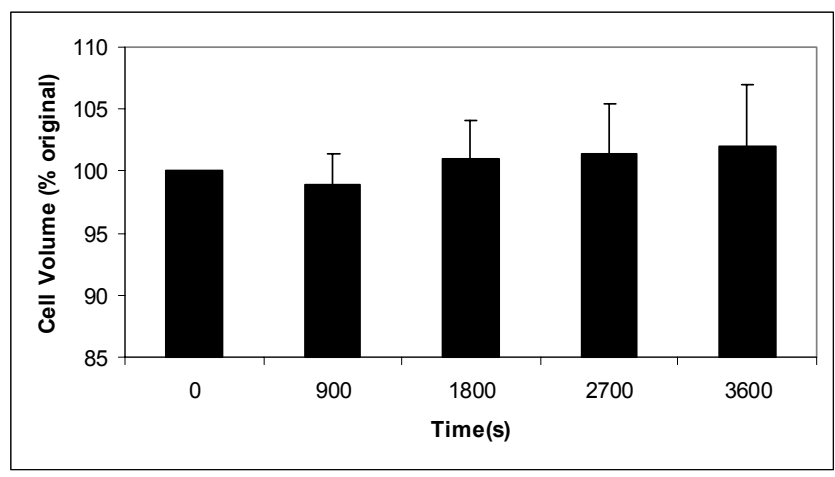


We also wanted to correct for bleaching effects of Fluorescein dextran if there were any. One of the problems associated with photobleaching as explained before was that for certain cross sections, the analysis software (Optimas) picked a lower area at the established threshold $(115,255)$ which consequently resulted in a lower volume value (This was observed visually by the researcher during analysis as described earlier). Sometimes due to the effect of bleaching with time, some parts of the cell appeared as dark as the background. As a result, at the established threshold $(115,255)$, sometimes the areas which were part of the cell were not picked. This resulted in the analysis software sometimes giving a lower cell volume.

To correct this anomaly, we conducted a study to correct the threshold fall-off with time due to bleaching before we performed our poking experiments with Fluorescein dextran.

\subsection{Methods}

The cell/gel mixture was prepared as before but instead of injecting it in the mold, a thin film of the cell/gel mixture was added onto a glass slide. To this film, $10 \mu \mathrm{l}$ of $100 \mu$-mol. fluorescein dextran was added and left to diffuse for 10 minutes in a dark room. The glass slide was then placed on the confocal microscope and serial cross sections of a single cell were taken at three different times $(0,15$ and 30 minutes). 22 slices of the cell were taken each time with the thickness between each slice being constant. An excitation wavelength of 488 $\mathrm{nm}$ was used and laser intensity was set at $10 \%$ (To avoid bleaching). Images were taken with a pinhole diameter of $388 \mu \mathrm{m}$. 
The scanned images were then exported to Optimas software for analysis. The total cell cross sectional area at 0 minutes was calculated with an initial threshold (since the thickness remained constant, it was enough to calculate the CS area). Then thresholds were varied for the cross sectional images taken at 15 and 30 minutes till the total cross-sectional area obtained under a particular threshold approximately equaled the area calculated at 0 minutes using the initial threshold. (Refer Appendix 4).

For example, in the first experiment an initial threshold of $(0,160)$ [The images are black cells on a white background. Therefore the threshold would be $(0,160)$ instead of $(160,255)]$ was used for the optical sections scanned at 0 minutes to give a total area of $1274.03 \mu \mathrm{m}^{2}$. For the images obtained after 15 minutes, several thresholds $[(0,135),(0,110)$ and $(0,133)]$ were used to calculate the total area. At $(0,133)$ the total cross sectional area computed was 1266 . 6 $\mu \mathrm{m}^{2}$ which was approximately close to the area obtained at 0 minutes. So this threshold was selected. This process was repeated for the images obtained at 30 minutes.

The experiment was repeated 3 more times to obtain 4 sets of data. 


\subsection{Results}

A graph was drawn between time and threshold with time as the $X$ axis and threshold as the $\mathrm{Y}$ axis. (Refer Table 2 and Figure 17) and an exponential equation of the kind $\mathbf{y}=y_{0} . e^{-b x}$ was obtained for each experiment wherein $\mathbf{y}$ is the corrected threshold due to the effect of photobleaching, $\mathbf{x}$ is the time and $\mathbf{y}_{\mathrm{o}}$ and $\mathbf{b}$ are constants. From the four experiments, the average $\mathbf{y}_{0}$ was 181.82 and average $\mathbf{b}$ was 0.0156 and the following exponential equation was obtained:

$$
y=181.82 e^{-0.0156 x}
$$

Figure 17: Graph showing threshold versus time

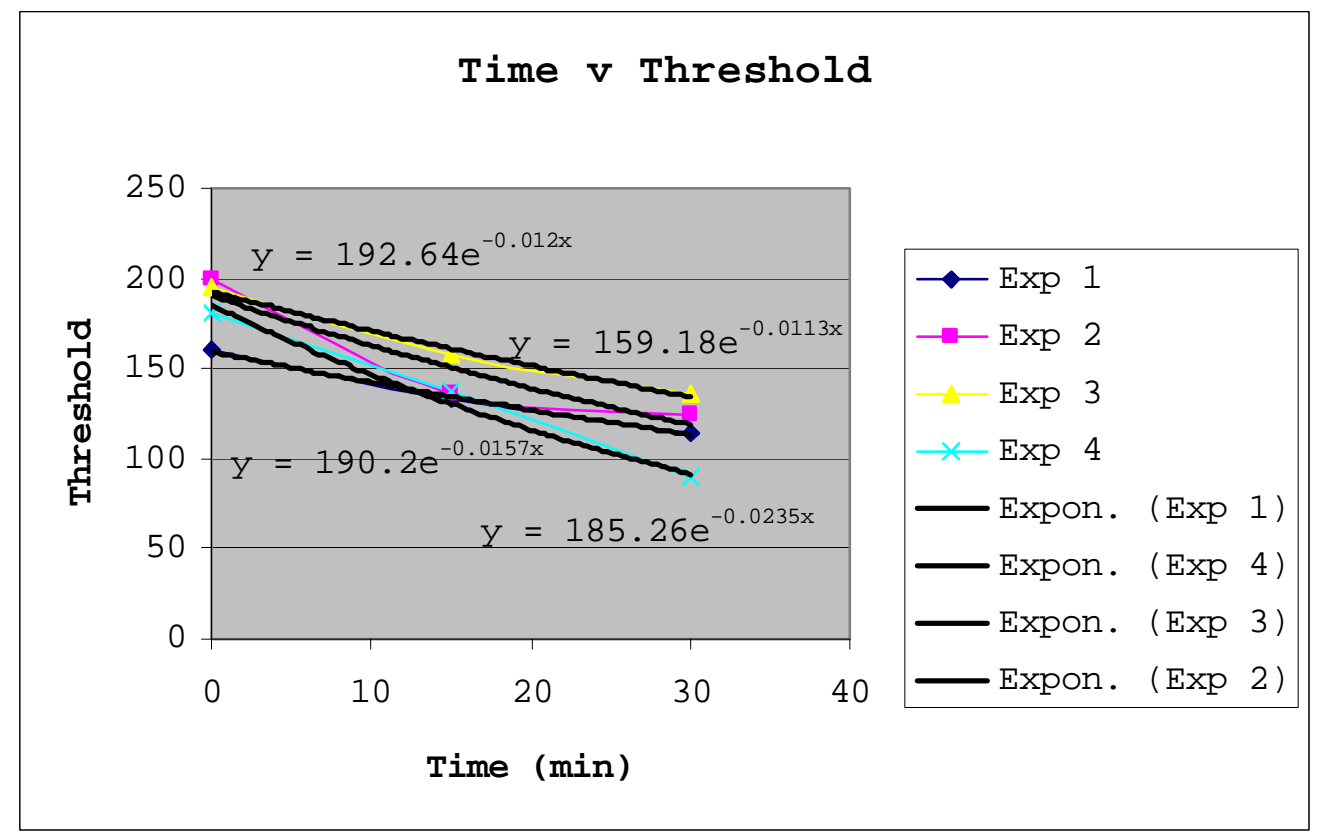

Table 2: Average yo and $b$ values calculated from 4 experiments

\begin{tabular}{|l|r|r|r|r|}
\hline & \multicolumn{2}{|l|}{$\begin{array}{l}\text { Exponential } \\
\text { Fit }\end{array}$} & & \\
\hline & Experiment 1 & Experiment 2 & Experiment 3 & Experiment 4 \\
\hline $\mathrm{Y}_{0}$ & 159.18 & 190.2 & 192.64 & 185.26 \\
\hline $\mathrm{b}$ & 0.0113 & 0.0157 & 0.012 & 0.0235 \\
\hline $\mathrm{r}^{2}$ & 0.9973 & 0.879 & 0.9864 & 0.9803 \\
\hline Ave $\mathrm{Y}_{0}$ & 181.82 & & & \\
\hline Ave b & 0.0156 & & & \\
\hline
\end{tabular}




\subsection{Discussion}

An experiment to correct the fall-off of threshold with time due to photobleaching was examined. An exponential equation which would negate this bleaching effect was formed. The equation $y=181.82 e^{-0.0156 x}$ carried a certain implication to it. It meant that if a cell was poked 10 minutes after taking the unpoked stack of images, then the threshold $\mathbf{y}$ that should be used while analyzing the poked images would be $181.82 \mathrm{e}^{-0.0156^{*} 10}$ which gives a corrected threshold value of $(0,155)$. The significance of this experiment was to find a threshold that would enable repeatable identification of the cell border after taking into account the effect of photobleaching.

This meant that any reduction in cell volume would be due to the effect of cell poking alone and not due to photobleaching. 


\section{Chapter 6: Cell Poking Experiments with Fluorescein Dextran using a control cell.}

\subsection{Introduction}

After correcting for threshold fall-off with time due to bleaching effects, we attempted to examine the effect of poking on cell volume change using Fluorescein dextran stain. We prepared the cell/gel mixture in the custom made mold using normal procedures. As described in chapter 3 , cross sectional image stacks of a cell were taken before and after poking. After noting down the time taken to poke the cell, we incorporated it in to the exponential equation described previously and obtained a new threshold value to be used for post-poking images.

But that didn't solve the photobleaching problem. In our analysis, we found that the Optimas software still couldn't differentiate between the cell and its surroundings for certain sections, especially the first and the last 2-4 confocal sections of the cell.

There could be several reasons for this problem. The first and the foremost problem was that we were also analyzing the first and the last few confocal sections of the cell where the probability of skewed results were more likely to appear. In the first and the last $2-4$ confocal sections, the cell and its surroundings look almost similar and are difficult to delineate. Secondly, when the threshold was corrected using the cell images obtained from the thin film of gel, the laser light was turned off except when the images were scanned at the required time intervals. Cell poking is a delicate method which takes time and the 
laser light needs to be switched on during the entire poking period in order to see pipette enter the cell. This may have led to rapid photobleaching than would have been the case had the laser been turned off.

Therefore we adopted a new strategy wherein instead of one cell, two cells were scanned simultaneously. After staining with fluorescein dextran, two cells were visualized under the viewing field instead of one. One cell was used as the control and the other was used as the experimental cell.

The use of control cells has been a standard operating procedure in many mechanotransduction experiments. Smith found that exposure of chondrocytes to intermittent hydrostatic pressure increased type II collagen mRNA expression almost five-fold after a 4 hour application when compared to unloaded control cells [65]. Another study discovered that exposing human vascular smooth muscle cells to 5 days of chronic cyclical mechanical strain increased fibronectin concentration by $48 \%$ and collagen concentration by $50 \%$ when compared with control cells grown in static conditions. [66].

The control cell in our study was used for correcting threshold fall-off due to bleaching. The poking experiments were performed on the experimental cell. Scanning both the control and experimental cell at the same time meant that both control and experimental cell would be subjected to the laser light for the same time. This meant that once the photobleaching effect was accounted for using the control cell, any reduction in volume would be due to the effect of poking and would give a better idea of the influence of internal fluid pressure on cell volume. 
Another change we introduced in our study was to ignore the first and last few images of the confocal scanning sections. As illustrated earlier, the photobleaching effect was maximum in the first and the last 2-4 sections. In order to avoid these images skewing the results, we ignored these sections while doing our analysis and concentrated on images 5-18 (We scanned 22 sections totally). As we ignored these images, we measured the largest cell cross sectional area and not the volume. The difference between the largest cross sectional area of the cell before and after poking indicated the true effect of poking alone.

\subsection{Methods}

ATDC 5 cells (Riken Cell Bank, Japan) were cultured, trypsinized and mixed with agarose solution using protocols explained previously. The mixture was then injected into the custom made mold as before. Once the cell/gel mixture solidified to give a $500 \mu \mathrm{m}$ cube, $10 \mu \mathrm{l}$ of $100 \mu$-mol. concentration Fluorescein dextran was added. After keeping the mixture in a dark room to allow the stain to diffuse into the gel, the cell/gel construct was observed under the confocal microscope.

Two cells were brought under focus. One was used as the experimental cell and the other was used as control. A laser intensity of $10 \%$ was set and a pin hole diameter of $388 \mu \mathrm{m}$ was used. An argon laser set at $488 \mathrm{~nm}$ was employed. After aligning the micropipette with the experimental cell, image stacks of cross section of the fluorescent cells (Both control and experimental cell) were taken. Then the experimental cell was poked with the micropipette and another set of cross sectional images were scanned (Refer figure 18). 
Figure 18: Cross Sectional Image of a Bone Marrow Control and Experimental Before and After Poking (The cell on the top right is the control and the experimental cell is on the bottom left. The background shows the effect of dye bleaching with time).

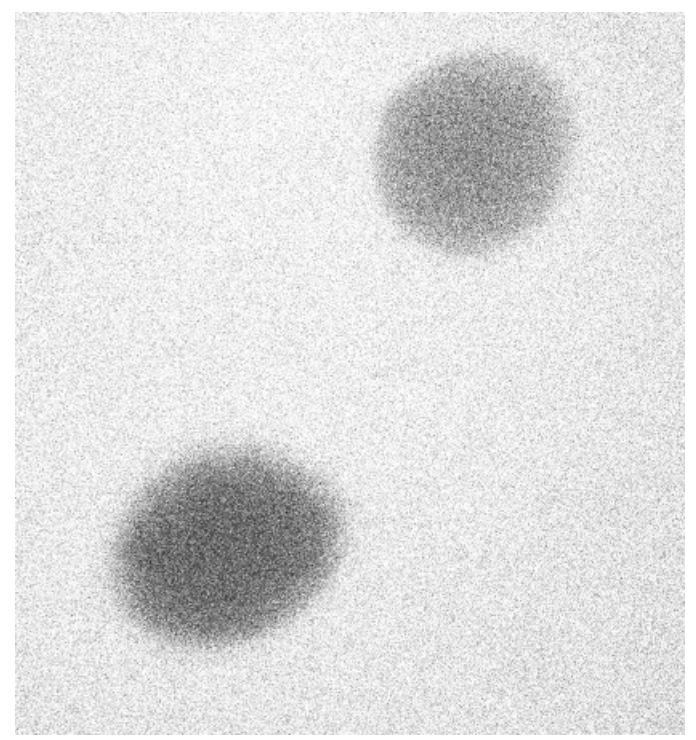

Before Poking

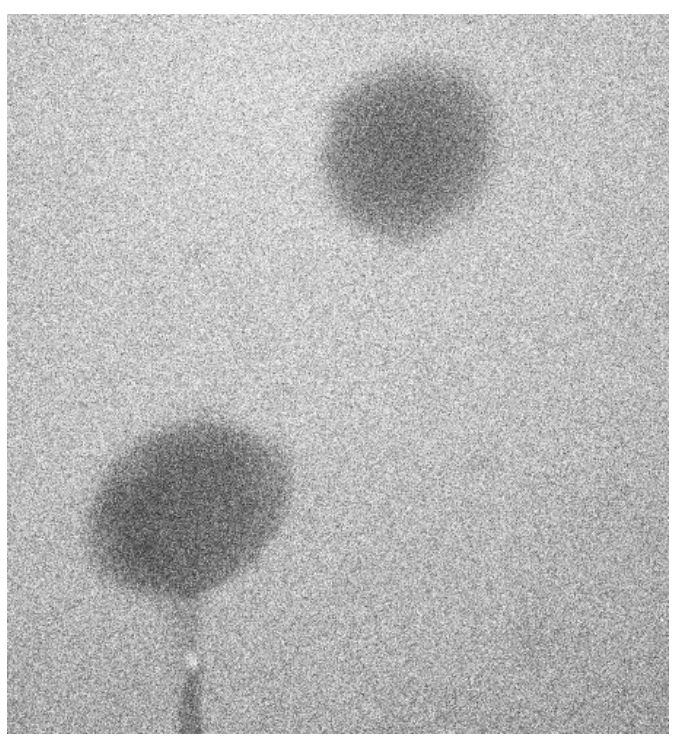

After Poking

After taking the cross sections, the images were analyzed. As said earlier, the first 4 and the last 4 confocal sections were ignored. Ignoring the images meant that the actual cell volume cannot be obtained accurately. Therefore the largest cross sectional area of the experimental cell before and after poking was chosen and the percentage difference in the areas was taken as the change in cell area due to poking. But to compute this change, the threshold fall-off due to bleaching effect was corrected first using the control cell.

During analysis of the control and experimental cell before poking, an initial threshold which best differentiated the cell boundary and its surrounding was chosen. Using this threshold, the cross sectional areas of the stacks were calculated. From this, the largest cross sectional area was selected. Then the control cell after poking was analyzed using different thresholds and the largest 
cross sectional area was computed as before. The threshold which gave an area approximately equal to the area obtained before poking was chosen (Refer figure 19 and Appendix 5).

Figure 19: Largest CS area (upper left) of control cell before poking was matched with the largest CS area of control cell (upper right) after poking by varying the threshold. After setting the threshold, the CS area of experimental cell before (bottom left) and after poking (bottom right) was measured and percentage change in area calculated.

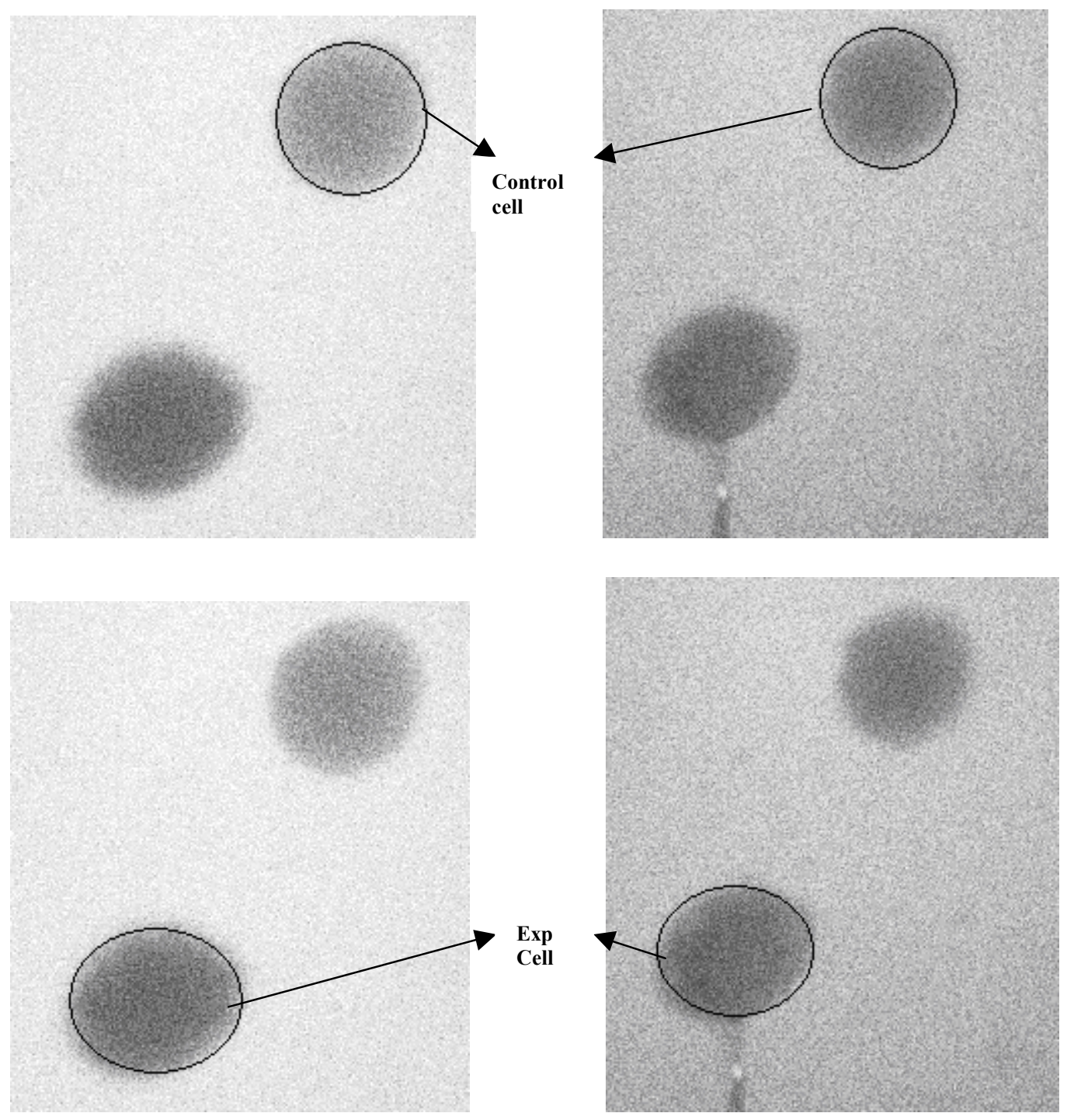

For example, in one experiment at an initial threshold of $(0,225)$ the largest cross sectional area of the control cell was $121.42 \mu \mathrm{m}^{2}$ before poking. 
The threshold was now varied for the control cell after poking and largest cross sectional area was computed. At a threshold of $(0,200)$ the cross sectional area of 121.36 was obtained which approximately equaled the area calculated before poking. The same set of thresholds was now used for the experimental cell also and the largest cross sectional area was calculated as before. Any reduction in this area was then considered to be due to the effect of poking. The use of control cell and correcting for threshold fall-off meant that the effect of dye bleaching was eliminated and any change in area was actually proportional to the change in fluid pressure.

The experiment was repeated 4 more times to totally obtain 5 sets of data. In order to see if poking has the same effect on other cells also, another batch of 5 experiments were conducted using Bone Marrow cells. The data generated from these experiments were tabulated, and compared with the results obtained using CMFDA dye. 


\subsection{Results}

The effect of internal fluid pressure on cell area was studied using poking experiments. Cell/gel mixture was stained with Fluorescein dextran dye and confocal sections of control and experimental cell were taken before and after poking and change in the largest cross sectional area of the cell was computed.

Table 3 shows that the cell area reduced in both cell lines. The mean change in area in ATDC 5 cell line was $15.3 \%$ with a standard deviation of $10.96 \%$. Similarly, the mean change in area of Bone Marrow cells was $15.96 \%$ with a standard deviation of $10.95 \%$. This showed that presence of internal fluid pressure in cells and this change in area was consistent in the two cell lines.

A paired T-test was done on both cell lines to determine if there are any significant differences before and after poking. A prob $>$ [t] value of 0.0071 for the ATDC 5 cell line and a prob > [t] value of 0.0079 for the Bone Marrow cell line was attained. This showed that there was a significant difference in cell area before and after poking.

A power analysis was performed to see if there any significant differences in percent reduction in area between the two cell lines. A power value of 0.051 was generated which showed that there are no significant differences between cell lines due to poking. A least significant number (LSN) of 4138 was acquired which meant that a large number of samples were required to get any significant difference between the two cell lines. 


\begin{tabular}{|c|c|c|c|c|c|c|c|}
\hline $\begin{array}{l}\text { Exp } \\
\text { No }\end{array}$ & Exp Type & Threshold & Control & Experimental & Decrease in & $\begin{array}{c}\text { Mean } \\
\text { Change }\end{array}$ & $\begin{array}{l}\text { Std } \\
\text { Dev }\end{array}$ \\
\hline & & & Cell & Cell & in Area & In Area & \\
\hline & ATDC5 Cells & & $\begin{array}{c}\text { Sq. } \\
\text { Microns }\end{array}$ & Sq.Microns & $\%$ & $\%$ & $\%$ \\
\hline & Before Poking & 0,225 & 121.416 & 146.341 & & & \\
\hline \multirow[t]{3}{*}{1} & & & & & 15.27 & & \\
\hline & After Poking & 0,200 & 121.367 & 123.99 & & & \\
\hline & Before Poking & 0,160 & 99.945 & 282.484 & & & \\
\hline \multirow[t]{4}{*}{2} & & & & & 12.23 & & \\
\hline & After Poking & 0,122 & 98.658 & 247.931 & & & \\
\hline & & & & & & & \\
\hline & Before Poking & 0,228 & 58.305 & 81.715 & & & \\
\hline \multirow[t]{4}{*}{3} & & & & & 5.6 & 15.3 & 10.9622 \\
\hline & After Poking & 0,187 & 57.393 & 77.137 & & & \\
\hline & & & & & & & \\
\hline & Before Poking & 0,228 & 104.359 & 95.529 & & & \\
\hline \multirow[t]{4}{*}{4} & & & & & 33.85 & & \\
\hline & After Poking & 0,187 & 104.001 & 63.19 & & & \\
\hline & & & & & & & \\
\hline & Before Poking & 0,190 & 112.505 & 191.108 & & & \\
\hline \multirow[t]{5}{*}{5} & & & & & 9.55 & & \\
\hline & After Poking & 0,132 & 112.293 & 172.863 & & & \\
\hline & & & & & & & \\
\hline & BM Cells & & & & & & \\
\hline & Before Poking & 0,160 & 227.975 & 252.981 & & & \\
\hline \multirow[t]{4}{*}{6} & & & & & 30.7 & & \\
\hline & After Poking & 0,132 & 227.665 & 175.306 & & & \\
\hline & & & & & & & \\
\hline & Before Poking & 0,160 & 698.342 & 902.124 & & & \\
\hline \multirow[t]{4}{*}{7} & & & & & 12.74 & & \\
\hline & After Poking & 0,125 & 701.486 & 787.25 & & & \\
\hline & & & & & & & \\
\hline & Before Poking & 0,190 & 636.92 & 514.238 & & & \\
\hline \multirow[t]{4}{*}{8} & & & & & 5.53 & 15.968 & 10.9577 \\
\hline & After Poking & 0,185 & 636.387 & 485.794 & & & \\
\hline & & & & & & & \\
\hline & Before Poking & 0,165 & 170.973 & 565.734 & & & \\
\hline \multirow[t]{4}{*}{9} & & & & & 6.97 & & \\
\hline & After Poking & 0,145 & 170.077 & 526.277 & & & \\
\hline & & & & & & & \\
\hline & Before Poking & 0,210 & 452.838 & 511.615 & & & \\
\hline \multirow[t]{2}{*}{10} & & & & & 23.9 & & \\
\hline & After Poking & 0,170 & 453.685 & 389.32 & & & \\
\hline & & & & & & & \\
\hline
\end{tabular}

Table 3: Cell Area Values of Poking Experiments Using Fluorescein dextran dye. 


\subsection{Discussion}

The internal fluid pressure in cells was investigated using cell poking experiments. The results showed that cells changed in area due to poking and this reduction in area was consistent in both ATDC 5 and Bone Marrow cells. The use of control cell corrected for photobleaching effects of the dye. This confirmed that the reduction in area was due to change in fluid pressure alone. The paired T-test suggested that there was a 98 percent probability of significant difference in the cell cross sectional area before and after poking. The findings were also consistent with the results obtained from our previous studies using CMFDA dye. In that study we found the reduction in cell volume after poking was around $25 \%$ for ATDC 5 cells and $31 \%$ for Bone Marrow cells. Based on the results of our experiment generated using different laser intensities, we calculated that there was a $15 \%$ change in volume due to bleaching effect of the CMFDA. That meant that $10 \%$ volume reduction for ATDC 5 cells and $15 \%$ volume reduction for Bone Marrow could be attributed to internal fluid pressure. Also, these findings are consistent with the theory that some of the cell water might be restricted or structured [58].

However, there was a wide variation in the percentage area in cell volume and area measurements in both the stains. This suggested that more experiments may have to be done in order to get an accurate estimate.

Based on the results obtained from two different dyes and from two different cell lines, we could say with a certain degree of certainty that the change in cell volume and area was due to the effect of poking, which in turn is 
proportional to the change in fluid pressure. This method has the potential to detect change in fluid pressure in different cell lines and help in achieving the goal of measuring fluid pressure of a cell. This, in turn will help in accomplishing the ultimate goal of finding the bulk modulus $(K)$ of different cells since bulk modulus is defined as,

$$
K=\frac{-P}{(\Delta V / V)}
$$

Where $\mathrm{K}$ is the bulk modulus of the cell, $\mathrm{P}$ is the pressure inside the cell, $\Delta \mathrm{V}$ is the change in volume of the cell after compression and $\mathrm{V}$ is the volume of the cell. 


\section{Chapter 7: Characterizing Material Properties of Cell Using Experimental/ Elasticity Approach}

\subsection{Introduction}

As stated earlier, studies done by other researchers in our laboratory showed that during chondrogenesis (formation of cartilage), there is a change in actin cytoskeletal structure [48]. Also, it has generally been accepted that cytoskeletal structure plays an important role in determining cell properties [57, $11,12,13]$. Therefore, we assumed that as the cytoskeletal structure changes during chondrogenesis, the material properties and the fluid pressure of the cell will also change. We earlier measured the effect of fluid pressure on cells using poking experiments.

Therefore, we concentrated our second study on finding the cell material properties. We investigated a method to characterize the material properties of cells based on cell compression experiments using a 3-D experimental/elasticity approach. Many existing setups used to study cellular behavior subject cells to either tension (by growing cells on a membrane and stretching the membrane) or shear (by subjecting cells to fluid flow), but not compression (important for chondrocytes).

Normally, mechanical properties of chondrocytes were measured by using techniques such as Atomic Force Microscopy wherein cells were indented on a 2-D culture dish [67]. Benya and Shafer showed that chondrocytes maintained in a flattened configuration in a monolayer culture lose their differentiated 
phenotype [68] But the same cells maintained in a rounded configuration in agarose culture recovered the chondrocyte phenotype. This showed that 3-D configuration is important for chondrocyte phenotype.

Therefore, we devised a method in which cells embedded in gels in a 3D culture were compressed to determine the mechanical properties of cells

\subsection{Cell/Gel Compression Experiments to Determine Volume Change}

\subsubsection{Introduction}

Initially, the cell/gel compression experiments were performed to determine whether the cell compressed when the gel was compressed. Once it was determined that the cell embedded in gel compressed, then the change in volume due to compression was calculated.

\subsubsection{Methods}

The experimental setup used for this experiment was the same used for poking experiments, with one exception. Both the brass pieces in the custom made mold used for poking experiments were fixed. For this experiment, only one brass piece was fixed. The other brass piece was made movable and was connected to a micrometer to apply the load to the cell/gel mixture.

ATDC 5 cells (Riken Cell Bank, Japan) were cultured, trypsinized and mixed with agarose solution using protocols explained previously. The mixture was then injected into the custom made mold as before. Once the cell/gel mixture solidified to give a $500 \mu \mathrm{m}$ cube, $10 \mu \mathrm{l}$ of $100 \mu \mathrm{m}$ concentration CMFDA dye was added. After keeping the mixture in a dark room to allow the stain to 
diffuse into the gel, the cell/gel construct was observed under the confocal microscope.

Confocal serial sections of the uncompressed cell were then scanned. A total of 28 cross sections were scanned using a 100X objective at a constant thickness of 0.45 microns. A laser intensity of $10 \%$ was set and a pin hole diameter of $388 \mu \mathrm{m}$ was used. An argon laser set at $488 \mathrm{~nm}$ was employed.

Using the micrometer, the cell/gel mixture was compressed to approximately $30 \%$ of its thickness. Confocal sections were again taken as before using the same parameters (Refer Fig 20).

Figure 20: Largest Confocal Section of uncompressed (left) and compressed cell (right)
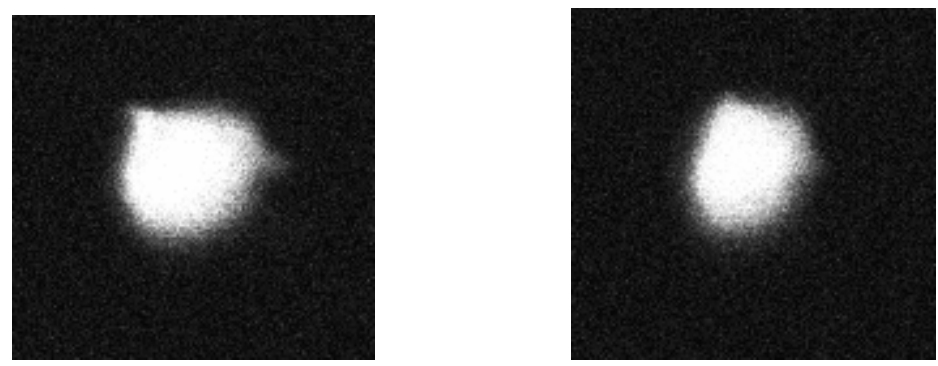

The confocal sections were then analyzed using Optimas. A threshold of $(115,255)$ was used (Based on fluorescent microspheres calibration) and the cell volume was computed for both the uncompressed and compressed cell using the same procedures applied for cell poking experiments. The percentage change in volume was computed from this data. 


\subsubsection{Results}

The change in volume of cells when gel is compressed was studied. Table 4 shows there is a mean compression of $25.73 \%$ in cell volume with a standard deviation of $7.4 \%$.

Table 4: Change in Volume of Cell due to Compression of Gel

\begin{tabular}{|c|c|c|c|c|c|c|}
\hline Exp No & $\begin{array}{c}\text { Original } \\
\text { Volume }\end{array}$ & $\begin{array}{c}\text { Compressed } \\
\text { Volume }\end{array}$ & Threshold & $\begin{array}{c}\text { Change in } \\
\text { Volume }\end{array}$ & Mean & Stdev \\
\hline & Cubic Microns & Cubic Microns & & $\%$ & $\%$ & $\%$ \\
\hline 1 & 1340.75 & 925.59 & 115 & 30.96 & 25.725 & 7.4034 \\
\hline 2 & 1327.41 & 1055.41 & 115 & 20.49 & & \\
\hline
\end{tabular}

\subsubsection{Discussion}

The results of the experiment show that the cell also compressed when load was applied on the gel. As expected, the cell size reduced in X-direction and increased in Y-direction. The change in cell shape obtained from this experiment was later used to find the mechanical properties of the cells (explained later). 


\subsection{Compression Experiments to Determine Gel Properties}

\subsubsection{Introduction}

The material property of gel used for embedding the cells is another important parameter required to find the stiffness of cells. Two standard gels, alginate and agarose, generally used for embedding cells were tested for this purpose. Alginate, a biological material derived from sea algae, is made up of linear block copolymers of $\beta$-D-mannuronic acid and $\alpha$-L-guluronic acid [69]. Alginate provides a three-dimensional matrix for cell culture when cross-linked by divalent ions such as calcium. The cells embedded in alginate can be easily recovered by chelating the cross-linking calcium ions. Agarose is a colloid extracted from sea weed and is a linear polysaccharide made up of the basic repeat unit agarobiose. Agarose gels have high strength and can stain and destain relatively easily. Both agarose and alginate have been used in a number of studies to embed cells [5].

A procedure was developed to prepare $1.2 \%, 2 \%$ and $3 \%$ agarose/alginate gels and compress them in a custom-devised loading apparatus. The values from the gel compression experiment were then incorporated in the experimental/elasticity solution to find the stiffness of cells. 


\subsubsection{Methods}

A new experimental setup was designed for this experiment. The setup consisted of a fixed platen, a loading platen connected to a load cell $(20 \mathrm{~g}$, Entran, Fairfield, New Jersey), a micrometer to compress the gel, and a DVRT (DVRT Microstrain, Burlington, VT) to measure displacement. A custom made mold (different from the one used for poking experiments) was used to generate the agarose and alginate gel (Refer Figure 21).

Figure 21: Experimental Setup (left) and Custom-made mold to generate big gel (right)
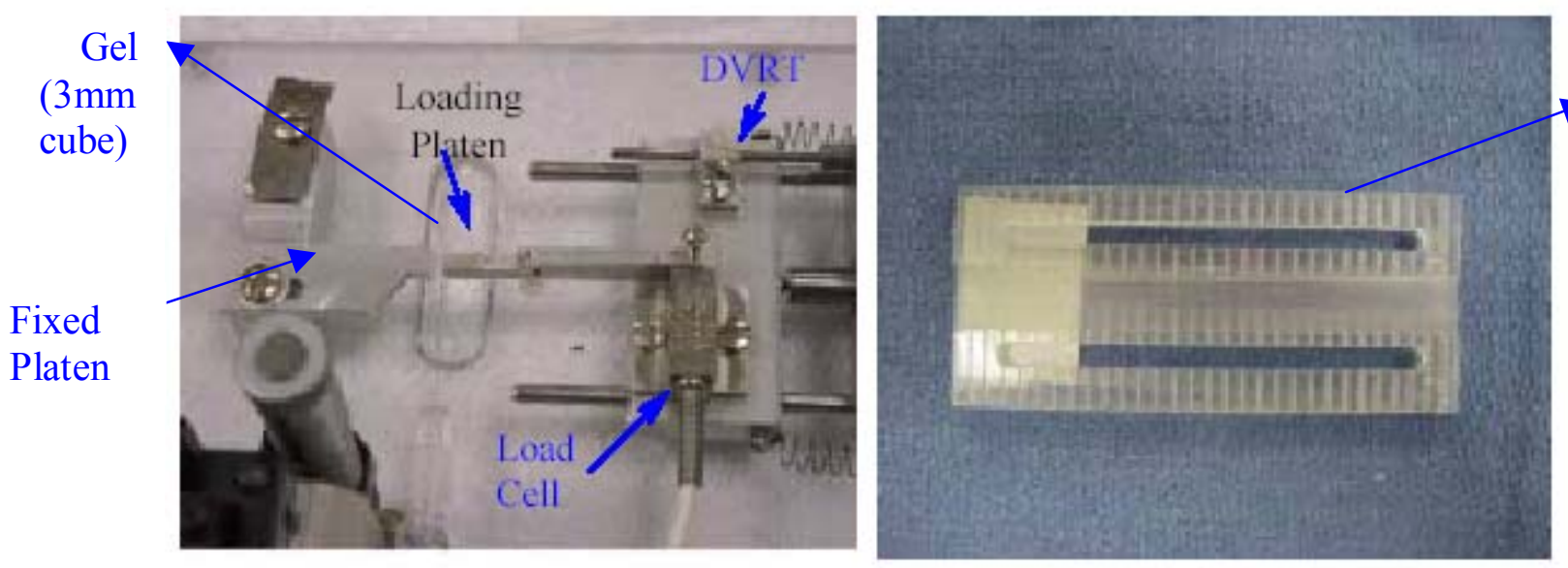

Gel formed in the mold

Required amount of agarose (Depending on percentage of agarose made) was mixed with distilled water in a beaker and then heated in a microwave. The molten agarose was then poured into the custom made mold and left to cool in a refrigerator for 2 minutes. After cooling, approximate $3 \mathrm{~mm}$ cubical blocks of agarose were cut.

The dimensions of the agarose were found using a dial gauge and the cross wires of a light microscope. The cubical agarose blocks were then placed in the customized experimental setup between the fixed and loading platen. The 
gel was then compressed in steps using the micrometer. After each compression, the gels were allowed to stress-relax and equilibrate. The load cell measured the load applied on the gel and the DVRT measure the displacement of the gel at each step. The data for deformation and loading were acquired using Labtech Software (LABTECH NOTEBOOK ${ }^{\text {TM }}$, MA) in a Gateway 2000 computer. 5 experiments were performed for each agarose concentration $(1.2 \%$, $2 \%, 3 \%$ ). To ensure repeatability of the experimental setup, inter and intraobserver repeatability tests were carried out. Similarly, 5 sets of experiments for each concentration $(1.2 \%, 2 \%, 3 \%)$ were obtained with alginate gel.

\subsubsection{Results}

The material properties of agarose/alginate gel were examined using a customized apparatus. Load-Time and Displacement-Time curves were obtained using Microsoft Excel for each compression experiment (See Figure 22).

Figure 22: Load-Time and Displacement-Time Curves for $3 \mathrm{~mm}$ cubes of $2 \%$ agarose (The Viscelastic behavior of agarose can be observed here)
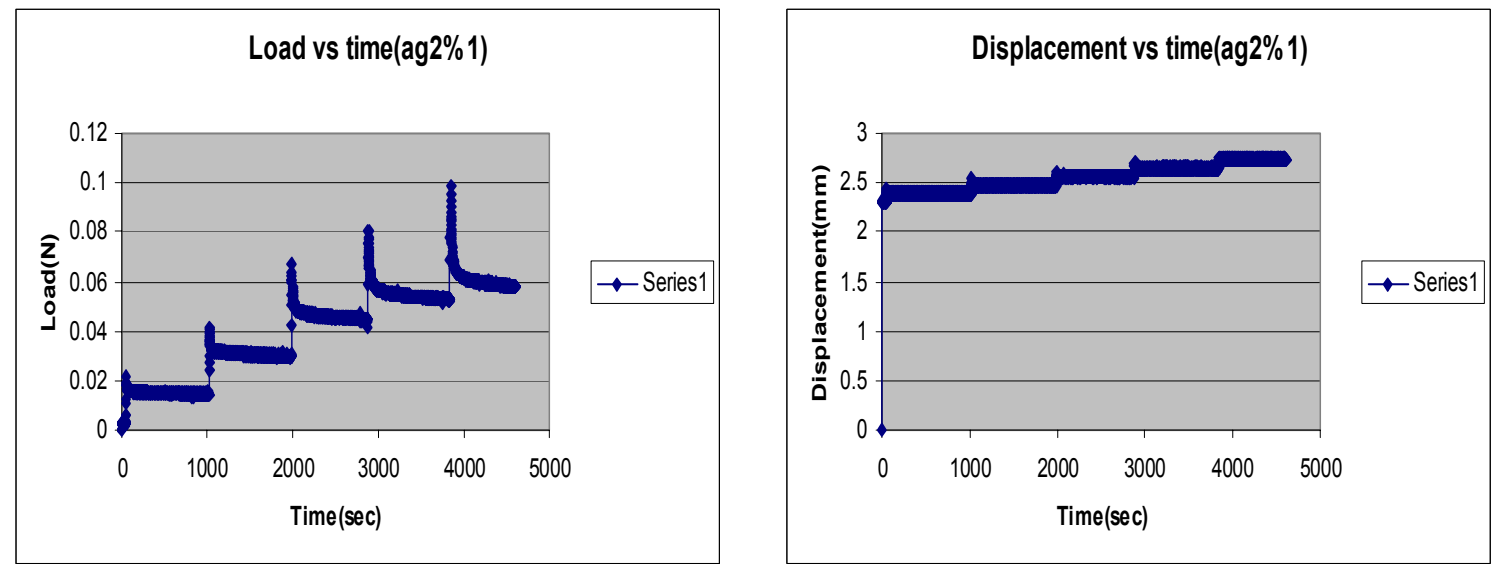

After each compression, the gel was allowed to stress-relax and equilibrate (see graph). The equilibrated data obtained from these curves were 
then used to calculate the stress-strain values, from which the gel modulus was obtained (See Figure 23). The following formulas were used to calculate the stress, strain and gel stiffness values.
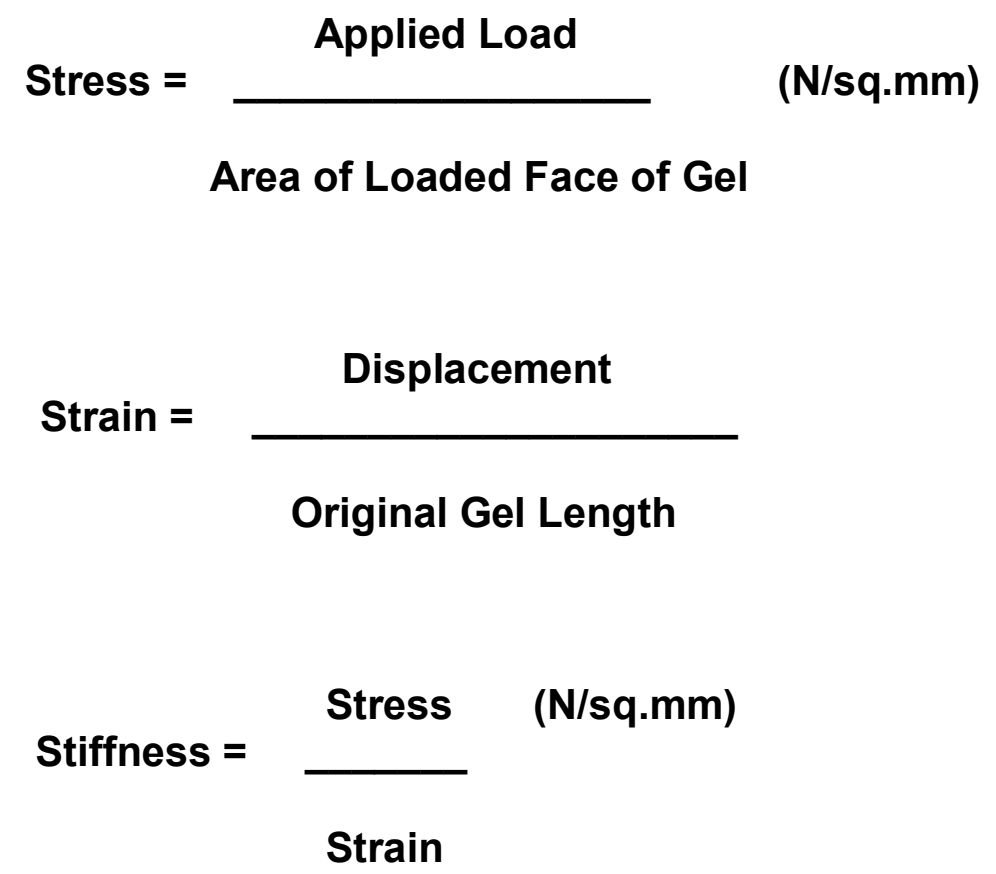

The Stress-Strain graphs were thus obtained for each experiment.

Figure 23: Stress-Strain curve with trend line (Stiffness of the gel is $40.8 \mathrm{KPa}$ )

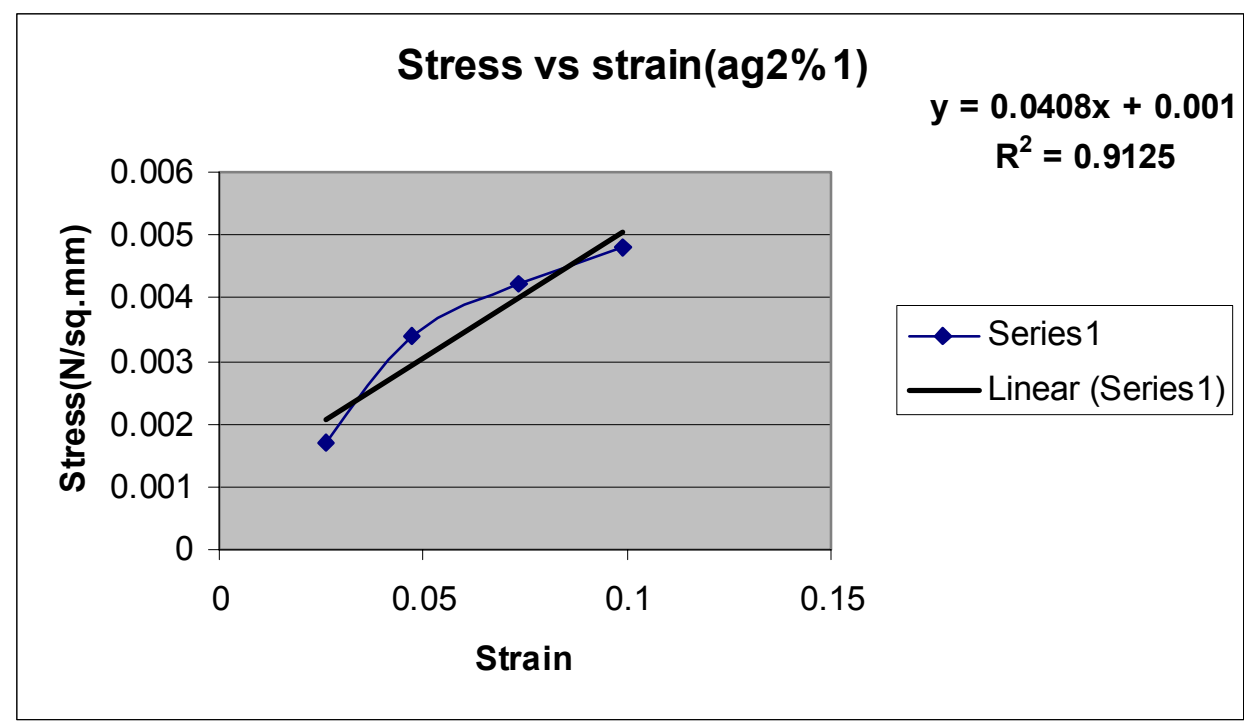


The stiffness was obtained for all the experiments ( 5 agarose and 5 alginate) using this procedure. Table 5 illustrates all the stiffness values for both gels with mean and standard deviations. 


\begin{tabular}{|c|c|c|c|c|c|c|c|c|c|}
\hline Agarose & Conc(\%) & $E($ Kpa) & Mean & $\begin{array}{l}\text { Std } \\
\text { Dev }\end{array}$ & Alginate & Conc(\%) & E(Kpa) & Mean & StdDev \\
\hline & $1.20 \%$ & 18.2 & 19 & 6.1086 & & 1.2 & 6.5 & 7.3 & 2.5758 \\
\hline & & 27 & & & & & 3.6 & & \\
\hline & & 22.5 & & & & & 10.4 & & \\
\hline & & 16.4 & & & & & 8.9 & & \\
\hline & & 10.9 & & & & & 7.1 & & \\
\hline & & & & & & & & & \\
\hline & & & & & & & & & \\
\hline & & & & & & & & & \\
\hline & & & & & & & & & \\
\hline & $2.00 \%$ & 40.8 & 40.98 & 16.361 & & $2.00 \%$ & 30.9 & 30.9 & 2.9112 \\
\hline & & 49 & & & & & 27.1 & & \\
\hline & & 16 & & & & & 29.2 & & \\
\hline & & 60.4 & & & & & 34.5 & & \\
\hline & & 38.7 & & & & & 32.8 & & \\
\hline & & & & & & & & & \\
\hline & & & & & & & & & \\
\hline & & & & & & & & & \\
\hline & & & & & & & & & \\
\hline & $3.00 \%$ & 104.5 & 102.34 & 25.958 & & $3.00 \%$ & 38.4 & 42.12 & 7.7082 \\
\hline & & 128.7 & & & & & 46.2 & & \\
\hline & & 87.5 & & & & & 37.1 & & \\
\hline & & 124.5 & & & & & 53.7 & & \\
\hline & & 66.5 & & & & & 35.2 & & \\
\hline
\end{tabular}

Table 5: Stiffness Values for Agarose and Alginate Gel

Inter and Intra-Observer repeatability tests were performed for agarose gel to ensure that the experiment could be performed repeatedly with consistent results. For inter-repeatability tests, the same experiment was repeated on each gel four times. 2 different gels were tested 4 times each. Table 6 shows that the inter-repeatability was pretty high with low standard deviation.

Table 6: Inter-Repeatability Test using two different agarose gels (Four Experiments were repeated on each gel)

\begin{tabular}{|r|r|r|l|l|r|r|r|l|}
\hline Gel 1 & $\mathrm{E}(\mathrm{KPa})$ & Avg(Kpa) & Std dev & & Gel 2 & $\mathrm{E}(\mathrm{KPa})$ & Avg(Kpa) & Std dev \\
\hline & 116.8 & 120.3 & 3.24037 & & & 96 & 94.75 & 2.076054 \\
\hline & 118.8 & & & & & 97 & & \\
\hline & 124.3 & & & & & 93.3 & & \\
\hline & 121.3 & & & & & 92.7 & & \\
\hline
\end{tabular}


For intra-repeatability, two different observers performed the compression test two times each. Table 7 shows intra-observer repeatability was also pretty high.

Table 7: Intra-Observer Repeatability with two different observers (Each observer tested the gel 2 times)

\begin{tabular}{|c|c|c|c|c|}
\hline Conc & $\begin{array}{c}\text { E (Observer } \\
\text { 1) }\end{array}$ & $\begin{array}{c}\text { E (Observer } \\
\text { 2) }\end{array}$ & Mean & StdDev \\
\hline \% & Kpa & Kpa & Kpa & Kpa \\
\hline 3 & 88 & 86.9 & 88.45 & 0.636 \\
\hline 3 & 88.9 & 90.3 & 88.6 & 0.106 \\
\hline
\end{tabular}

\subsubsection{Discussion}

The material properties of alginate and agarose gels were found using compression experiments. As expected, the stiffness of the gels increased with concentration. The inter and intra-observer repeatability results were consistent. However, there was a wide variation in the gel stiffness values. One possible reason could be due to the use of non-uniform gels for the experiment. All the gels didn't have the same measurements as they were cut manually. While doing the analysis, we found that the gel measurements made a difference to the stiffness value. Another possible reason for the variation could be the presence of inclusions or air bubbles in the gel. Despite these limitations, the results of our study were in the range of values obtained by Nussinovitch [70].

Figure 24: Graphical comparison of Nussinovitch and our results.
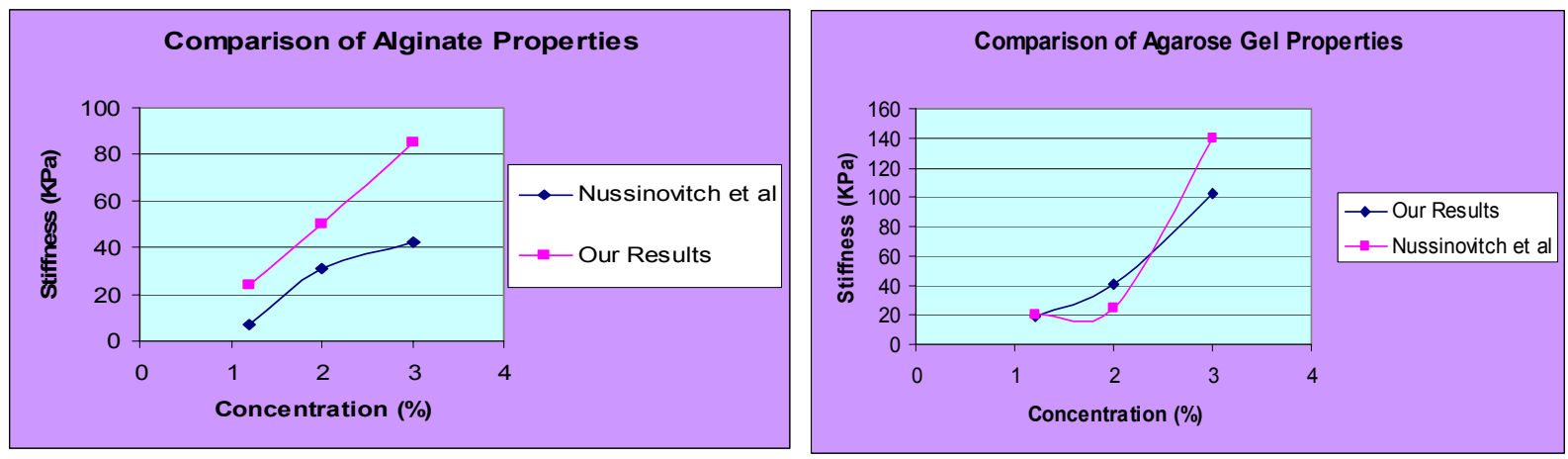
Also, the stiffness values were repeatable indicating that our experimental setup was precise. The accuracy of cell properties depends on the correctness of gel properties. In our literature research, we found that the gel properties vary from one study to another. Our experiments also showed that the gel properties is equipment-dependent and therefore using properties from other studies would render the results dubious.

After obtaining the gel properties, we proceeded to find the radial deformation of the cell when they were compressed. We then incorporated this data into an elasticity solution to obtain the material properties of the cell.

\subsection{Determining Radial Deformation and Curve Fitting}

The confocal images obtained from cell/gel compression experiment (explained in section 7.2) were post processed in the following manner to find the cell material properties. The largest cross section of the uncompressed and compressed cell was taken and analyzed using a threshold of $(115,255)$

Figure 25: Largest Cross Section of Uncompressed (left) and Compressed Cell (right) (The cell reduces laterally and increases longitudinally)
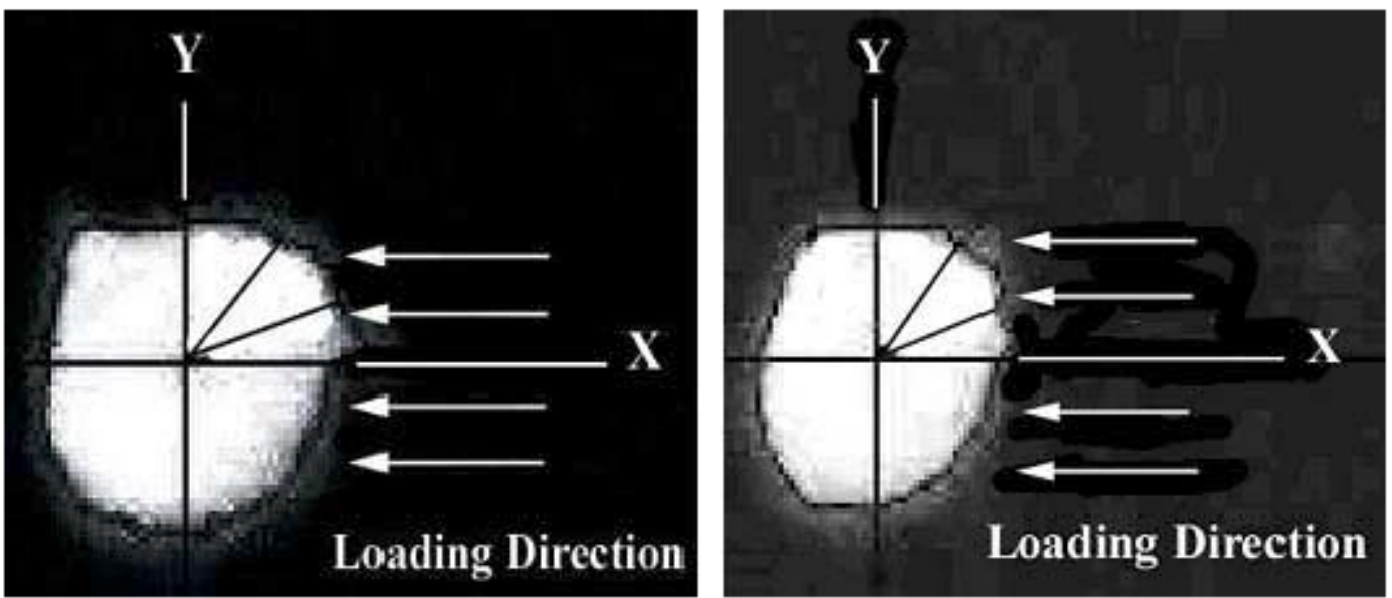
The arrows represent the loading direction and the black lines show the thresholded cell boundary. The radius of the cell for uncompressed and compressed cell was calculated at various angles $(0,10,20 \ldots 90)$ with respect to the loading axis. The difference in radii $\left(U_{r}\right)$ was then plotted against the angles (Refer Fig 25) with respect to loading axis. The cell, as expected, reduced in size after compression in the lateral direction (in the direction of loading) to give a positive $U_{r}$ and increased in size in the longitudinal direction (perpendicular to the loading direction) to give a negative $U_{r}$.

Figure 26: Plot of Radial Deformation at Various Angles

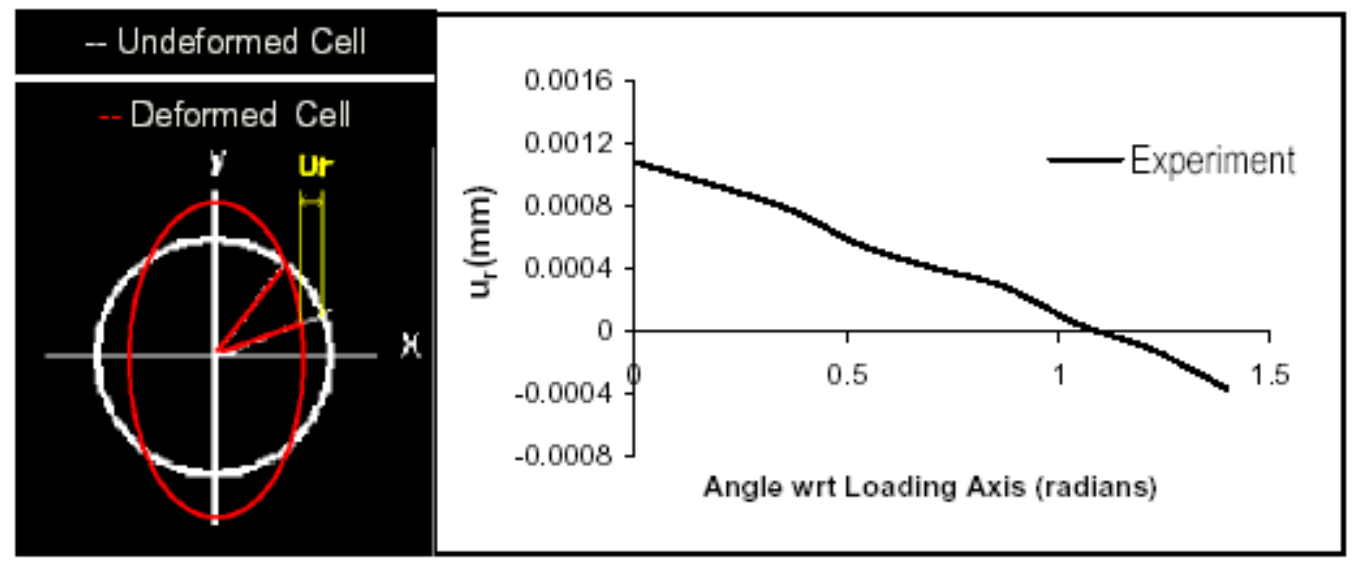

Figure from:

http://kitkat.wvu.edu:8080/files/3580.1.Ayvalasomayajula Madhavi thesis.pdf.

Goodier derived a closed form solution of a spherical inclusion (in our case - cell) in an infinite medium (in our case - agarose gel), when subjected to compressive loading [71]. The solution assumes continuous stress and deformation fields and no slip at the cell-gel boundary. The medium and the inclusion are considered to be elastic and axisymmetry is presumed.

In our study, the material properties of the gel, the stress applied, the radius of the cell and a stiffness value of the cell were given as inputs to the 
Goodier equation (see appendix). The cell and gel was assumed to be incompressible $\left(v_{t}=0.5\right)$. The radial deformation of the cell as a function of angle with respect to loading axis was obtained as output. The experimental data for radial deformation of the cell was curve fit with the theoretical solution using a commercially available software (Maple, Waterloo, Canada and Kaliedagraph, Reading PA) to obtain modulus of elasticity of the cell (Refer Fig 26). The experimental part was done by this researcher while the elasticity solution was done by another researcher in our laboratory.

Figure 27: Curve Fit of Theoretical and Experimental Radial Deformation Values. This fit was obtained at a cell stiffness value of $390 \mathrm{~Pa}$.

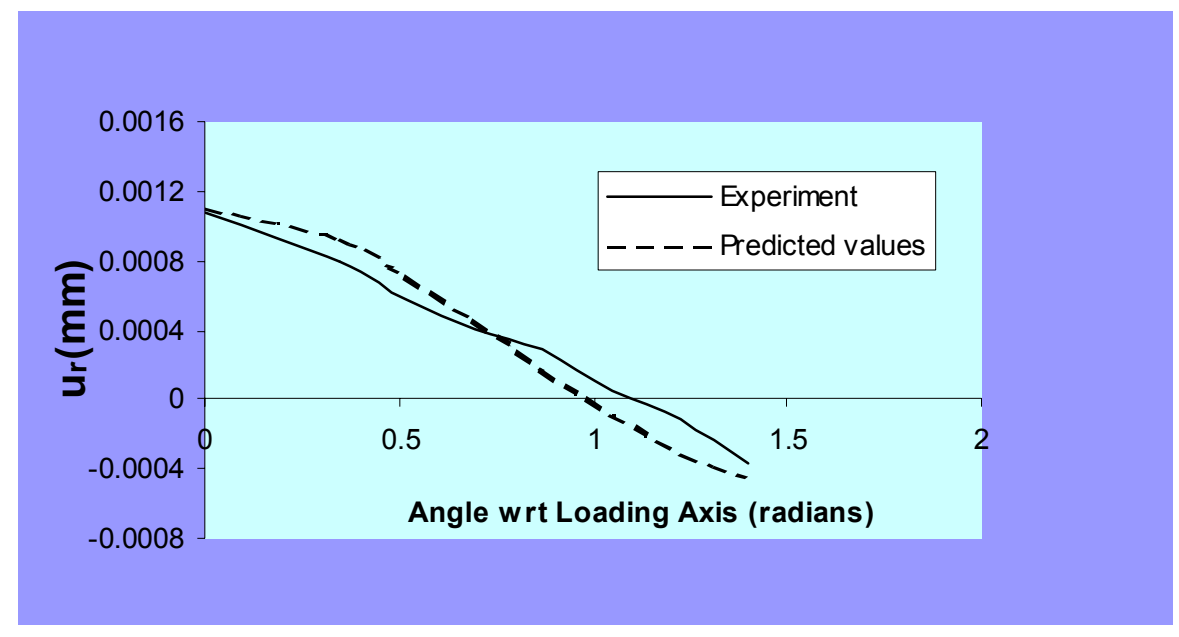

The modulus of elasticity of the cell that best fit the experimental values was $390 \mathrm{~Pa}$. A parametric analysis showed that radial deformation of the cell was affected more by the gel modulus and applied stress than by the cell stiffness. A repeat of the experiment yielded a stiffness value of $424 \mathrm{~Pa}$. Our results fall in the same order of magnitude as those obtained by other people [11]. Guilak obtained a stiffness value of $3600 \mathrm{~Pa}$ for non-osteoarthritic cells and a modulus 
value of $5000 \mathrm{~Pa}$ for osteoarthritic cells However, in order to get repeatable estimates of cell stiffness, the applied stress and gel modulus values have to be very accurate. This requires a better experimental setup wherein uniform gels with same measurements can be created more often. Also a more sensitive load cell should be used as applied stress is an important parameter.

The method has potential to detect difference in stiffness values between two cells or in the same cell, before and after certain treatments like altering its cytoskeletal structure. 


\section{Chapter 8: Conclusion and Future Studies}

\subsection{Discussion}

In this thesis study, we developed a method to ascertain the presence of internal fluid pressure in individual cells via its role in changing cell volume and cross-sectional area and thereby possibly on the cell material properties. Individual cells were embedded in agarose gels, stained with two different dyes and the change in cell volume/area when poked with a micropipette was studied using confocal microscopy. Two different cells lines were examined for this purpose. Also as a secondary study, the cell material properties were found using compression experiments with an experimental/elasticity approach.

Initially, we performed our fluid pressure experiments using CMFDA, an intracellular dye which localizes on living cells. Using a confocal microscope, we poked ATDC5 and Bone Marrow cells and obtained optical serial sections of the cell before and poking. We found that there was a $25 \%$ and $31 \%$ reduction in cell volume in ATDC5 and Bone Marrow cells respectively. We also found that the volume change was significant before and after poking. But we also experienced photobleaching effects which skewed our results to a certain extent.

To correct for these photobleaching effects, we obtained confocal scans of cells under different laser intensities and analyzed the measured change in cell volume. We found that photobleaching effect increased with higher intensities and at the lowest laser intensity of $10 \%$ there was a $15 \%$ reduction in cell volume. After correcting for this percentage reduction in volume due to bleaching 
effects, we estimated that there would be a $10 \%$ reduction in volume for ATDC 5 cells and $16 \%$ reduction in volume for Bone Marrow cells due to poking effect alone. To ascertain this, we conducted further studies with an extracellular dye, Fluorescein dextran, where photobleaching effects are considered to be minimal.

Next, we studied the photobleaching effect of cells stained with Fluorescein dextran dye. We took cross sectional images of a cell at various times and analyzed the threshold fall off with time. We obtained an exponential equation which would correct for the fall in threshold due to dye bleaching. But we still faced photobleaching effects.

Therefore, we conducted poking studies by taking confocal sections of two cells at the same time. One cell was used as the control to correct for threshold fall-off and the other cell was used for poking. Our results were consistent with the results obtained from our earlier study on cells stained with CMFDA dye. Other studies showed that not all the water in the cell is free and that some fluid, especially the vicinal fluid, is structured [58]. Guilak found that acute changes in the osmotic environment influenced chondrocyte deformation indicating that fluid stress or pressure has an effect on the cell material properties and morphology [22]. Our cell poking experiments confirmed that possibility.

As a secondary study, we developed an experimental/elasticity solution to determine the material properties of cells. We first determined whether a cell compressed when the gel in which the cell is embedded in is compressed. Then we examined the change in volume and radial deformation of the cell due to compression using cross sectional images obtained from confocal microscope. 
Next, we found out the material properties of gel alone. We then incorporated these values into an elasticity solution developed by Goodier [71] to determine the cell stiffness.

\subsection{Limitations}

The study developed an effective way to investigate the effect of internal fluid pressure of cells on cell volume and cross-sectional area. However, there are some limitations with this study.

There was a wide variation in the cell volume and area results obtained for the two cell lines. The standard deviation was over $10 \%$ for both the dyes, CMFDA and Fluorescein dextran, which is pretty significant. We conducted 10 experimental ( 5 for each cell line) studies where the images were clear. More number of studies need to be done to bring down the standard deviation to as low a value as possible.

Both dyes had photobleaching problems which couldn't be eliminated. Though corrections were put in place, it didn't completely solve the problem. Hence, the results are not completely accurate. The photobleaching effect on cell volume should be brought down to less than $5 \%$ for more accurate results i.e. variation in cell volume due to bleaching shouldn't be more than $5 \%$. This can be overcome to an extent by performing more experiments wherein the concentration of the dye, and other parameters that affect bleaching such as pinhole diameter are varied until the $5 \%$ percentage reduction in cell volume is reached. 
Also, the confocal sections depended highly on the threshold. A small variance in the threshold made a significant difference to the cell volume and area measurements. As threshold is user-dependent, it lends itself to errors in measurement.

The cell stiffness value obtained from the elasticity/experimental approach, despite falling in the same order of magnitude as other people, is not completely accurate. Parametric analysis showed that cell stiffness value is highly dependent on the accuracy of gel modulus properties. But the gel moduli generated in our studies have a wide variation. We obtained our gel stiffness values separately by creating bigger gels in an experimental setup different from the one used for compression experiment. If we use a gel whose stiffness matches that of the cell more closely, this limitation can be overcome. This can be done by finding the material properties of the gel in the same experimental setup used for the compression experiments. For this, a more sensitive setup is needed.

\subsection{Future Studies}

Osmotic challenge studies in which cells embedded in gels are exposed to different osmotic environments can further validate the presence of internal fluid pressure in cells.

Though the study ascertained the presence of internal fluid pressure, it didn't quantify it. Measuring fluid pressure in the cell and investigating the change in shape and volume of the cell when this pressure is altered would give a more 
accurate prediction of the behavior of cell to different mechanical environments.

An extremely sensitive pressure transducer is required for this purpose. 


\section{References}

1. Mow, V. C., A. Ratcliffe, and A. R. Poole, Cartilage and diarthrodial joints as paradigms for hierarchical materials and structures. Biomaterials, 1992. 13: p. $67-97$.

2. Temenoff, J. S., and A.G. Mikos, Review: Tissue Engineering for regeneration of articular cartilage. Biomaterials, 2000. 21: p. 431-440.

3. Martin, I., et al., Modulation of the mechanical properties of tissue engineered cartilage. Biorheology, 2000. 37 (1-2): p. 141-147.

4. Guilak, F. and V. C. Mow, The mechanical environment of the chondrocyte: a biphasic finite element model of cell-matrix interactions in articular cartilage. J Biomech, 2000. 33(12): p. 1663-73.

5. Freeman P.M., et al., Chondrocyte Cells Respond Mechanically to Compressive Loads. J Orthop Res, 1994. 12(3): p. 311-319.

6. Guilak, F., A. Ratcliffe, and V. C. Mow, Chondrocyte Deformation and Loacl Tissue Strain in Articular'Cartilage: A Confocal Microscopy Study. J Orthop Res, 1995. 13(3): p. 410-421.

7. Buckwalter, J. A., T. A. Einhorn, and S. R. Simon, Orthopaedic Basic Science. $2^{\text {nd }}$ Edition ed. 2000: American Academy of Orthopaedic Surgeons.

8. Akizuki, S., et al., Tensile properties of human knee joint cartilage: I. Influence of ionic conditions, weight bearing, and fibrillation on the tensile modulus. J Orthop Res, 1986. 4(4): p. 379-392. 
9. Shue-Fen Tung., Effects of Dynamic and Static Mechanical Compression on Chondrocyte Metabolism of Aggrecan and Type I/ Collagen, BUG journal, 2001. 3: p. 123-127.

10. Wakatsuki, T., et al., Effects of Cytochalasin $D$ and latrunculin $B$ on mechanical properties of cells, Journal of Cell Science, 2000. 114: p. 1025-36.

11. Guilak, F., et al., Viscoelastic Properties of Intervertebral Disc Cells, SPINE, 1999. 24(23): p. 2475-83.

12. Ingber, D.E., et al., Cellular Tensegrity: exploring how mechanical changes in the cytoskeleton regulate cell growth, migration, and tissue pattern during morphogenesis. Int. Rev. Cytol., 1994. 150: p. 173-224.

13. Wang, N., Mechanical Interactions Among Cytoskeletal Filaments. Hypertension, 1998. 32: p. 162-165.

14. Petersen, N. O., W. B. McConnaughey, and E. L. Elson, Dependence of locally measured cellular deformability on position of the cell, temperature, and cytochalasin B. Proc. Natl. Acad. Sci., 1982. 79: p. 5327-31.

15. Rotsch, C., and M. Radmacher., Drug-Induced Changes of Cytoskeletal Structure and Mechanics in Fibroblasts: An Atomic Force Microscopy Study. Biophys J., 2000. 78: p. 520-535.

16. Wang, N., et al., Mechanical behavior in living cells consistent with the tensegrity model. Proc Natl Acad Sci., 2001. 98(14): p. 7765-77.

17. Stamenovic, D., et al., Cell prestress. II. Contribution of microtubules. Am J Physiol Cell Physiol., 2002. 282: p. C617-C624. 
18. Smith, A.E., On uniquely determining cell-wall material properties with the compression experiment. Chem Eng Sci, 1998. 53(23): p. 3913-22.

19. Smith, A.E., Wall material properties of yeast cells: Part I. Cell measurements and compression experiments. Chem Eng Sci, 2000. 55: p. 2031-41.

20. Ingber, D. E., Cellular tensegrity: defining new rules of biological design that govern the cytoskeleton. Journal of Cell Science, 1993. 104: p. 613627.

21. Hodge, W.A., et al., Contact Pressures in the Human Hip Joint Measured in vivo. Proc Natl Acad Sci, 1986. 83(9): p. 2879-83.

22. Guilak, F., G. R. Erickson, and H. P. Ting-Beall, The Effects of Osmotic Stress on the Viscoelastic and Physical Properties of Articular Chondrocytes. Biophys J, 2002. 82: p. 720-727.

23. Guilak, F., The deformation behavior and viscoelastic properties of chondrocytes in articular cartilage. Biorheology, 2000. 37(1-2): p. 27-44.

24. Kaab, M. J., et al., Deformation of chondrocytes in articular cartilage under compressive load: a morphological study. Cells Tissues Organs, 2003. 175(3): p. 133-139.

25. Holmvall, K., et al., Chondrocyte and chondrosarcoma cell integrins with affinity for collagen type II and their response to mechanical stress. Exp Cell Res, 1995. 221(2): p. 496-503.

26. Fitzgerald, J. B., et al., Mechanical Compression of Cartilage Explants Induces Multiple Time-Dependent Gene Expression Patterns and Involves 
Intracellular Calcium and Cyclic AMP. J Biol. Chem., 2004. 279(19): p. 19502-11.

27. Guilak, F., et al., The effects of matrix compression on proteoglycan metabolism in articular cartilage explants. Osteoarthritis Cartilage, 1994. 2(2): p. 91-101.

28. Bonassar, L. J., et al., The effect of dynamic compression on the response of articular cartilage to insulin-like growth factor-I. J Orthop Res, 2001. 19(1): p. 11-17.

29. Jin, M., et al., Tissue Shear Deformation Stimulates Proteoglycan and Protein Biosynthesis in Bovine Cartilage Explants. Arch. Biochem. Biophys., 2001. 395(1): p. 41-48.

30. Ikenoue, T., et al., Mechanoregulation of human articular chondrocyte aggrecan and type II collagen expression by intermittent hydrostatic pressure in vitro. J Orthop. Res., 2003. 21(1): p. 110-116.

31. Gray, M. L., et al., Mechanical and physiochemical determinants of the chondrocyte biosynthetic response. J Orthop Res., 1988. 6(6): p. 777-792.

32. Hall, A. C., et al., The effects of hydrostatic pressure on matrix synthesis in articular cartilage. J Orthop Res., 1991. 9: p. 1-10.

33. Mauck R. L., et al., Functional tissue engineering of articular cartilage through dynamic loading of chondrocyte-seeded agarose gels. J Biomech Engg., 2000. 122(3): p. 252-260. 
34. Durrant L. A., et al., Organisation of the chondrocyte cytoskeleton and its response to changing mechanical conditions in organ culture. J Anat., 1999. 194(3): p. 343-53.

35. Burger, E. H., and J. Klein-Nulend, Microgravity and Bone Cell Mechanosensitivity. Bone, 1998. 22(5): p. 127S-130S.

36. Ingber, D. E., Tensegrity: the architectural basis of cellular mechanotransduction. Annu. Rev. Physiol., 1997. 59: p. 575-599.

37. Hatton, J. P., et al., A Short Pulse of Mechanical Force Induces Gene Expression and Growth in MC3T3-E1 Osteoblasts via an ERK 1/2 Pathway. J Bone Miner., 2002. 18(1): p. 58-66.

38. Elder, S.H., et al., Effect of compressive loading on chondrocyte differentiation in agarose cultures of chick limb-bud cells. J Orthop. Res., 2000. 18(1): p. 78-86.

39. Wright, M., Effects of intermittent pressure-induced strain on the electrophysiology of cultured human chondrocytes: evidence for the presence of stretch-activated membrane ion channels. Clinical Science, 1996. 90: p. 61-71.

40. Sadoshima, J., Mechanical stretch rapidly activates multiple signal transduction pathways in cardiac myocetes: potential involvement of an autocrine/paracrine mechanism. The EMBO journal, 1993. 12(4): 1681-92.

41. Ewers, B. J., et al., The extent of matrix damage and chondrocyte death in mechanically traumatized articular cartilage explants depends on rate of loading. J Orthop. Res., 2001. 19: 779-784. 
42. Fatt, P., and B. Katz, Membrane potentials at the motor end-plate. $J$ Physiol., 1950. 3(3-4): p. 46-47.

43. Davidson, R. M., D. W. Tatakis, and A. L. Auerbach, Multiple forms of mechanosensitive ion channels in osteoblast-like cells. Pflugers Arch., 1990. 416: p. 646-651.

44. Kirber, M. T., et al., Multiple pathways responsible for the stretch-induced increase in $\mathrm{Ca}^{2+}$ concentration in toad stomach smooth muscle cells. $\mathrm{J}$ Physiol., 2000. 524(1): p. 3-17.

45. Lee, D. A., et al., Chondrocyte deformation within compressed agarose constructs at the cellular and sub-cellular levels. J Biomech., 2000. 33(1): p. 81-95.

46. Shieh, A. C., and K. A. Athanasiou, Principles of cell mechanics for cartilage tissue engineering. Ann Biomed. Eng., 2003. 31(1): p. 1-11.

47. Dennerll, T. J., et al., Tension and compression in the cytoskeleton of PC12 neurites. II: Quantitative measurements. J Cell. Biol., 1988. 107: p. 665-674.

48. Ayyalasomayajula, M. V S., Influence of Rearrangement of Actin Cytoskelton on the Overall Material Properties of ATDC5 cells during Chondrogenesis. Master's Thesis, 2004. West Virginia University.

49. Alenghat, F. J., and D. E. Ingber, Mechanotransduction: All Signals Point to Cytoskeleton, Matrix, and Integrins. Sci STKE., 2002. 119: PE6.

50. Miyamoto, S., et al., Integrin function: molecular hierarchies of cytoskeletal and signaling molecules. J Cell Biol., 1995. 131: p. 791-805. 
51. Wright, M.O., et al., Hyperpolarisation of cultured human chondrocytes following cyclic pressure-induced strain: evidence of a role for alpha 5 beta 1 integrin as a chondrocyte mechanoreceptor. J Orthop Res.,1997. 15: p. 741-747.

52. Maroudas, A. Phyicochemical properties of articular cartilage. In Adult Articular Cartilage. Pitman Medical, Tunbridge Wells., 1979. p. 215-290.

53. Wong, M., et al., Chondrocyte biosynthesis correlates with local tissue strain in statically compressed adult articular cartilage. J Orthop Res., 1997. 15(2): p. 189-196.

54. Guilak, F., et al., Mechanical and biochemical changes in the superficial zone of articular cartilage in canine experimental osteoarthritis. J Orthop Res., 1994. 12(4): p. 474-484.

55. Gudi, S., J. P. Nolan, and J.A. Frangos, Modulation of GTPase activity of G proteins by fluid shear stress and phospholipid composition. Proc Natl Acad Sci., 1998. 95(5): p. 2515-9.

56. Guilak, F., Compression-Induced Changes in the Shape and Volume of the Chondrocyte Nucleus. J Biomech., 1995. 28(12): p. 1529-41.

57. Venkatesan, V., Finite Element Analysis of cell subjected to compressive loading. Master's Thesis, 2002. West Virginia University.

58. Pollack, G. H., Cells, Gels and the Engines of Life. Ebner and Sons, Seattle Washington, 2001. p. 53-75.

59. Porter, K.R., M.C. Beckerle, and M.A. McNiven, The cytoplasmic matrix. Mod. Cell Biol., 1983. 2: p. 259-302. 
60. Andersson, R. M., et al., Characterization of probe binding and comparison of its influence on fluorescence lifetime of two $\mathrm{pH}$-sensitive benzo[c]xanthene dyes using intensity-modulated multiple-wavelength scanning technique. Anal Biochem., 2000. 283(1): p. 104-110.

61. Adlakha R. C., et al., Localization of mitotic factors on metaphase chromosomes. J Cell Sci., 1982. 54: p. 193-206.

62. Pissis, P., et al., A Dielectric Study of the State of Water in Plant Stems. J Exp Bot., 1987. 38: p. 1528-40.

63. Guilak, F., Volume and surface area measurement of viable chondrocytes in situ using geometric modeling of serial confocal sections. J Microsc., 1994. 173(3): p. 245-256.

64. Cahalan, M. D., et al., Two-photon tissue imaging: seeing the immune system in a fresh light. Nat Rev Immunol., 2002. 2(11): p. 872-880.

65. Smith, L. R., et al., Time-dependent effects of intermittent hydrostatic pressure on articular chondrocyte type /I collagen and aggrecan mRNA expression. JRRD, 2000. 37(2): 153-162.

66. O' Callaghan, C. J., and B. Williams, Mechanical Strain-Induced Extracellular Matrix Production by Human Vascular Smooth Muscle Cells: Role of TGF- $ß_{1}$. Hypertension, 2000. 36: 319-324.

67. Hung, C. T., K. D. Costa, and E. X. Guo, Apparent and Transient Mechanical Properties of Chondrocytes during Osmotic Loading using Triphasic Theory and AFM Indentation. BED, 2001. 50: p. 1-2. 
68. Benya, P.D., and J. D. Shaffer, Dedifferentiated chondrocytes reexpress the differentiated collagen phenotype when cultured in agarose gels. Cell, 1982. 30: p. 215-224.

69. LeRoux, M. A., F. Guilak, and L. A. Setton, Compressive and shear properties of alginate gel: effects of sodium ions and alginate concentration. J Biomed Mater Res., 1999. 47(1): 46-53.

70. Nussinovitch, A., M. Peleg and M. D. Normand, A modified Maxwell and a non-exponential model for characterization of the stress relaxation of agar and alginate gels. J. Food Science, 1989. 54(4), 1013-16.

71. Goodier, J. N., Concentration of stress around spherical and cylindrical inclusions and flows. J Applied Mechanics, 1933. 55: p. 39-44. 


\section{Appendix 1}

\section{Calibration Using Fluorescent Microspheres}

Confocal Sections of fluorescent microspheres of known volume and diameter $(D=15 \mu \mathrm{m})$ were scanned and reconstructed using different thresholds. The threshold which gave a bead volume approximately equal to the actual volume was chosen for experimental purposes. A total of 45 slices were scanned with the thickness of each slice being $0.3 \mu \mathrm{m}$. The pinhole diameter was set at $0.88 \mu \mathrm{m}$.

\begin{tabular}{|c|c|c|c|}
\hline Experiment 1 & 91,255 & 115,255 & 127,255 \\
\hline & 0 & 0 & 0 \\
\hline & 0 & 0 & 0 \\
\hline & 0 & 0 & 0 \\
\hline & 84.2975 & 0 & 0 \\
\hline & 94.938 & 0 & 0 \\
\hline & 107.748 & 0 & 0 \\
\hline & 117.975 & 103.099 & 96.281 \\
\hline & 129.649 & 115.083 & 108.988 \\
\hline & 141.219 & 126.24 & 120.661 \\
\hline & 147.934 & 136.364 & 131.302 \\
\hline & 156.818 & 145.248 & 142.355 \\
\hline & 163.533 & 154.236 & 151.446 \\
\hline & 169.835 & 162.913 & 159.814 \\
\hline & 177.583 & 169.215 & 166.116 \\
\hline & 182.541 & 174.587 & 171.798 \\
\hline & 185.847 & 180.372 & 177.376 \\
\hline & 188.017 & 183.678 & 182.438 \\
\hline & 192.665 & 186.054 & 184.607 \\
\hline & 195.558 & 189.876 & 187.707 \\
\hline & 196.384 & 192.872 & 191.529 \\
\hline & 197.934 & 195.764 & 193.492 \\
\hline & 201.653 & 197.314 & 194.835 \\
\hline & 201.55 & 199.174 & 196.694 \\
\hline & 202.273 & 198.967 & 197.417 \\
\hline & 202.686 & 198.45 & 197.624 \\
\hline & 202.789 & 198.657 & 196.178 \\
\hline & 202.893 & 198.45 & 196.384 \\
\hline
\end{tabular}




\begin{tabular}{|c|c|c|c|}
\hline & 200.93 & 196.384 & 192.665 \\
\hline & 200.723 & 193.285 & 189.36 \\
\hline & 199.897 & 190.599 & 187.707 \\
\hline & 198.037 & 188.533 & 183.988 \\
\hline & 196.074 & 185.537 & 180.785 \\
\hline & 192.355 & 179.855 & 175 \\
\hline & 187.087 & 174.587 & 168.388 \\
\hline & 179.752 & 166.012 & 162.19 \\
\hline & 174.07 & 158.781 & 153.306 \\
\hline & 165.186 & 148.657 & 143.388 \\
\hline & 157.025 & 138.223 & 130.165 \\
\hline & 141.839 & 123.967 & 115.186 \\
\hline & 131.095 & 109.711 & 101.446 \\
\hline & 114.153 & 94.5248 & 84.7107 \\
\hline & 97.4174 & 0 & 0 \\
\hline & 0 & 0 & 0 \\
\hline & 0 & 0 & 0 \\
\hline & 0 & 0 & 0 \\
\hline Area & 6579.96 & 5855.269 & 5713.327 \\
\hline Volume & 1973.988 & 1756.581 & 1713.998 \\
\hline
\end{tabular}




\begin{tabular}{|c|c|c|c|}
\hline Experiment 2 & 91,255 & 115,255 & 127,255 \\
\hline & 0 & 0 & 0 \\
\hline & 0 & 0 & 0 \\
\hline & 83.1612 & 0 & 0 \\
\hline & 96.5909 & 0 & 0 \\
\hline & 112.707 & 0 & 0 \\
\hline & 121.591 & 103.616 & 97.4174 \\
\hline & 131.198 & 116.426 & 108.058 \\
\hline & 141.736 & 127.169 & 121.074 \\
\hline & 150.207 & 138.43 & 131.302 \\
\hline & 157.645 & 146.591 & 140.909 \\
\hline & 165.702 & 155.269 & 152.893 \\
\hline & 172.314 & 163.636 & 159.711 \\
\hline & 176.24 & 169.731 & 167.355 \\
\hline & 182.748 & 176.756 & 173.45 \\
\hline & 188.223 & 181.508 & 178.099 \\
\hline & 192.045 & 185.95 & 183.574 \\
\hline & 194.628 & 189.463 & 187.293 \\
\hline & 196.798 & 193.182 & 191.012 \\
\hline & 198.554 & 195.661 & 192.665 \\
\hline & 200.826 & 197.934 & 196.074 \\
\hline & 203.409 & 198.76 & 197.107 \\
\hline & 203.822 & 200 & 198.554 \\
\hline & 205.579 & 202.686 & 200.413 \\
\hline & 205.682 & 201.136 & 199.38 \\
\hline & 205.785 & 202.169 & 200.31 \\
\hline & 205.165 & 201.24 & 199.277 \\
\hline & 206.302 & 201.136 & 198.14 \\
\hline & 207.231 & 200.723 & 198.14 \\
\hline & 205.888 & 199.277 & 196.178 \\
\hline & 205.888 & 198.14 & 194.008 \\
\hline & 204.132 & 195.455 & 191.839 \\
\hline & 203.202 & 192.459 & 189.153 \\
\hline & 199.38 & 188.843 & 183.988 \\
\hline & 197.624 & 182.231 & 177.479 \\
\hline & 192.149 & 176.446 & 170.041 \\
\hline & 183.781 & 167.975 & 162.81 \\
\hline & 177.066 & 159.504 & 152.893 \\
\hline & 164.876 & 147.831 & 137.087 \\
\hline & 152.686 & 132.335 & 123.244 \\
\hline & 140.496 & 0 & 107.851 \\
\hline & 124.483 & 0 & 92.654 \\
\hline & 108.678 & 0 & 0 \\
\hline & 87.0868 & 0 & 0 \\
\hline Area & 7053.305 & 5989.668 & 6051.432 \\
\hline Volume & 2115.991 & 1796.9 & 1815.43 \\
\hline
\end{tabular}




\section{Appendix 2}

\section{Analysis of Cell Poking Experiments Stained with CMFDA Dye.}

The confocal sections of ATDC5 and Bone Marrow cells stained with CMFDA dye were thresholded before an poking and cell volume was computed by adding up individual cross sectional areas and multiplying the total C.S.A with the thickness of the slice.

ATDC 5 cells

\begin{tabular}{|c|c|c|}
\hline Experiment 1 & $\begin{array}{c}\text { Threshold Used } \\
(115,255)\end{array}$ & \\
\hline & Before Poking & After Poking \\
\hline & 115,255 & 115,255 \\
\hline & 0 & 0 \\
\hline & 0 & 0 \\
\hline & 0 & 0 \\
\hline & 0 & 0 \\
\hline & 30.5128 & 0 \\
\hline & 50.1271 & 0 \\
\hline & 60.0156 & 19.3373 \\
\hline & 65.4079 & 31.3437 \\
\hline & 66.141 & 36.4753 \\
\hline & 62.4593 & 37.1106 \\
\hline & 56.0407 & 36.2798 \\
\hline & 49.7035 & 33.0216 \\
\hline & 33.2497 & 27.7271 \\
\hline & 22.8398 & 22.0416 \\
\hline & 11.371 & 14.841 \\
\hline & 0 & 0 \\
\hline & 0 & 0 \\
\hline & 0 & 0 \\
\hline & 0 & 0 \\
\hline & 0 & 0 \\
\hline & 0 & 0 \\
\hline & 0 & 0 \\
\hline Total Area & 507.8684 & 258.178 \\
\hline Volume & 837.98286 & 425.9937 \\
\hline $\begin{array}{l}\text { Change in } \\
\text { Volume }=49.16 \%\end{array}$ & & \\
\hline
\end{tabular}




\begin{tabular}{|c|c|c|}
\hline Experiment 2 & Before Poking & After Poking \\
\hline & 115,255 & 115,255 \\
\hline & 0 & 0 \\
\hline & 0 & 0 \\
\hline & 0 & 0 \\
\hline & 0 & 0 \\
\hline & 0 & 0 \\
\hline & 0 & 0 \\
\hline & 0 & 0 \\
\hline & 19.1092 & 20.8035 \\
\hline & 34.8299 & 28.3136 \\
\hline & 45.3701 & 35.1883 \\
\hline & 54.9166 & 37.0618 \\
\hline & 57.4906 & 41.9816 \\
\hline & 45.6634 & 30.2522 \\
\hline & 37.7134 & 22.8724 \\
\hline & 22.3511 & 14.5478 \\
\hline & 8.01512 & 0 \\
\hline & 0 & 0 \\
\hline & 0 & 0 \\
\hline & 0 & 0 \\
\hline & 0 & 0 \\
\hline & 0 & 0 \\
\hline & 0 & 0 \\
\hline & 0 & 0 \\
\hline & 0 & 0 \\
\hline & 0 & 0 \\
\hline & 0 & 0 \\
\hline & 0 & 0 \\
\hline & 0 & 0 \\
\hline & 0 & 0 \\
\hline & 0 & 0 \\
\hline & 0 & 0 \\
\hline & 0 & 0 \\
\hline Tot Area & 325.45942 & 231.0212 \\
\hline \multirow[t]{2}{*}{ Volume } & 471.916159 & 323.42968 \\
\hline & $\begin{array}{c}\text { Change in Volume= } \\
31.46 \%\end{array}$ & \\
\hline
\end{tabular}




\begin{tabular}{|c|c|c|}
\hline Experiment 3 & Before Poking & After Poking \\
\hline & 115,255 & 115,255 \\
\hline & 0 & 0 \\
\hline & 0 & 0 \\
\hline & 0 & 0 \\
\hline & 0 & 0 \\
\hline & 0 & 0 \\
\hline & 0 & 0 \\
\hline & 17.8385 & 16.4864 \\
\hline & 34.9277 & 30.187 \\
\hline & 41.8513 & 40.3362 \\
\hline & 47.4879 & 43.122 \\
\hline & 49.9153 & 46.0543 \\
\hline & 49.2799 & 45.3538 \\
\hline & 48.3351 & 43.4509 \\
\hline & 44.0017 & 39.033 \\
\hline & 38.8701 & 34.048 \\
\hline & 34.0805 & 29.9427 \\
\hline & 27.8248 & 25.2672 \\
\hline & 22.9864 & 20.9012 \\
\hline & 18.0503 & 13.6029 \\
\hline & 11.1593 & 8.01512 \\
\hline & 0 & 0 \\
\hline & 0 & 0 \\
\hline & 0 & 0 \\
\hline & 0 & 0 \\
\hline & 0 & 0 \\
\hline & 0 & 0 \\
\hline & 0 & 0 \\
\hline & 0 & 0 \\
\hline Total Area & 486.6088 & 435.80072 \\
\hline Volume & 656.92188 & 566.540936 \\
\hline & $\begin{array}{c}\text { Change in Volume= } \\
13.76 \%\end{array}$ & \\
\hline
\end{tabular}




\begin{tabular}{|c|c|c|}
\hline Experiment 4 & Before Poking & After Poking \\
\hline & 115,255 & 115,255 \\
\hline & 0 & 0 \\
\hline & 0 & 0 \\
\hline & 0 & 0 \\
\hline & 0 & 0 \\
\hline & 45.7937 & 15.3297 \\
\hline & 80.8028 & 48.1885 \\
\hline & 98.511 & 72.69 \\
\hline & 105.63 & 85.0873 \\
\hline & 105.223 & 88.9157 \\
\hline & 99.0649 & 89.3718 \\
\hline & 87.3843 & 85.3968 \\
\hline & 72.0057 & 75.0358 \\
\hline & 49.9967 & 57.8652 \\
\hline & 12.3485 & 40.7924 \\
\hline & 0 & 18.2947 \\
\hline & 0 & 0 \\
\hline & 0 & 0 \\
\hline & 0 & 0 \\
\hline & 0 & 0 \\
\hline & 0 & 0 \\
\hline & 0 & 0 \\
\hline & 0 & 0 \\
\hline Total Area & 756.7606 & 676.9679 \\
\hline Volume & 1778.387 & 1421.633 \\
\hline & $\begin{array}{c}\text { Change in Volume }= \\
20.06 \%\end{array}$ & \\
\hline
\end{tabular}




\begin{tabular}{|c|c|c|}
\hline Experiment 5 & Before Poking & After Poking \\
\hline & 115,255 & 115,255 \\
\hline & 0 & 0 \\
\hline & 0 & 0 \\
\hline & 0 & 0 \\
\hline & 0 & 0 \\
\hline & 0 & 16.6982 \\
\hline & 17.3824 & 47.4879 \\
\hline & 55.9429 & 67.8516 \\
\hline & 76.502 & 77.4143 \\
\hline & 87.9056 & 79.1411 \\
\hline & 87.7427 & 74.7426 \\
\hline & 81.5848 & 65.7989 \\
\hline & 68.4217 & 54.5908 \\
\hline & 53.1572 & 39.5706 \\
\hline & 29.6168 & 9.20435 \\
\hline & 0 & 0 \\
\hline & 0 & 0 \\
\hline & 0 & 0 \\
\hline & 0 & 0 \\
\hline & 0 & 0 \\
\hline & 0 & 0 \\
\hline & 0 & 0 \\
\hline & 0 & 0 \\
\hline Total Area & 558.2561 & 532.5004 \\
\hline Volume & 1172.338 & 1011.751 \\
\hline & $\begin{array}{c}\text { Change in Volume }= \\
13.69 \%\end{array}$ & \\
\hline
\end{tabular}




\section{Bone Marrow Cells}

\begin{tabular}{|c|c|c|}
\hline Experiment 1 & Before Poking & After Poking \\
\hline & 115,255 & 115,255 \\
\hline & 0 & 0 \\
\hline & 0 & 0 \\
\hline & 0 & 0 \\
\hline & 0 & 0 \\
\hline & 0 & 0 \\
\hline & 0 & 20.0867 \\
\hline & 0 & 55.78 \\
\hline & 65.0007 & 88.15 \\
\hline & 103.529 & 103.121 \\
\hline & 121.497 & 107.39 \\
\hline & 127.574 & 99.4559 \\
\hline & 122.866 & 87.759 \\
\hline & 112.163 & 70.1323 \\
\hline & 95.8067 & 50.0167 \\
\hline & 68.5358 & 21.1456 \\
\hline & 38.4791 & 0 \\
\hline & 0 & 0 \\
\hline & 0 & 0 \\
\hline & 0 & 0 \\
\hline & 0 & 0 \\
\hline & 0 & 0 \\
\hline & 0 & 0 \\
\hline Total Area & 855.4513 & 703.0372 \\
\hline Volume & 2010.311 & 1616.986 \\
\hline & $\begin{array}{c}\text { Change in Volume = } \\
19.57 \%\end{array}$ & \\
\hline
\end{tabular}




\begin{tabular}{|c|c|c|}
\hline Experiment 2 & Before Poking & After Poking \\
\hline & 115,255 & 115,255 \\
\hline & 0 & 0 \\
\hline & 0 & 0 \\
\hline & 0 & 0 \\
\hline & 0 & 0 \\
\hline & 0 & 55.3564 \\
\hline & 95.823 & 133.634 \\
\hline & 153.509 & 208.018 \\
\hline & 213.183 & 241.024 \\
\hline & 248.746 & 258.634 \\
\hline & 266.503 & 262.381 \\
\hline & 275.56 & 251.189 \\
\hline & 276.277 & 236.234 \\
\hline & 264.206 & 205.412 \\
\hline & 242.425 & 164.685 \\
\hline & 211.488 & 116.154 \\
\hline & 169.409 & 68.2751 \\
\hline & 113.01 & 16.2909 \\
\hline & 85.675 & 0 \\
\hline & 0 & 0 \\
\hline & 0 & 0 \\
\hline & 0 & 0 \\
\hline & 0 & 0 \\
\hline Total Area & 2615.814 & 2217.287 \\
\hline Volume & 6801.116 & 5432.354 \\
\hline & $\begin{array}{c}\text { Change in Volume }= \\
20.13 \%\end{array}$ & \\
\hline
\end{tabular}




\begin{tabular}{|c|c|c|}
\hline Experiment 3 & Before Poking & After Poking \\
\hline & 115,255 & 115,255 \\
\hline & 0 & 0 \\
\hline & 0 & 0 \\
\hline & 0 & 0 \\
\hline & 0 & 0 \\
\hline & 0 & 0 \\
\hline & 29.0467 & 0 \\
\hline & 108.253 & 39.3914 \\
\hline & 131.06 & 77.6913 \\
\hline & 135.556 & 80.1512 \\
\hline & 131.533 & 80.982 \\
\hline & 121.726 & 68.0145 \\
\hline & 104.473 & 50.1271 \\
\hline & 79.2063 & 32.3211 \\
\hline & 53.3852 & 0 \\
\hline & 29.8449 & 0 \\
\hline & 8.56901 & 0 \\
\hline & 0 & 0 \\
\hline & 0 & 0 \\
\hline & 0 & 0 \\
\hline & 0 & 0 \\
\hline & 0 & 0 \\
\hline & 0 & 0 \\
\hline Total Area & 932.6531 & 428.6786 \\
\hline Volume & 1772.041 & 835.9233 \\
\hline & $\begin{array}{c}\text { Change in Volume = } \\
52.83 \%\end{array}$ & \\
\hline
\end{tabular}




\begin{tabular}{|c|c|c|}
\hline Experiment 4 & Before Poking & After Poking \\
\hline & 115,255 & 115,255 \\
\hline & 0 & 0 \\
\hline & 0 & 0 \\
\hline & 0 & 0 \\
\hline & 0 & 0 \\
\hline & 0 & 0 \\
\hline & 51.0231 & 22.009 \\
\hline & 104.457 & 74.4657 \\
\hline & 136.42 & 117.49 \\
\hline & 147.302 & 132.706 \\
\hline & 150.007 & 128.845 \\
\hline & 145.624 & 118.288 \\
\hline & 137.854 & 102.975 \\
\hline & 124.088 & 80.1512 \\
\hline & 104.946 & 63.6322 \\
\hline & 86.244 & 50.98 \\
\hline & 60.651 & 9.1229 \\
\hline & 38.9352 & 0 \\
\hline & 0 & 0 \\
\hline & 0 & 0 \\
\hline & 0 & 0 \\
\hline & 0 & 0 \\
\hline & 0 & 0 \\
\hline Total Area & 1287.551 & 900.665 \\
\hline Volume & 2381.97 & 1621.197 \\
\hline & $\begin{array}{c}\text { Change in Volume }= \\
31.94 \%\end{array}$ & \\
\hline
\end{tabular}




\begin{tabular}{|c|c|c|}
\hline Experiment 5 & Before Poking & After Poking \\
\hline & 115,255 & 115,255 \\
\hline & 0 & 0 \\
\hline & 0 & 0 \\
\hline & 0 & 0 \\
\hline & 45.028 & 0 \\
\hline & 106.217 & 45.4353 \\
\hline & 178.336 & 115.388 \\
\hline & 248.778 & 198.895 \\
\hline & 288.235 & 252.02 \\
\hline & 321.582 & 274.225 \\
\hline & 340.594 & 281.311 \\
\hline & 349.554 & 277.173 \\
\hline & 335.592 & 254.089 \\
\hline & 321.207 & 224.847 \\
\hline & 298.726 & 174.084 \\
\hline & 269.973 & 134.041 \\
\hline & 233.611 & 31.1482 \\
\hline & 183.81 & 0 \\
\hline & 122.247 & 0 \\
\hline & 52.1146 & 0 \\
\hline & 6.98879 & 0 \\
\hline & 0 & 0 \\
\hline & 0 & 0 \\
\hline Total Area & 3702.593 & 2262.657 \\
\hline Volume & 8145.705 & 5656.641 \\
\hline & $\begin{array}{c}\text { Change in Volume }= \\
30.56 \%\end{array}$ & \\
\hline
\end{tabular}




\section{Appendix 3}

\section{Photobleaching Experiment Analysis}

Confocal scans of a cell stained with CMFDA dye were taken at 0 and 5 minutes under a particular laser intensity and the reduction in cell volume after 5 minutes was computed for that intensity. 5 different laser intensities (10\%, 15\%, $20 \%, 30 \%$, and $40 \%)$ were used. A threshold of $(115,255)$ was used for analysis. The largest confocal cross section of the cell at 0 and 5 minutes when $10 \%$ laser intensity is shown below to give a better understanding of the bleaching effect (Refer Fig 27).

Figure 28: Cell Stained with CMFDA at 0 min (left) and 5 min (right)
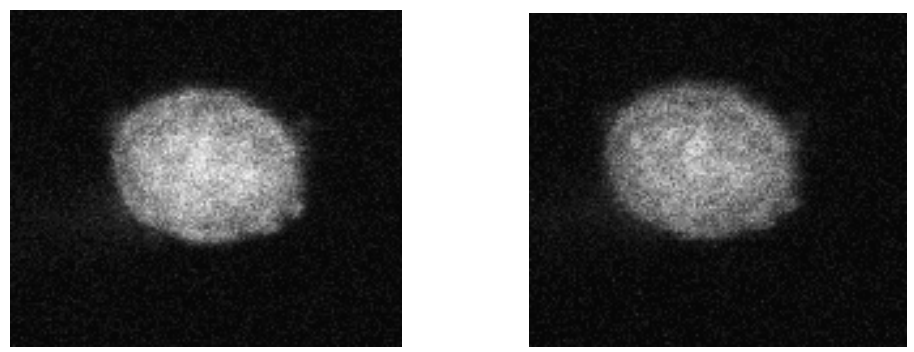
$10 \%$ Laser

\begin{tabular}{|c|c|c|}
\hline Experiment 1 & Threshold- $(115,255)$ & \\
\hline & $0 \mathrm{~min}$ & $5 \mathrm{~min}$ \\
\hline & 0 & 0 \\
\hline & 0 & 0 \\
\hline & 0 & 0 \\
\hline & 0 & 0 \\
\hline & 0 & 0 \\
\hline & 60.8465 & 38.8701 \\
\hline & 75.1499 & 59.7876 \\
\hline & 94.031 & 76.388 \\
\hline & 101.623 & 84.2891 \\
\hline & 97.9082 & 78.9294 \\
\hline & 92.5323 & 65.9292 \\
\hline & 82.9532 & 53.3201 \\
\hline & 74.4005 & 27.0429 \\
\hline & 63.8603 & 10.2144 \\
\hline & 0 & 0 \\
\hline & 0 & 0 \\
\hline & 0 & 0 \\
\hline & 0 & 0 \\
\hline & 0 & 0 \\
\hline & 0 & 0 \\
\hline & 0 & 0 \\
\hline & 0 & 0 \\
\hline Area & 743.3049 & 494.7708 \\
\hline \multirow[t]{2}{*}{ Volume } & 966.2964 & 816.3718 \\
\hline & Volume Reduction $=15 \%$ & \\
\hline
\end{tabular}


$15 \%$ laser

\begin{tabular}{|c|c|c|}
\hline Experiment 2 & Threshold- $(115,255)$ & \\
\hline & $0 \mathrm{~min}$ & $5 \min$ \\
\hline & 0 & 0 \\
\hline & 0 & 0 \\
\hline & 0 & 0 \\
\hline & 0 & 0 \\
\hline & 0 & 0 \\
\hline & 15.1994 & 0 \\
\hline & 38.3488 & 17.4638 \\
\hline & 60.8628 & 41.2974 \\
\hline & 85.3806 & 50.4366 \\
\hline & 89.942 & 75.0195 \\
\hline & 90.5448 & 75.8178 \\
\hline & 85.5272 & 67.933 \\
\hline & 71.0609 & 50.681 \\
\hline & 55.7474 & 34.8975 \\
\hline & 15.5578 & 7.03766 \\
\hline & 0 & 0 \\
\hline & 0 & 0 \\
\hline & 0 & 0 \\
\hline & 0 & 0 \\
\hline & 0 & 0 \\
\hline & 0 & 0 \\
\hline & 0 & 0 \\
\hline Area & 608.1717 & 420.5843 \\
\hline \multirow[t]{2}{*}{ Volume } & 821.0318 & 630.8764 \\
\hline & Volume Reduction $=23 \%$ & \\
\hline
\end{tabular}


$20 \%$ Laser

\begin{tabular}{|c|c|c|}
\hline Experiment 3 & Threshold- $(115,255)$ & \\
\hline & $0 \mathrm{~min}$ & $5 \mathrm{~min}$ \\
\hline & 0 & 0 \\
\hline & 0 & 0 \\
\hline & 0 & 0 \\
\hline & 0 & 0 \\
\hline & 38.528 & 28.7208 \\
\hline & 62.557 & 57.2625 \\
\hline & 82.8718 & 75.7363 \\
\hline & 95.2691 & 83.6537 \\
\hline & 100.645 & 84.8918 \\
\hline & 96.0022 & 73.2438 \\
\hline & 85.2014 & 60.7161 \\
\hline & 72.5922 & 46.2987 \\
\hline & 61.5144 & 32.0442 \\
\hline & 49.003 & 19.9563 \\
\hline & 34.2272 & 11.0615 \\
\hline & 24.5015 & 0 \\
\hline & 8.14545 & 0 \\
\hline & 0 & 0 \\
\hline & 0 & 0 \\
\hline & 0 & 0 \\
\hline & 0 & 0 \\
\hline & 0 & 0 \\
\hline Area & 811.0583 & 573.5857 \\
\hline \multirow[t]{2}{*}{ Volume } & 1419.352 & 975.0957 \\
\hline & Volume Reduction $=31 \%$ & \\
\hline
\end{tabular}




\section{$30 \%$ laser}

\begin{tabular}{|c|c|c|}
\hline Experiment 4 & Threshold- $(115,255)$ & \\
\hline & $0 \mathrm{~min}$ & $5 \mathrm{~min}$ \\
\hline & 0 & 0 \\
\hline & 0 & 0 \\
\hline & 0 & 0 \\
\hline & 0 & 0 \\
\hline & 0 & 21.2107 \\
\hline & 13.3422 & 55.7311 \\
\hline & 41.1019 & 70.8002 \\
\hline & 67.7212 & 75.492 \\
\hline & 77.284 & 74.205 \\
\hline & 83.9958 & 68.9919 \\
\hline & 86.0159 & 58.5169 \\
\hline & 83.2464 & 36.9803 \\
\hline & 75.997 & 20.9501 \\
\hline & 67.542 & 0 \\
\hline & 55.4542 & 0 \\
\hline & 38.0229 & 0 \\
\hline & 21.8135 & 0 \\
\hline & 0 & 0 \\
\hline & 0 & 0 \\
\hline & 0 & 0 \\
\hline & 0 & 0 \\
\hline & 0 & 0 \\
\hline Area & 711.537 & 482.8782 \\
\hline \multirow[t]{2}{*}{ Volume } & 1209.613 & 772.6051 \\
\hline & Volume Reduction $=36 \%$ & \\
\hline
\end{tabular}




\section{$40 \%$ laser}

\begin{tabular}{|c|c|c|}
\hline Experiment 5 & Threshold- $(115,255)$ & \\
\hline & $0 \mathrm{~min}$ & $5 \min$ \\
\hline & 0 & 0 \\
\hline & 0 & 0 \\
\hline & 0 & 0 \\
\hline & 0 & 0 \\
\hline & 0 & 0 \\
\hline & 0 & 34.0154 \\
\hline & 0 & 69.0082 \\
\hline & 40.7109 & 88.8179 \\
\hline & 75.3942 & 97.501 \\
\hline & 97.7616 & 85.1435 \\
\hline & 114.053 & 72.4945 \\
\hline & 122.117 & 50.654 \\
\hline & 120.553 & 28.3461 \\
\hline & 117.93 & 7.6893 \\
\hline & 106.722 & 0 \\
\hline & 90.952 & 0 \\
\hline & 71.517 & 0 \\
\hline & 45.1095 & 0 \\
\hline & 22.2045 & 0 \\
\hline & 0 & 0 \\
\hline & 0 & 0 \\
\hline & 0 & 0 \\
\hline Area & 1025.025 & 533.6699 \\
\hline \multirow[t]{2}{*}{ Volume } & 1742.542 & 933.9223 \\
\hline & $\begin{array}{c}\text { Volume Reduction }= \\
46.4 \%\end{array}$ & \\
\hline
\end{tabular}




\section{Appendix 4}

\section{Threshold Determination using Fluorescein Dextran Dye}

A thin film of cell/gel mixture stained with Fluorescein dextran were spread on a glass slide and confocal cross sectional images of a cell were taken at 0,15 and 30 minutes to correct for threshold fall off due bleaching (Refer Fig 28). An initial threshold which clearly demarcated the cell boundary and its surroundings was chosen to measure the total area of images (A constant thickness was maintained. So it was not necessary to measure cell volume). Then images taken at 15 and 30 minutes were analyzed by varying the threshold till the total C.S.A approximately matched the C.S.A obtained at 0 minutes using the initial threshold.

Figure 29: Largest Cross Sectional Image at 0,15 and 30 minutes (Notice the change in the cell and its background due to bleaching effect)

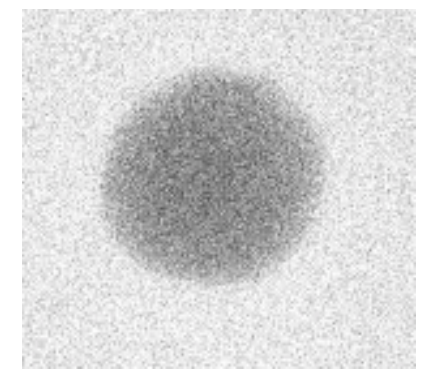

$0 \mathrm{~min}$

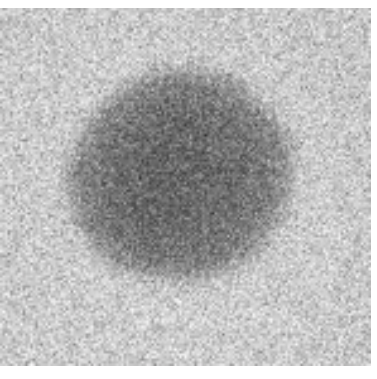

$15 \min$

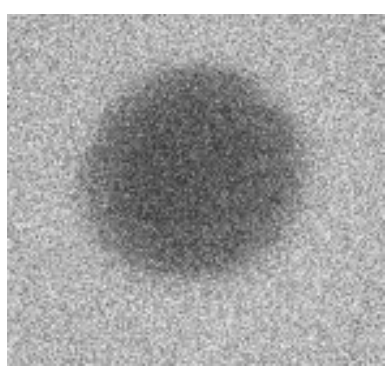

$30 \mathrm{~min}$ 


\begin{tabular}{|c|c|c|c|c|c|c|c|}
\hline Experiment & & & & & & & \\
\hline Time & $0 \mathrm{~min}$ & $15 \mathrm{~min}$ & & $30 \mathrm{~min}$ & & & \\
\hline \multirow[t]{23}{*}{ Threshold } & $(0,160)$ & $(0,135)$ & $(0,133)$ & $(0,120)$ & $(0,115)$ & $(0,113)$ & $(0,114)$ \\
\hline & 0 & 0 & 0 & 0 & 0 & 0 & 0 \\
\hline & 0 & 0 & 0 & 0 & 0 & 0 & 0 \\
\hline & 0 & 0 & 0 & 0 & 0 & 0 & 0 \\
\hline & 17.6919 & 23.9639 & 21.4062 & 23.1 & 13.9939 & 0 & 8.50384 \\
\hline & 56.3339 & 55.945 & 58.8264 & 71.9406 & 50.705 & 53.7599 & 50.085 \\
\hline & 85.739 & 89.9257 & 86.1951 & 103.317 & 93.3631 & 85.8041 & 81.98 \\
\hline & 105.467 & 117.066 & 114.248 & 125.195 & 115.78 & 109.573 & 113.12 \\
\hline & 125.098 & 128.274 & 125.13 & 135.345 & 127.753 & 125.749 & 126.759 \\
\hline & 132.087 & 129.659 & 127.134 & 134.66 & 128.942 & 126.173 & 127.769 \\
\hline & 130.686 & 126.613 & 124.039 & 133.879 & 127.786 & 124.365 & 126.482 \\
\hline & 122.768 & 124.088 & 119.705 & 132.217 & 121.139 & 117.425 & 119.233 \\
\hline & 117.865 & 115.063 & 112.863 & 123.876 & 115.698 & 110.175 & 112.016 \\
\hline & 105.598 & 102.926 & 98.4621 & 119.57 & 106.314 & 101.639 & 104.18 \\
\hline & 89.1112 & 91.3919 & 86.9282 & 118.418 & 98.2 & 84.4194 & 90.333 \\
\hline & 74.2213 & 80.5259 & 72.4782 & 99.2604 & 66.9556 & 61.8891 & 63.8766 \\
\hline & 53.8414 & 68.7801 & 60.8302 & 89.4207 & 61.7099 & 49.8175 & 52.0657 \\
\hline & 38.6257 & 42.5518 & 32.9239 & 71.4518 & 42.9265 & 39.2448 & 40.043 \\
\hline & 18.8974 & 29.4376 & 25.4301 & 65.305 & 38.1533 & 17.9851 & 24.1268 \\
\hline & 0 & 21.6995 & 0 & 83.6211 & 10.866 & 0 & 0 \\
\hline & 0 & 0 & 0 & 40.548 & 0 & 0 & 0 \\
\hline & 0 & 0 & 0 & 13.1793 & 0 & 0 & 0 \\
\hline & 0 & 0 & 0 & 0 & 0 & 0 & 0 \\
\hline Area & 1274.0308 & 1347.9104 & 1266.5994 & 1684.3039 & 1320.2853 & 1208.0189 & 1240.5729 \\
\hline
\end{tabular}




\begin{tabular}{|c|c|c|c|c|c|c|}
\hline Experiment & & & & & & \\
\hline Time & $0 \mathrm{~min}$ & $15 \mathrm{~min}$ & & & & $30 \mathrm{~min}$ \\
\hline \multirow[t]{23}{*}{ Threshold } & $(0,200)$ & $(0,135)$ & $(0,136)$ & $(0,137)$ & $(0,120)$ & $(0,125)$ \\
\hline & 0 & 0 & 0 & 0 & 0 & 0 \\
\hline & 0 & 0 & 0 & 0 & 0 & 0 \\
\hline & 0 & 0 & 0 & 0 & 0 & 0 \\
\hline & 9.98632 & 0 & 0 & 0 & 0 & 0 \\
\hline & 36.1821 & 0 & 0 & 0 & 0 & 26.3098 \\
\hline & 57.5068 & 31.5392 & 33.9665 & 37.4365 & 34.4715 & 51.8 \\
\hline & 72.9017 & 52.7499 & 54.5745 & 57.2788 & 58.077 & 66.6949 \\
\hline & 80.2978 & 62.2312 & 66.141 & 70.1323 & 65.8478 & 73.0158 \\
\hline & 84.0284 & 73.7 & 75.9807 & 77.1 & 74.9707 & 81.7803 \\
\hline & 88.036 & 86.2603 & 88.6876 & 86.2114 & 78.2451 & 93.2491 \\
\hline & 86.8793 & 84.4357 & 85.1851 & 87.8894 & 79.2715 & 87.0096 \\
\hline & 84.2239 & 82.8555 & 85.8693 & 87.9708 & 78.6361 & 87.3843 \\
\hline & 78.6361 & 86.1299 & 88.4107 & 90.1212 & 72.7225 & 79.8742 \\
\hline & 74.4982 & 82.66 & 83.9958 & 87.6776 & 67.5094 & 76.6975 \\
\hline & 69.2689 & 78.1 & 79.4181 & 82.8555 & 64.67 & 77.284 \\
\hline & 62.4593 & 72.2012 & 73.7814 & 77.9356 & 61.9868 & 79.4995 \\
\hline & 55.9918 & 65.0169 & 64.3979 & 71.7777 & 42.5518 & 63.2087 \\
\hline & 51.3163 & 59.7387 & 62.8014 & 68.3892 & 33.38 & 74.3842 \\
\hline & 46.25 & 62.1986 & 64.2839 & 74.4331 & 0 & 0 \\
\hline & 0 & 0 & 0 & 0 & 0 & 0 \\
\hline & 0 & 0 & 0 & 0 & 0 & 0 \\
\hline & 0 & 0 & 0 & 0 & 0 & 0 \\
\hline Area & 1038.4629 & 979.8171 & 1007.4939 & 1057.2091 & 812.3402 & 1018.1919 \\
\hline
\end{tabular}




\begin{tabular}{|c|c|c|c|c|c|c|}
\hline Experiment 3 & & & & & & \\
\hline Time & $0 \mathrm{~min}$ & $15 \mathrm{~min}$ & & $30 \mathrm{~min}$ & & \\
\hline \multirow[t]{23}{*}{ Threshold } & $(0,195)$ & $(0,158)$ & $(0,157)$ & $(0,135)$ & $(0,137)$ & $(0,136)$ \\
\hline & 0 & 0 & 0 & 0 & 0 & 0 \\
\hline & 0 & 0 & 0 & 0 & 0 & 0 \\
\hline & 0 & 0 & 0 & 15.3297 & 26.375 & 22.3185 \\
\hline & 0 & 11.4199 & 8.19432 & 60.8139 & 66.646 & 65.95 \\
\hline & 29.01 & 65.7663 & 62.41 & 94.9107 & 106.2 & 98.7554 \\
\hline & 74.6286 & 101.232 & 97.8105 & 124.65 & 124.153 & 122.182 \\
\hline & 99.8306 & 119.982 & 118.598 & 142.382 & 145.445 & 144.402 \\
\hline & 122.247 & 146.064 & 144.288 & 147.53 & 153.04 & 150.332 \\
\hline & 146.944 & 160.384 & 158.82 & 156.637 & 158.201 & 157.419 \\
\hline & 153.884 & 170.598 & 169.507 & 154.698 & 158.999 & 157.598 \\
\hline & 162.176 & 169.116 & 168.757 & 155.79 & 158.136 & 157.06 \\
\hline & 163.691 & 167.373 & 165.874 & 150.104 & 153.362 & 150.903 \\
\hline & 160.514 & 161.573 & 161.035 & 141.161 & 144.924 & 144.598 \\
\hline & 154.356 & 155.334 & 154.34 & 133.471 & 135.524 & 135.28 \\
\hline & 147.302 & 139.825 & 137.821 & 118.06 & 124.365 & 121.318 \\
\hline & 139.613 & 127.998 & 125.684 & 100.824 & 110.469 & 103.252 \\
\hline & 129.366 & 109.377 & 106.396 & 83.7026 & 90.6099 & 86.8304 \\
\hline & 107.732 & 88.98 & 82.5785 & 63.2412 & 72.022 & 67.5909 \\
\hline & 90.5936 & 69.6436 & 66.646 & 62.4104 & 66.0433 & 63.8929 \\
\hline & 73.5534 & 68.7801 & 66.0921 & 36.1984 & 51.38 & 40.8087 \\
\hline & 58.1585 & 45.8263 & 31.083 & 8.2269 & 10.2958 & 9.82341 \\
\hline & 34.0317 & 19.6305 & 11.5177 & 0 & 8.29206 & 0 \\
\hline Area & 2047.6314 & 2098.9027 & 2037.4521 & 1950.1408 & 2064.4821 & 2000.3142 \\
\hline
\end{tabular}




\begin{tabular}{|c|c|c|c|c|c|}
\hline Experiment & & & & & \\
\hline Time & 0 min & $15 \mathrm{~min}$ & & $30 \mathrm{~min}$ & \\
\hline \multirow[t]{23}{*}{ Threshold } & $(0,180)$ & $(0,138)$ & $(0,90)$ & $(0,88)$ & $(0,89)$ \\
\hline & 0 & 0 & 0 & 0 & 0 \\
\hline & 0 & 0 & 0 & 0 & 0 \\
\hline & 12.1367 & 20.9338 & 48.4165 & 0 & 0 \\
\hline & 60.0156 & 87.14 & 85.2828 & 43.8877 & 18.0992 \\
\hline & 118.402 & 138.196 & 135.882 & 123.56 & 74.9544 \\
\hline & 151 & 152.76 & 150.446 & 138.864 & 128.519 \\
\hline & 175.6 & 159.129 & 160.97 & 151.978 & 145.282 \\
\hline & 181.823 & 168.383 & 166.525 & 158.592 & 153.476 \\
\hline & 182.8 & 166.18 & 168.432 & 158.983 & 161.671 \\
\hline & 176.496 & 157.305 & 160.14 & 153.965 & 164.424 \\
\hline & 168.089 & 141.5 & 155.138 & 146.015 & 158.136 \\
\hline & 156.02 & 138.277 & 146.178 & 136.567 & 148.605 \\
\hline & 154.063 & 130.571 & 156.295 & 139.466 & 141.063 \\
\hline & 134.172 & 133.455 & 153.379 & 118.614 & 145.25 \\
\hline & 117.36 & 107.569 & 145.63 & 100.906 & 137.837 \\
\hline & 102.698 & 111.576 & 155.822 & 100.499 & 112.684 \\
\hline & 94.3243 & 99.64 & 152.027 & 89.3881 & 119.005 \\
\hline & 88.4107 & 96.1 & 142.268 & 82.1875 & 128.046 \\
\hline & 77.2677 & 83.0835 & 104.783 & 90.25 & 93.4608 \\
\hline & 67.22 & 95.432 & 0 & 0 & 0 \\
\hline & 0 & 0 & 0 & 0 & 0 \\
\hline & 0 & 0 & 0 & 0 & 0 \\
\hline Area & 2217.898 & 2187.23 & 2387.614 & 1933.722 & 2030.512 \\
\hline
\end{tabular}




\section{Appendix - 5}

\section{Analysis of Cell Poking Experiments with Fluorescein Dextran}

Two cells (control and experimental) stained with Fluorescein Dextran were visualized and confocal sections were taken before poking. Then the cell was poked and cross sectional images were scanned again after poking.

Using an initial threshold which best demarcated the cell boundary and its environment, the C.S. areas of the stack (both control and experimental) before poking was calculated. From this, the largest cross sectional area was chosen. Then the threshold was varied until the largest cross sectional area of the control cell after poking approximately equaled the largest cross sectional area of control cell before poking.

Using this corrected threshold, the largest C.S. area of the experimental cell after poking was calculated from which the reduction in the experimental cell area was calculated. 


\section{ATDC 5 Cells}

\begin{tabular}{|c|c|c|c|c|c|}
\hline \multirow{2}{*}{ Experiment 1} & \multicolumn{2}{|c|}{$\begin{array}{l}\text { Before } \\
\text { Poking }\end{array}$} & \multicolumn{2}{|r|}{$\begin{array}{c}\text { After } \\
\text { Poking }\end{array}$} & \multirow[b]{2}{*}{$\begin{array}{c}\text { Cell after } \\
\text { poking }\end{array}$} \\
\hline & $\begin{array}{l}\text { Control } \\
\text { cell }\end{array}$ & $\begin{array}{l}\text { Cell before } \\
\text { Poking }\end{array}$ & $\begin{array}{c}\text { Control } \\
\text { cell }\end{array}$ & $\begin{array}{c}\text { Control } \\
\text { cell }\end{array}$ & \\
\hline Threshold & 0,225 & 0,225 & 0,195 & 0,200 & 0,200 \\
\hline & 0 & 0 & 0 & 0 & 0 \\
\hline & 0 & 0 & 0 & 0 & 0 \\
\hline & 0 & 0 & 0 & 0 & 11.8272 \\
\hline & 0 & 0 & 0 & 0 & 18.0515 \\
\hline & 0 & 42.9591 & 0 & 0 & 77.0722 \\
\hline & 0 & 113.841 & 0 & 12.2833 & 123.99 \\
\hline & 0 & 138.03 & 53.7436 & 71.4356 & 101.997 \\
\hline & 0 & 146.341 & 97.8757 & 105.842 & 88.44 \\
\hline & 46.7711 & 143.115 & 112.44 & 118.223 & 80.7051 \\
\hline & 103.268 & 128.356 & 114.215 & 121.367 & 69.9205 \\
\hline & 121.416 & 69.4969 & 105.891 & 117.783 & 68.45 \\
\hline & 115.242 & 74.1236 & 95.3832 & 110.534 & 51.2186 \\
\hline & 99.912 & 42.2912 & 81.9595 & 95.67 & 40.73 \\
\hline & 68.0796 & 33.266 & 85.4131 & 91.687 & 38.4954 \\
\hline & 22.3185 & 24.42 & 72.51 & 81.41 & 0 \\
\hline & 9.44872 & 0 & 71.0934 & 65.8315 & 0 \\
\hline & 0 & 0 & 71.9569 & 61.968 & 0 \\
\hline & 0 & 0 & 0 & 0 & 0 \\
\hline & 0 & 0 & 0 & 0 & 0 \\
\hline & 0 & 0 & 0 & 0 & 0 \\
\hline & 0 & 0 & 0 & 0 & 0 \\
\hline & 0 & 0 & 0 & 0 & 0 \\
\hline $\begin{array}{c}\text { Area } \\
\text { Reduction }\end{array}$ & $15.27 \%$ & & & & \\
\hline
\end{tabular}




\begin{tabular}{|c|c|c|c|c|c|}
\hline \multirow[t]{2}{*}{ Experiment 2} & \multicolumn{2}{|c|}{$\begin{array}{l}\text { Before } \\
\text { Poking }\end{array}$} & \multicolumn{2}{|r|}{$\begin{array}{c}\text { After } \\
\text { Poking }\end{array}$} & \multirow[b]{2}{*}{$\begin{array}{c}\text { Cell after } \\
\text { poking }\end{array}$} \\
\hline & $\begin{array}{l}\text { Control } \\
\text { cell }\end{array}$ & $\begin{array}{l}\text { Cell before } \\
\text { Poking }\end{array}$ & $\begin{array}{c}\text { Control } \\
\text { cell }\end{array}$ & $\begin{array}{c}\text { Control } \\
\text { cell }\end{array}$ & \\
\hline Threshold & 0,160 & 0,160 & 0,120 & 0,122 & 0,122 \\
\hline & 0 & 0 & 0 & 0 & 0 \\
\hline & 0 & 0 & 0 & 0 & 0 \\
\hline & 0 & 0 & 0 & 0 & 0 \\
\hline & 0 & 11.0941 & 0 & 0 & 0 \\
\hline & 0 & 76.9582 & 0 & 0 & 57.7838 \\
\hline & 17.9037 & 153.721 & 16.5678 & 40.4666 & 128.405 \\
\hline & 48.4002 & 209.094 & 57.28 & 67.9493 & 184.902 \\
\hline & 71.2726 & 255.115 & 74.987 & 98.6576 & 247.931 \\
\hline & 76.4206 & 280.725 & 71.9894 & 82.4319 & 245.862 \\
\hline & 99.9446 & 282.484 & 78.5547 & 69.725 & 0 \\
\hline & 0 & 0 & 0 & 0 & 0 \\
\hline & 0 & 0 & 0 & 0 & 0 \\
\hline & 0 & 0 & 0 & 0 & 0 \\
\hline & 0 & 0 & 0 & 0 & 0 \\
\hline & 0 & 0 & 0 & 0 & 0 \\
\hline & 0 & 0 & 0 & 0 & 0 \\
\hline & 0 & 0 & 0 & 0 & 0 \\
\hline & 0 & 0 & 0 & 0 & 0 \\
\hline & 0 & 0 & 0 & 0 & 0 \\
\hline & 0 & 0 & 0 & 0 & 0 \\
\hline & 0 & 0 & 0 & 0 & 0 \\
\hline & 0 & 0 & 0 & 0 & 0 \\
\hline $\begin{array}{c}\text { Area } \\
\text { Reduction }\end{array}$ & $12.23 \%$ & & & & \\
\hline
\end{tabular}




\begin{tabular}{|c|c|c|c|c|c|}
\hline \multirow[t]{2}{*}{ Experiment 3} & \multicolumn{2}{|c|}{$\begin{array}{l}\text { Before } \\
\text { Poking }\end{array}$} & \multicolumn{2}{|r|}{$\begin{array}{c}\text { After } \\
\text { Poking }\end{array}$} & \multirow[b]{2}{*}{$\begin{array}{c}\text { Cell after } \\
\text { poking }\end{array}$} \\
\hline & $\begin{array}{c}\text { Control } \\
\text { cell }\end{array}$ & $\begin{array}{l}\text { Cell before } \\
\text { Poking }\end{array}$ & $\begin{array}{c}\text { Control } \\
\text { cell }\end{array}$ & $\begin{array}{c}\text { Control } \\
\text { cell }\end{array}$ & \\
\hline Threshold & 0,228 & 0,228 & 0,188 & 0,187 & 0,187 \\
\hline & 0 & 0 & 0 & 0 & 0 \\
\hline & 0 & 0 & 0 & 0 & 0 \\
\hline & 0 & 0 & 0 & 0 & 0 \\
\hline & 0 & 0 & 0 & 0 & 0 \\
\hline & 0 & 0 & 0 & 0 & 0 \\
\hline & 0 & 0 & 0 & 0 & 0 \\
\hline & 0 & 6.02763 & 0 & 0 & 0 \\
\hline & 19.5002 & 40.7435 & 0 & 0 & 0 \\
\hline & 48.3839 & 58.2562 & 23.4752 & 23.1168 & 30.073 \\
\hline & 58.3051 & 81.7151 & 41.0205 & 36.5568 & 47.2599 \\
\hline & 54.2161 & 77.675 & 50.909 & 48.6446 & 77.1374 \\
\hline & 43.3989 & 72.527 & 58.9241 & 57.3928 & 76.6161 \\
\hline & 35.2372 & 62.7036 & 54.3627 & 52.978 & 70.7025 \\
\hline & 30.4314 & 45.0606 & 47.2599 & 46.0543 & 68.5032 \\
\hline & 0 & 16.2746 & 34.1131 & 26.212 & 45.0769 \\
\hline & 0 & 0 & 0 & 0 & 28.6231 \\
\hline & 0 & 0 & 0 & 0 & 14.0427 \\
\hline & 0 & 0 & 0 & 0 & 0 \\
\hline & 0 & 0 & 0 & 0 & 0 \\
\hline & 0 & 0 & 0 & 0 & 0 \\
\hline & 0 & 0 & 0 & 0 & 0 \\
\hline & 0 & 0 & 0 & 0 & 0 \\
\hline $\begin{array}{c}\text { Area } \\
\text { Reduction }\end{array}$ & $5.60 \%$ & & & & \\
\hline
\end{tabular}




\begin{tabular}{|c|c|c|c|c|c|}
\hline \multirow[t]{2}{*}{ Experiment 4} & \multicolumn{2}{|c|}{$\begin{array}{l}\text { Before } \\
\text { Poking }\end{array}$} & \multicolumn{2}{|r|}{$\begin{array}{c}\text { After } \\
\text { Poking }\end{array}$} & \multirow[b]{2}{*}{$\begin{array}{c}\text { Cell afte } \\
\text { poking }\end{array}$} \\
\hline & $\begin{array}{c}\text { Control } \\
\text { cell }\end{array}$ & $\begin{array}{c}\text { Cell before } \\
\text { Poking }\end{array}$ & $\begin{array}{c}\text { Control } \\
\text { cell }\end{array}$ & $\begin{array}{c}\text { Control } \\
\text { cell }\end{array}$ & \\
\hline Threshold & 0,135 & 0,135 & 0,135 & 0,139 & 0,139 \\
\hline & 0 & 0 & 0 & 0 & 0 \\
\hline & 0 & 0 & 0 & 0 & 0 \\
\hline & 0 & 0 & 0 & 0 & 0 \\
\hline & 0 & 0 & 0 & 0 & 0 \\
\hline & 0 & 0 & 39.7009 & 61.6936 & 0 \\
\hline & 52.9943 & 0 & 45.4679 & 91.33 & 0 \\
\hline & 94.5197 & 37.9252 & 82.4808 & 92.6463 & 12.3648 \\
\hline & 104.099 & 58.6472 & 89.0623 & 97.0611 & 26.5867 \\
\hline & 104.017 & 79.8254 & 93.1024 & 104.001 & 60.8628 \\
\hline & 104.359 & 95.5298 & 85.5272 & 91.0172 & 63.19 \\
\hline & 91.2453 & 89.9257 & 0 & 0 & 60.26 \\
\hline & 0 & 0 & 0 & 0 & 47.5531 \\
\hline & 0 & 0 & 0 & 0 & 0 \\
\hline & 0 & 0 & 0 & 0 & 0 \\
\hline & 0 & 0 & 0 & 0 & 0 \\
\hline & 0 & 0 & 0 & 0 & 0 \\
\hline & 0 & 0 & 0 & 0 & 0 \\
\hline & 0 & 0 & 0 & 0 & 0 \\
\hline & 0 & 0 & 0 & 0 & 0 \\
\hline & 0 & 0 & 0 & 0 & 0 \\
\hline & 0 & 0 & 0 & 0 & 0 \\
\hline & 0 & 0 & 0 & 0 & 0 \\
\hline $\begin{array}{c}\text { Area } \\
\text { Reduction }\end{array}$ & $33.85 \%$ & & & & \\
\hline
\end{tabular}




\begin{tabular}{|c|c|c|c|c|}
\hline \multirow[t]{2}{*}{ Experiment 5} & \multicolumn{2}{|c|}{$\begin{array}{l}\text { Before } \\
\text { Poking }\end{array}$} & \multicolumn{2}{|c|}{ After Poking } \\
\hline & $\begin{array}{c}\text { Control } \\
\text { cell }\end{array}$ & $\begin{array}{l}\text { Cell before } \\
\text { Poking }\end{array}$ & $\begin{array}{c}\text { Control } \\
\text { cell }\end{array}$ & $\begin{array}{c}\text { Cell after } \\
\text { poking }\end{array}$ \\
\hline Threshold & 0,190 & 0,190 & 0,132 & 0,132 \\
\hline & 0 & 0 & 0 & 0 \\
\hline & 0 & 0 & 0 & 0 \\
\hline & 0 & 0 & 0 & 0 \\
\hline & 0 & 0 & 0 & 0 \\
\hline & 0 & 20.53 & 0 & 10.4262 \\
\hline & 0 & 72.3641 & 0 & 77.4143 \\
\hline & 8.25948 & 117.588 & 16.7633 & 113.482 \\
\hline & 39.7986 & 117.588 & 54.9003 & 118.93 \\
\hline & 58.6961 & 153.639 & 83.0672 & 129.643 \\
\hline & 84.843 & 183.37 & 101.509 & 153.525 \\
\hline & 98.788 & 191.108 & 111.593 & 164.929 \\
\hline & 108.383 & 187.72 & 112.293 & 172.863 \\
\hline & 112.505 & 177.375 & 108.204 & 145.331 \\
\hline & 101.704 & 165.222 & 98.9997 & 140.232 \\
\hline & 90.32 & 148.312 & 102.861 & 124.756 \\
\hline & 83.3768 & 131.3 & 86.0974 & 0 \\
\hline & 70.2626 & 109.247 & 0 & 0 \\
\hline & 75.7689 & 102.76 & 0 & 0 \\
\hline & 62.3941 & 96.0185 & 0 & 0 \\
\hline & 0 & 93.5097 & 0 & 0 \\
\hline & 0 & 0 & 0 & 0 \\
\hline & 0 & 0 & 0 & 0 \\
\hline $\begin{array}{c}\text { Area } \\
\text { Reduction }\end{array}$ & $9.55 \%$ & & & \\
\hline
\end{tabular}




\section{Bone Marrow Cells}

\begin{tabular}{|c|c|c|c|c|c|}
\hline \multirow[t]{2}{*}{ Experiment 1} & \multicolumn{2}{|c|}{$\begin{array}{l}\text { Before } \\
\text { Poking }\end{array}$} & & \multirow{2}{*}{$\begin{array}{c}\text { After } \\
\text { Poking } \\
\begin{array}{c}\text { Control } \\
\text { cell }\end{array} \\
\end{array}$} & \multirow[b]{2}{*}{$\begin{array}{c}\text { Cell after } \\
\text { poking }\end{array}$} \\
\hline & $\begin{array}{c}\text { Control } \\
\text { cell }\end{array}$ & $\begin{array}{l}\text { Cell before } \\
\text { Poking }\end{array}$ & $\begin{array}{c}\text { Control } \\
\text { cell }\end{array}$ & & \\
\hline Threshold & 0,160 & 0,160 & 0,130 & 0,132 & 0,132 \\
\hline & 0 & 0 & 0 & 0 & 0 \\
\hline & 0 & 0 & 0 & 0 & 0 \\
\hline & 0 & 0 & 0 & 0 & 0 \\
\hline & 0 & 0 & 0 & 0 & 0 \\
\hline & 45.81 & 65.0821 & 0 & 0 & 0 \\
\hline & 117.93 & 143.865 & 34.0643 & 51.3163 & 0 \\
\hline & 171.462 & 196.468 & 113.857 & 123.68 & 0 \\
\hline & 185.63 & 237.586 & 182.344 & 193.927 & 33.771 \\
\hline & 196.517 & 247.051 & 210.511 & 217.369 & 120.732 \\
\hline & 233.497 & 252.981 & 223.29 & 225.645 & 175.306 \\
\hline & 227.975 & 243.19 & 214.893 & 227.665 & 174.801 \\
\hline & 217.597 & 225.596 & 196.875 & 204.418 & 170.989 \\
\hline & 207.008 & 203.05 & 172.521 & 186.319 & 142.61 \\
\hline & 189.66 & 185.309 & 151.408 & 161.035 & 114.46 \\
\hline & 157.891 & 159.357 & 103.952 & 107.36 & 71.2401 \\
\hline & 129.073 & 140.346 & 64.74 & 79.3692 & 40.5806 \\
\hline & 102.323 & 120.422 & 41.0205 & 47.1947 & 17.2195 \\
\hline & 94.1451 & 109.67 & 0 & 25.8862 & 0 \\
\hline & 46.4127 & 89.0786 & 0 & 0 & 0 \\
\hline & 24.3712 & 68.6824 & 0 & 0 & 0 \\
\hline & 0 & 0 & 0 & 0 & 0 \\
\hline & 0 & 0 & 0 & 0 & 0 \\
\hline $\begin{array}{c}\text { Area } \\
\text { Reduction }\end{array}$ & $30.70 \%$ & & & & \\
\hline
\end{tabular}




\begin{tabular}{|c|c|c|c|c|c|}
\hline \multirow[t]{2}{*}{ Experiment 2} & \multicolumn{2}{|c|}{$\begin{array}{l}\text { Before } \\
\text { Poking }\end{array}$} & & \multirow{2}{*}{$\begin{array}{c}\text { After } \\
\text { Poking } \\
\begin{array}{c}\text { Control } \\
\text { cell }\end{array}\end{array}$} & \multirow[b]{2}{*}{$\begin{array}{c}\text { Cell after } \\
\text { poking }\end{array}$} \\
\hline & $\begin{array}{c}\text { Control } \\
\text { cell }\end{array}$ & $\begin{array}{l}\text { Cell before } \\
\text { Poking }\end{array}$ & $\begin{array}{c}\text { Control } \\
\text { cell }\end{array}$ & & \\
\hline Threshold & 0,160 & 0,160 & 0,130 & 0,125 & 0,125 \\
\hline & 0 & 0 & 0 & 0 & 0 \\
\hline & 0 & 0 & 0 & 0 & 0 \\
\hline & 0 & 0 & 0 & 0 & 0 \\
\hline & 0 & 0 & 308.696 & 257.966 & 0 \\
\hline & 370.064 & 74.7263 & 389.32 & 396.37 & 0 \\
\hline & 505.066 & 239.558 & 535.987 & 482.504 & 81.0472 \\
\hline & 610.322 & 404.063 & 627.069 & 597.289 & 277.108 \\
\hline & 682.36 & 518.213 & 704.728 & 667.568 & 413.479 \\
\hline & 698.342 & 647.954 & 715.219 & 701.486 & 522.04 \\
\hline & 689.854 & 759.221 & 695.051 & 671.103 & 617.588 \\
\hline & 522.4 & 855.907 & 662.713 & 639.743 & 692.868 \\
\hline & 502.264 & 898.524 & 593.07 & 558.712 & 752.216 \\
\hline & 497.426 & 902.124 & 536.215 & 506.858 & 787.225 \\
\hline & 402.809 & 859.035 & 451.65 & 429.281 & 762.837 \\
\hline & 365.6 & 798.24 & 310.325 & 366.512 & 700.655 \\
\hline & 327.968 & 713.867 & 336.13 & 331.862 & 630.343 \\
\hline & 248.729 & 596.295 & 273.671 & 295.289 & 543.708 \\
\hline & 245.031 & 492.311 & 0 & 233.677 & 426.675 \\
\hline & 0 & 390.265 & 0 & 0 & 346.8 \\
\hline & 0 & 0 & 0 & 0 & 0 \\
\hline & 0 & 0 & 0 & 0 & 0 \\
\hline & 0 & 0 & 0 & 0 & 0 \\
\hline $\begin{array}{c}\text { Area } \\
\text { Reduction }\end{array}$ & $12.74 \%$ & & & & \\
\hline
\end{tabular}




\begin{tabular}{|c|c|c|c|c|c|}
\hline \multirow[t]{2}{*}{ Experiment 3} & \multicolumn{2}{|c|}{$\begin{array}{l}\text { Before } \\
\text { Poking }\end{array}$} & \multicolumn{2}{|r|}{$\begin{array}{c}\text { After } \\
\text { Poking }\end{array}$} & \multirow[b]{2}{*}{$\begin{array}{c}\text { Cell after } \\
\text { poking }\end{array}$} \\
\hline & $\begin{array}{l}\text { Control } \\
\text { cell }\end{array}$ & $\begin{array}{l}\text { Cell before } \\
\text { Poking }\end{array}$ & $\begin{array}{l}\text { Control } \\
\text { cell }\end{array}$ & $\begin{array}{c}\text { Control } \\
\text { cell }\end{array}$ & \\
\hline Threshold & 0,190 & 0,190 & 0,170 & 0,185 & 0,185 \\
\hline & 0 & 0 & 0 & 0 & 0 \\
\hline & 0 & 0 & 0 & 0 & 233.905 \\
\hline & 0 & 0 & 0 & 0 & 310.586 \\
\hline & 0 & 162.518 & 0 & 143.783 & 386.96 \\
\hline & 0 & 282.663 & 156.963 & 210.918 & 452.72 \\
\hline & 0 & 382.021 & 291.656 & 403.053 & 470.546 \\
\hline & 181.481 & 454.516 & 400.87 & 479.327 & 476.443 \\
\hline & 308.973 & 487.554 & 463.66 & 537.192 & 485.794 \\
\hline & 430.259 & 508.52 & 520.233 & 581.699 & 468.51 \\
\hline & 504.38 & 514.238 & 555.356 & 609.56 & 445.67 \\
\hline & 561.612 & 512.87 & 591.408 & 636.387 & 423.547 \\
\hline & 600.222 & 503.014 & 572.49 & 620.113 & 415.695 \\
\hline & 621.12 & 490.73 & 579.21 & 628.47 & 331.959 \\
\hline & 636.09 & 483.53 & 520.918 & 582.204 & 304.412 \\
\hline & 636.92 & 472.517 & 461.195 & 546.005 & 286.068 \\
\hline & 621.46 & 422.406 & 396.83 & 507.282 & 231.347 \\
\hline & 599.163 & 314.691 & 324.661 & 453.164 & 210.201 \\
\hline & 538.251 & 295.73 & 258.911 & 396.064 & 214.127 \\
\hline & 466.522 & 294.279 & 165.99 & 346.214 & 0 \\
\hline & 0 & 0 & 0 & 0 & 0 \\
\hline & 0 & 0 & 0 & 0 & 0 \\
\hline & 0 & 0 & 0 & 0 & 0 \\
\hline $\begin{array}{c}\text { Area } \\
\text { Reduction }\end{array}$ & $5.53 \%$ & & & & \\
\hline
\end{tabular}




\begin{tabular}{|c|c|c|c|c|}
\hline \multirow[t]{2}{*}{ Experiment 4} & \multicolumn{2}{|c|}{$\begin{array}{l}\text { Before } \\
\text { Poking }\end{array}$} & \multicolumn{2}{|c|}{ After Poking } \\
\hline & $\begin{array}{l}\text { Control } \\
\text { cell }\end{array}$ & $\begin{array}{l}\text { Cell before } \\
\text { Poking }\end{array}$ & $\begin{array}{l}\text { Control } \\
\text { cell }\end{array}$ & $\begin{array}{c}\text { Cell after } \\
\text { poking }\end{array}$ \\
\hline Threshold & 0,165 & 0,165 & 0,145 & 0,145 \\
\hline & 0 & 0 & 0 & 0 \\
\hline & 0 & 0 & 0 & 0 \\
\hline & 0 & 0 & 0 & 0 \\
\hline & 59.3151 & 174.036 & 51.2674 & 141.34 \\
\hline & 98.9509 & 267.773 & 93.5423 & 283.722 \\
\hline & 158.706 & 430.34 & 134.4 & 388.782 \\
\hline & 170.973 & 495.878 & 170.077 & 450.785 \\
\hline & 157.908 & 532.223 & 156.73 & 488.938 \\
\hline & 144.24 & 533.69 & 149.599 & 511.26 \\
\hline & 136.664 & 565.734 & 141.079 & 526.277 \\
\hline & 124.169 & 560.944 & 128.649 & 524.322 \\
\hline & 109.3 & 550.37 & 128.11 & 502.33 \\
\hline & 96.328 & 498.094 & 120.715 & 464.75 \\
\hline & 75.5083 & 483.057 & 118.63 & 416.737 \\
\hline & 42.4541 & 445.409 & 72.12 & 383.911 \\
\hline & 22.6443 & 389.41 & 0 & 318.976 \\
\hline & 0 & 371.937 & 0 & 312.476 \\
\hline & 0 & 334.322 & 0 & 244.005 \\
\hline & 0 & 234.133 & 0 & 226.476 \\
\hline & 0 & 0 & 0 & 0 \\
\hline & 0 & 0 & 0 & 0 \\
\hline & 0 & 0 & 0 & 0 \\
\hline $\begin{array}{c}\text { Area } \\
\text { Reduction }\end{array}$ & $6.97 \%$ & & & \\
\hline
\end{tabular}




\begin{tabular}{|c|c|c|c|c|}
\hline \multirow[t]{2}{*}{ Experiment 5} & \multicolumn{2}{|c|}{$\begin{array}{l}\text { Before } \\
\text { Poking }\end{array}$} & \multicolumn{2}{|c|}{ After Poking } \\
\hline & $\begin{array}{l}\text { Control } \\
\text { cell }\end{array}$ & $\begin{array}{l}\text { Cell before } \\
\text { Poking }\end{array}$ & $\begin{array}{c}\text { Control } \\
\text { cell }\end{array}$ & $\begin{array}{c}\text { Cell after } \\
\text { poking }\end{array}$ \\
\hline Threshold & 0,210 & 0,210 & 0,144 & 0,144 \\
\hline & 0 & 0 & 0 & 0 \\
\hline & 0 & 0 & 0 & 0 \\
\hline & 0 & 0 & 0 & 0 \\
\hline & 0 & 56.285 & 0 & 0 \\
\hline & 0 & 216.148 & 0 & 97.6802 \\
\hline & 0 & 330.819 & 0 & 202.936 \\
\hline & 0 & 425.062 & 0 & 228.154 \\
\hline & 0 & 476.313 & 0 & 380.49 \\
\hline & 33.5429 & 500.244 & 103.138 & 389.32 \\
\hline & 183.989 & 511.615 & 237.994 & 361.104 \\
\hline & 297.244 & 504.073 & 342.679 & 292.438 \\
\hline & 380.539 & 465.333 & 411.508 & 196.387 \\
\hline & 435.488 & 422.749 & 452.561 & 101.28 \\
\hline & 449.954 & 350.58 & 453.685 & 0 \\
\hline & 452.838 & 255.278 & 420.142 & 0 \\
\hline & 429.069 & 213.557 & 339.812 & 0 \\
\hline & 378.519 & 117.946 & 247.459 & 0 \\
\hline & 296.901 & 24.3712 & 135.752 & 0 \\
\hline & 214.812 & 0 & 29.0792 & 0 \\
\hline & 167.796 & 0 & 0 & 0 \\
\hline & 83.784 & 0 & 0 & 0 \\
\hline & 0 & 0 & 0 & 0 \\
\hline $\begin{array}{c}\text { Area } \\
\text { Reduction }\end{array}$ & $23.90 \%$ & & & \\
\hline
\end{tabular}




\section{Appendix - 6}

\section{Determining Radial Deformation of Cell and Curve Fitting using Goodier Equations}

Cell/gel mixture stained with CMFDA dye was compressed to $30 \%$ of gel thickness and confocal serial sections of the cell were taken before and after compression. From the image stack, the image with the largest C.S. area was chosen (both uncompressed and compressed cell) and the difference in radii $\left(U_{r}\right)$ at various angles were computed and a plot was drawn between radial deformation $\left(U_{\mathrm{r}}\right)$ and angle with respect to loading axis.

\begin{tabular}{|c|c|c|c|}
\hline & Undeformed & Deformed & $\begin{array}{c}\text { Radial } \\
\text { Deformation } \\
\text { Ur }=\mathbf{U}_{\mathbf{1}} \mathbf{U}_{\mathbf{2}}\end{array}$ \\
\hline Angle(e) & $\mathbf{U}_{\mathbf{1}}$ & $\mathbf{U}_{\mathbf{2}}$ & $\boldsymbol{\mu m}$ \\
\hline Deg & $\mu \mathrm{m}$ & $\mu \mathrm{m}$ & 1.083 \\
\hline 0 & 4.91 & 3.827 & 1.175 \\
\hline 10 & 5.544 & 4.369 & 0.798 \\
\hline 20 & 5.197 & 4.399 & 0.564 \\
\hline 30 & 5.226 & 4.662 & 0.411 \\
\hline 40 & 4.969 & 4.558 & 0.286 \\
\hline 50 & 4.77 & 4.484 & 0.049 \\
\hline 60 & 4.693 & 4.644 & -0.115 \\
\hline 70 & 4.293 & 4.408 & -0.362 \\
\hline 80 & 3.959 & 4.321 & -0.037 \\
\hline 90 & 4.079 & 4.116 & \\
\hline
\end{tabular}

This data was curve fit with the radial deformations obtained from Goodier's theoretical solution. According to Goodier, 1933, radial deformation in the medium (i.e. agarose gel) is given by, $\mathrm{u}_{\mathrm{r}}^{\mathrm{b}}=-\left(\mathrm{A} / \mathrm{r}^{2}\right)-\left(3 \mathrm{~B} / \mathrm{r}^{4}\right)+\left[\left(5-4 \mathrm{v}_{\mathrm{b}}\right) /\left(1-2 \mathrm{v}_{\mathrm{b}}\right)\right] \mathrm{C} / 3 \mathrm{r}^{2}+\left[-\left(9 \mathrm{~B} / \mathrm{r}^{4}\right)+\left[\left(5-4 \mathrm{v}_{\mathrm{b}}\right) /\left(1-2 \mathrm{v}_{\mathrm{b}}\right)\right] \mathrm{C} / \mathrm{r}^{2}\right](\cos 2 \theta)$

Radial deformation in the inclusion (i.e. cell) is given by, $\mathrm{u}_{\mathrm{r}}^{\mathrm{t}}=\mathrm{Hr}+\mathrm{Fr}+2 \mathrm{v}_{\mathrm{t}} \mathrm{Gr}^{3}+\left[3 \mathrm{Fr}+6 \mathrm{v}_{\mathrm{t}} \mathrm{Gr}^{3}\right](\cos 2 \theta)$ 
A through $\mathrm{H}$ are constants that depend on material properties of the cell and gel (modulus of elasticity and Poisson's ratio), the applied stress $(\mathrm{T})$ and radius (a) of the cell. $\Theta$ is angle with respect to the loading axis. Superscripts b denote medium (gel) and t denotes inclusion (cell). 